\title{
Deep ocean ventilation, carbon isotopes, marine sedimentation and the deglacial $\mathrm{CO}_{2}$ rise
}

\author{
T. Tschumi ${ }^{1}$, F. Joos ${ }^{1,2}$, M. Gehlen ${ }^{3}$, and C. Heinze ${ }^{4,5,6}$ \\ ${ }^{1}$ Climate and Environmental Physics, Physics Institute, University of Bern, Sidlerstrasse 5, 3012 Bern, Switzerland \\ ${ }^{2}$ Oeschger Centre for Climate Change Research, University of Bern, 3012 Bern, Switzerland \\ ${ }^{3}$ Laboratoire du Climat et de l'Environnement (LSCE), L'Orme des Merisiers Bât. 712, 91191 Gif-sur-Yvette, France \\ ${ }^{4}$ Geophysical Institute, University of Bergen, Allegaten 70, 5007 Bergen, Norway \\ ${ }^{5}$ Bjerknes Centre for Climate Research, Bergen, Norway \\ ${ }^{6}$ Uni Bjerknes Centre, Uni Research, Bergen, Norway
}

Received: 25 August 2010 - Published in Clim. Past Discuss.: 27 September 2010

Revised: 14 May 2011 - Accepted: 13 June 2011 - Published: 22 July 2011

\begin{abstract}
The link between the atmospheric $\mathrm{CO}_{2}$ level and the ventilation state of the deep ocean is an important building block of the key hypotheses put forth to explain glacialinterglacial $\mathrm{CO}_{2}$ fluctuations. In this study, we systematically examine the sensitivity of atmospheric $\mathrm{CO}_{2}$ and its carbon isotope composition to changes in deep ocean ventilation, the ocean carbon pumps, and sediment formation in a global 3D ocean-sediment carbon cycle model. Our results provide support for the hypothesis that a break up of Southern Ocean stratification and invigorated deep ocean ventilation were the dominant drivers for the early deglacial $\mathrm{CO}_{2}$ rise of $\sim 35 \mathrm{ppm}$ between the Last Glacial Maximum and $14.6 \mathrm{ka}$ BP. Another rise of $10 \mathrm{ppm}$ until the end of the Holocene is attributed to carbonate compensation responding to the early deglacial change in ocean circulation. Our reasoning is based on a multi-proxy analysis which indicates that an acceleration of deep ocean ventilation during early deglaciation is not only consistent with recorded atmospheric $\mathrm{CO}_{2}$ but also with the reconstructed opal sedimentation peak in the Southern Ocean at around $16 \mathrm{kaBP}$, the record of atmospheric $\delta^{13} \mathrm{C}_{\mathrm{CO}_{2}}$, and the reconstructed changes in the Pacific $\mathrm{CaCO}_{3}$ saturation horizon.
\end{abstract}

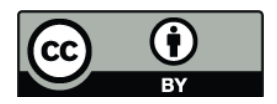

Correspondence to: $\mathrm{T}$. Tschumi (tschumi@climate.unibe.ch)

\section{Introduction}

Ancient air samples trapped in polar ice reveal that atmospheric $\mathrm{CO}_{2}$ has undergone large natural fluctuations with amplitudes of $90-100 \mathrm{ppm}$ between glacial and interglacial periods. Antarctic temperature closely parallels the recorded atmospheric $\mathrm{CO}_{2}$ concentration during at least the last eight glacial cycles (e.g., Lüthi et al., 2008).The global oceans have been identifie

The global oceans have been identified as the key regulator of the atmospheric carbon content on glacial-interglacial time-scales (e.g., Sigman and Boyle, 2000; Archer et al., 2000a; Siegenthaler and Wenk, 1984; Sarmiento and Toggweiler, 1984; Knox and McElroy, 1984). The ocean carbon cycle is driven by a multitude of different processes such as ocean circulation, the ocean carbon pumps and marine sediment formation which equilibrate with atmospheric $\mathrm{CO}_{2}$ on time-scales of months to millennia. The main focus of this study is to examine the millennial-scale response in atmospheric $\mathrm{CO}_{2}$ to changes in the ventilation rate of the deep ocean considering the carbon cycle feedbacks from implied modifications in marine biological production and sediment formation.

We perform a series of illustrative sensitivity experiments with the coupled Bern $3 \mathrm{D}+\mathrm{C}$ ocean-sediment carbon cycle model in which the rate of deep ocean ventilation is systematically varied by changing wind forcing. The time-dependent response for multiple carbon cycle proxies, such as $\delta^{13} \mathrm{C}$ - and $\Delta^{14} \mathrm{C}$-signatures in the ocean and the atmosphere but also

Published by Copernicus Publications on behalf of the European Geosciences Union. 
the depth of the $\mathrm{CaCO}_{3}$ saturation horizon and the sedimentation rate of $\mathrm{CaCO}_{3}$, organic carbon and opal are compared to available paleo-data to assess the importance of changes in deep ocean ventilation for glacial-interglacial $\mathrm{CO}_{2}$ variations.

Paleo-records of $\mathrm{CO}_{2}$ carbon isotope composition provide valuable insight into past sources and sinks of the atmospheric carbon reservoir. This information can be used to constrain contributions from the individual processes made responsible for the $\mathrm{CO}_{2}$ fluctuations (e.g., Elsig et al., 2009; Joos et al., 2004; Hughen et al., 2004; Smith et al., 1999; Leuenberger et al., 1992). Unfortunately, during glacial-interglacial transitions, there were generally several simultaneous processes generating similar imprints on $\mathrm{CO}_{2}$, $\delta^{13} \mathrm{C}_{\mathrm{CO}_{2}}$ and $\Delta{ }^{14} \mathrm{C}_{\mathrm{CO}_{2}}$. So far, the isotope records of atmospheric $\mathrm{CO}_{2}$ alone have not allowed for a unique quantitative process identification (Köhler et al., 2006a).

The timing and coevolution of the $\mathrm{CO}_{2}$ carbon isotope records over the last deglacation nevertheless indicate that the initial $\mathrm{CO}_{2}$ increase at the beginning of deglaciations was caused by the injection of some old carbon stock with low $\delta^{13} \mathrm{C}$ signature into the atmosphere, as both records of atmospheric $\delta^{13} \mathrm{C}_{\mathrm{CO}_{2}}$ and $\Delta^{14} \mathrm{C}_{\mathrm{CO}_{2}}$ exhibit a relatively rapid decline during the early deglaciation. Such a carbon release could in principle come from terrestrial or oceanic sources. Zeng (2003) proposes that there is a $547 \mathrm{GtC}$ carbon release from glacial to interglacial originating from organic carbon under the great ice sheets of the Northern Hemisphere. However, the observed atmospheric $\mathrm{CO}_{2}$ variations are not in phase with reconstructed sea level fluctuations. Recorded atmospheric $\mathrm{CO}_{2}$ concentrations show instead an extraordinary correlation with Southern Ocean (SO) climate changes. It thus appears more plausible that the dominant internal forcing feedback driving the deglacial $\mathrm{CO}_{2}$ rise is located in the Southern Ocean (e.g., Fischer et al., 2010).

There is evidence that low glacial $\mathrm{CO}_{2}$ concentrations can be at least partly attributed to an increased isolation of deep water masses from the atmosphere (e.g., Skinner et al., 2010; Boyle, 1988). Many authors postulate that during glacial times, there existed a relatively large and poorly ventilated abyssal water mass which led to a relocation of carbon from the atmosphere to the deep ocean. As most deep ocean watermasses are ventilated through the SO surface (e.g., Primeau, 2005), physical processes in this region are put forth as the responsible drivers of the postulated changes in deep ocean overturning (e.g., Fischer et al., 2010; Sigman and Boyle, 2000). It has been proposed that variations in deep ocean ventilation have resulted from (i) changes in $\mathrm{SO}$ wind forcing (Toggweiler et al., 2006), (ii) changes in SO buoyancy forcing (Watson and Naveira-Garabato, 2006) or (iii) changes in SO water column stratification (Schmittner and Galbraith, 2008; Francois et al., 1997). However, there is no broadly accepted consensus so far on the individual role of the different physical mechanisms nor on the magnitude of the associated $\mathrm{CO}_{2}$ variations during glacial-interglacial transitions.
Reconstructions of the glacial $\delta^{13} \mathrm{C}$ distribution from benthic foraminifera in the Pacific Ocean show that - relative to the Holocene - deep water below 2000-2500 m was more depleted in $\delta^{13} \mathrm{C}$ compared to the upper water mass (Matsumoto et al., 2002; Keigwin, 1998). In the Indian, Atlantic and Southern Oceans, reconstructed glacial-age vertical $\delta^{13} \mathrm{C}$ gradients point at the existence of a sharp chemocline at similar depths separating the well-ventilated water above from poorly ventilated water below (e.g., Hodell et al., 2003; McCorkle et al., 1998; Curry et al., 1988; Duplessy et al., 1988). These $\delta^{13} \mathrm{C}$-data support the "nutrient deepening" hypothesis (Boyle, 1988) calling for a transfer of nutrients and DIC from upper- and mid-depth waters to the deep ocean driven by a more efficient marine biological pump during glacial times. Several potential triggers for an increased biological pump efficiency during glacials have been suggested in the literature. For instance, reduced deep-water ventilation rates (e.g., Hodell et al., 2003), slowed organic matter degradation under colder water temperatures (Matsumoto et al., 2007; Kwon et al., 2009) or significantly increased aeolian iron supply to the ocean surface (Martin, 1990).

Jaccard et al. (2009) and Bradtmiller et al. (2010) have recently presented evidence for increased sequestration of remineralized carbon into the deep Pacific during the LGM. Their reasoning is based on the argument that a more efficient biological pump during glacial periods does not necessarily imply that total (= preformed + regenerated) nutrient concentrations in the deep ocean were significantly higher than during interglacials. Rather, the increase in biological pump efficiency would be mirrored in lower oxygen concentrations in the deep ocean together with an increase in regenerated nutrients which might be at least partially offset by a decrease in the preformed nutrient component (e.g., Ito and Follows, 2005).

Further evidence for a slowed deep ocean ventilation during glacial periods comes from recorded variations of opal burial in SO sediments (Anderson et al., 2009) and the occurrence of $\delta^{13} \mathrm{C}$ carbon isotope minima in planktic foraminifera at the beginning of glacial terminations (Spero and Lea, 2002). These signals have been interpreted to reflect an invigoration in SO ventilation during the last glacialinterglacial transition. As a consequence, the breakdown of surface water stratification and renewed Circumpolar Deep Water (CDW) upwelling in the SO would bring the postulated abyssal watermass - which was isolated from the atmosphere during the glacial period - to the ocean surface.

The large recorded drop in atmospheric $\Delta^{14} \mathrm{C}$ of about $300 \%$ over the course of the last deglaciation may further support this interpretation as the drop cannot be attributed solely to a decrease in stratospheric ${ }^{14} \mathrm{C}$-production (Hughen et al., 2004; Muscheler et al., 2004). Radiocarbon measurements on glacial-age sediments from the North Pacific (Galbraith et al., 2007; Marchitto et al., 2007) and from the deep Atlantic (Keigwin and Schlegel, 2002; Boyle, 1988) indicate that abyssal waters were indeed less ventilated during 
glacial times. However, surface-to-deep ${ }^{14} \mathrm{C}$-age differences reconstructed from a sediment core in the western equatorial Pacific show that late-glacial ventilation at a depth of $2.8 \mathrm{~km}$ was not significantly lower than today (Broecker et al., 2007). Summarizing the available evidence from carbon isotopes, Broecker and Barker (2007) come to the conclusion that the volume of an isolated abyssal reservoir during glacials is limited to no more than half of the ocean.

The "shelf hypothesis" (Broecker, 1982) is an alternative oceanic mechanism that has been put forth to explain the recorded glacial-interglacial $\mathrm{CO}_{2}$ fluctuations. This mechanism relies on changes in the biological pump turnover driven by shifts in organic matter accumulation on shallow shelves as sea level rises and falls. Atmospheric $p \mathrm{CO}_{2}$ would be reduced during glacial times through increased biological productivity promoted by an enhanced whole-ocean nutrient inventory. Paleo-data have revealed, however, that several prerequisites are not met which are required for the shelf hypothesis to explain the full glacial $\mathrm{CO}_{2}$ drawdown: For instance, there is no sufficiently large amount of organic sediments on shelf areas to provide additional nutrients during glacials (Peacock et al., 2006). Recent studies have suggested that an increase in the glacial nutrient inventory might be linked to changes in ventilation at intermediate depths rather than to changes in sea-level. A decreased volumetric extent of oxygen minimum zones would have reduced both the marine sinks for $\mathrm{NO}_{3}^{-}$(Deutsch et al., 2004) and for $\mathrm{PO}_{4}^{3-}$ (Wallmann, 2010).

Besides reorganizations of the ocean-internal carbon cycle and the terrestrial biosphere, transient imbalances between marine sediment formation and continental weathering fluxes may also have contributed significantly to the recorded millennial-scale variations in atmospheric $\mathrm{CO}_{2}$, $\delta^{13} \mathrm{C}_{\mathrm{CO}_{2}}$ and $\Delta^{14} \mathrm{C}_{\mathrm{CO}_{2}}$ (e.g., Archer et al., 2000a). Most prominently, the mechanism of carbonate compensation may have accounted for up to a third of the glacial-interglacial $\mathrm{CO}_{2}$ change without conflicting with reconstructed seafloor $\mathrm{CaCO}_{3}$ preservation patterns (Marchitto et al., 2005). Imbalances in the marine organic matter budget have received less attention in previous studies. Nevertheless, there is a priori no reason why excess burial or excess weathering of organic matter should not also have affected atmospheric $\mathrm{CO}_{2}$ levels in the past.

Numerical models allow a process-based interpretation of the recorded $\mathrm{CO}_{2}$ variations and to quantitatively test different scenarios of glacial-interglacial $\mathrm{CO}_{2}$ variations. A dilemma is that the application of comprehensive climatecarbon models for multi-millennial simulations and for exploring the sensitivity of results to uncertain parameters is restricted by their large CPU-demand. On the other hand, box models are inherently limited as they do not include ocean dynamics and only poorly represent the 3-D geometry of the ocean and ocean-sediment interactions.
The goal of this study is to explore the carbon cycle implications of altered deep ocean ventilation and biological carbon pumps together with the millennial-scale effects of implied changes in marine sediment formation. For this purpose, we use the global coarse-resolution 3-D Bern3D+C ocean model (Müller et al., 2006; Tschumi et al., 2008), which is coupled to a spatially-resolved dynamic model for marine sediment formation (Tschumi, 2009). This modelling framework allows for the simulation of multiple tracers over long time periods of several 10000 years which are required for sediment formation processes to relax to equilibrium.

The model simulates the cycling of total carbon $\left({ }^{12} \mathrm{C}+{ }^{13} \mathrm{C}+{ }^{14} \mathrm{C}\right)$ and the carbon isotopes ${ }^{13} \mathrm{C}$ and ${ }^{14} \mathrm{C}$ between the atmosphere, the terrestrial biosphere, the ocean reservoir, and the marine sediments. The ocean circulation field, the ocean carbon pumps and the formation of organic, opal, and $\mathrm{CaCO}_{3}$ sediments at the seafloor are calculated from prognostic dynamical equations discretized on 3-D grids. The terrestrial reservoir and the atmosphere are represented rather simplistically as single well-mixed boxes. The carbon stock on land is fixed $(2220 \mathrm{GtC})$, but not its isotopic composition.

As a starting point of this study, we have calculated the response of the coupled model to a change in the export ratio of organic matter to calcite (Sigman et al., 1998). This experiment served as a test for the model representation of carbonate compensation and allow us to compare our modelling framework to others. The second model experiment was an increase of the whole-ocean nutrient inventory by $30 \%$ (Sigman et al., 1998; Broecker and Peng, 1987) serving as a test for the "shelf hypothesis". Note that a $30 \%$-increase in whole-ocean nutrients during glacials is likely to be an upper limit of a realistic change (Deutsch et al., 2004; Wallmann, 2010). In contrast to previous similar experiments, in our model stimulated export production of organic matter will eventually relaxed back to initial rates as excess organic matter sedimentation removes the injected nutrients from the ocean in the long term. Therefore, the modeled shift in the Pacific $\mathrm{CaCO}_{3}$ saturation horizon in our experiment turned out to be small as opposed to previous studies (Heinze et al., 1991; Sigman et al., 1998). Finally, but as the main interest of this study, we have probed the response to variations in ocean deepwater ages driven by changes in $\mathrm{SO}$ wind forcing and the implied changes in SO deep convection for a range of different ocean ventilation time-scales. All of these sensitivity experiments started from the same model steady-state that is compatible with preindustrial boundary conditions for ocean physics and the biogeochemical cycles as described in Sect. 1.2.

The novel aspect of our analysis is the simulation of the time-dependent response to prototype scenarios considering ${ }^{13} \mathrm{C}$ - and ${ }^{14} \mathrm{C}$-cycling explicitely in a fully-coupled dynamical ocean-sediment model with sedimentation of all particulate species, i.e. the marine organic matter, $\mathrm{CaCO}_{3}$ and opal cycles are all represented as "open cycles" in this study. The 
broad range of processes and variables simulated increases the complexity of the ocean carbon cycle in the model, but it also allows for a more robust simultaneous comparison of the model results with multiple proxies. The systematic variations in deep ocean water ages through changes in the wind forcing and deep convection in the Southern Ocean represents a new approach to explore the sensitivity of atmospheric $\mathrm{CO}_{2}$ to deep ocean ventilation and marine sediment formation in 3-D models.

\subsection{Model description}

The version of the Bern $3 \mathrm{D}+\mathrm{C}$ carbon cycle model used here comprises an atmospheric, a terrestrial, an oceanic and a sedimentary reservoir which are coupled through the exchange of carbon and its isotopes ${ }^{13} \mathrm{C}$ and ${ }^{14} \mathrm{C}$. The model's ocean physics is based on the work of Edwards et al. (1998) as updated by Edwards and Marsh (2005) and Müller et al. (2006). The marine biogeochemical cycles are described by Parekh et al. (2008) and Tschumi et al. (2008) and the coupling to the sedimentary component in Tschumi (2009). Unless explicitly stated otherwise, the model is run under standard parameters as mentioned in these references.

Marine biogeochemical cycles and air-sea gas-exchange are implemented following OCMIP-2 (Orr et al., 1999; Najjar et al., 1999) with the addition of prognostic formulations for marine biological productivity as well as representations for the cycling of iron (Parekh et al., 2008), silica (Tschumi et al., 2008), ${ }^{13} \mathrm{C}$ and ${ }^{14} \mathrm{C}$.

Export production is a function of temperature, light, phosphate and iron following Doney et al. (1996). The competition between opal and calcite producers is modeled following formulations of the HAMOCC5 model of MaierReimer et al. (2005). The half-saturation constant for silicauptake is a function of local silica concentration and the ratio of silica to phosphorous uptake by opal producers varies with silica, light, iron and phosphate following Aumont and Bopp (2006).

The atmosphere is considered as a single well-mixed box. To calculate air-sea gas-exchange, a constant value for the square of the wind-speed $\bar{u}^{2}$ is employed which is set equal to the spatio-temporal mean of the climatology for $u^{2}$ provided by OCMIP-2 (Najjar et al., 1999).

The land biosphere model taken from Siegenthaler and Oeschger (1987) is composed of 4 well-mixed compartments with fixed carbon exchange fluxes and stocks: ground vegetation and leaves $(100 \mathrm{GtC})$, wood $(500 \mathrm{GtC})$, detritus $(120 \mathrm{GtC})$ and soils $(1500 \mathrm{GtC})$.

The sedimentary component is based on the model described by Gehlen et al. (2006) and Heinze et al. (1999) which represents sediment diagenesis in the top $10 \mathrm{~cm}$ beneath seafloor. Sediment formation, i.e. the accumulation of opal, $\mathrm{CaCO}_{3}$, organic matter and clay sediments is calculated on the basis of a set of dynamical equations for the sedimentary diagenetic processes. The redissolution and remineralization reactions all follow first order kinetics. Two types of remineralization reactions are considered, oxic respiration and denitrification. For more details on the sediment model component and model equations, please refer to the appendix.

In the model, cycling of ${ }^{13} \mathrm{C}$ is subject to the following fractionation effects: in the ocean, equilibrium fractionation is considered in the chemical carbonate equilibrium system (Mook, 1988). For air-sea gas-exchange, a kinetic fractionation is computed (Siegenthaler and Muennich, 1981). Further fractionations occur during marine photosynthesis (Freeman and Hayes, 1992) and the formation of calcium carbonate (Mook, 1988). In the land biosphere, isotopic fractionation is accounted for during photosynthesis.

Cycling of ${ }^{14} \mathrm{C}$ is simulated explicitly, i.e. the actual concentrations of ${ }^{14} \mathrm{C}$ are transported and not the ${ }^{14} \mathrm{C} /{ }^{12} \mathrm{C}$-ratio (Orr et al., 1999).

\subsection{Model spin-up and preindustrial steady state}

The coupled carbon cycle model was spun up by bringing the terrestrial biosphere, the ocean and the sediments into steady state under fixed atmospheric values for $p \mathrm{CO}_{2}(278.00 \mathrm{ppm})$, $\delta^{13} \mathrm{C}(-6.305 \%)$ and $\Delta^{14} \mathrm{C}(0.00 \%)$. A fixed production rate for ${ }^{14} \mathrm{C}$ was then prescribed and $p \mathrm{CO}_{2}, \delta{ }^{13} \mathrm{C}$ and $\Delta{ }^{14} \mathrm{C}$ were let evolve dynamically in the atmosphere to perform the subsequent sensitivity simulations. The remaining drifts in the control simulation was less than $3 \times 10^{-3} \mathrm{ppm} \mathrm{kyr}^{-1}$ in $p \mathrm{CO}_{2}$, less than $2 \times 10^{-5} \% \mathrm{kyr}^{-1}$ in $\delta^{13} \mathrm{C}$ and less than $3 \times 10^{-3} \% o \mathrm{kyr}^{-1}$ in $\Delta^{14} \mathrm{C}$. As the typical model response to the perturbations applied was much larger than that, the spun up model state is sufficiently close to equilibrium for our purposes.

The combined ocean/sediment compartment was separately intialized as follows before it was coupled interactively to the atmosphere. To spin up ocean physics in a first step, sea surface temperatures (SST) and salinities (SSS) were restored towards modern monthly observations (Levitus et al., 1994; Levitus and Boyer, 1994) and wind stress was prescribed according to the monthly climatology from NCEP/NCAR (Kalnay and et al., 1996). After 10000 model years, mixed boundary conditions were imposed for SST and SSS following Tschumi et al. (2008). Inspection of the modeled ocean circulation field and the temperature and salinity distributions at steady state revealed that the primary flow paths of the global ocean circulation and the important water masses were represented adequately (see Müller et al., 2006; Tschumi et al., 2008). The annual mean maximum Atlantic meridional overturning circulation (AMOC) amounted to $14.7 \mathrm{~Sv}$, comparing favorably to the estimate of $17 \pm 5 \mathrm{~Sv}$ (Talley et al., 2003).

In a second step, the steady state ocean circulation was then used to spin up marine biogeochemical cycles during 10000 model years. The resulting steady state fields of the modeled biogeochemical tracers successfully reproduced the 
large-scale patterns of the observed distributions in the modern ocean (see Tschumi et al., 2008; Müller et al., 2006, and Fig. 3). Simulated export fluxes for particulate organic matter $\left(12.76 \mathrm{GtC} \mathrm{yr}^{-1}\right), \mathrm{CaCO}_{3}\left(1.13 \mathrm{GtC} \mathrm{yr}^{-1}\right)$ and opal

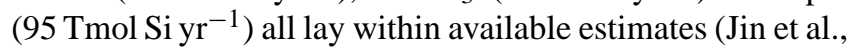
2006; Sarmiento and Gruber, 2006).

In a next phase, the sediments were "filled up" during 50000 years by imposing spatially uniform, but temporally variable weathering fluxes to the sea surface for phosphate, silicic acid, alkalinity, carbon, ${ }^{13} \mathrm{C}$ and ${ }^{14} \mathrm{C}$. The weathering rates were set equal to the net flux of the respective tracers across the ocean-sediment interface as diagnosed at each time-step such that annual mean ocean inventories are kept practically unchanged. As the sediment inventories converged to their steady state values, weathering rates stabilized to balance with the loss of solid matter that results from sediment burial. These values were diagnosed and prescribed subsequently as temporally constant weathering input. The ocean-sediment component was run into a new equilibrium during 30000 years in this new setup.

Simulated sediment accumulation amounted to $0.14 \mathrm{GtC} \mathrm{yr}^{-1}$ for organic matter and to $0.17 \mathrm{GtC} \mathrm{yr}^{-1}$ for $\mathrm{CaCO}_{3}$. These rates are roughly compatible with data-based estimates of $0.12-0.26 \mathrm{GtC} \mathrm{yr}^{-1}$ for organic matter burial and of $0.1-0.14 \mathrm{GtC} \mathrm{yr}^{-1}$ for $\mathrm{CaCO}_{3}$ burial (Sarmiento and Gruber, 2006; Feely et al., 2004). In a series of carbon pulse release experiments, $\mathrm{CO}_{2}$ neutralization time scales were found to be between 5-8 kyr for seafloor $\mathrm{CaCO}_{3}$ neutralization and between $8-13 \mathrm{kyr}$ for terrestrial $\mathrm{CaCO}_{3}$ neutralization (Tschumi, 2009). These values are compatible with previous studies (e.g., Archer et al., 1997). The model equations, the model parameters and the details of the ocean-sediment coupling can be found in Tschumi (2009).

Simulated sediment composition in the spun up coupled steady state is shown in Fig. 1a-c. Table 1 displays bulk numbers of the simulated particulate fluxes exported from the sea surface, deposited at the sea floor and accumulated in the sediments along with available estimates for the preindustrial time

\section{Model experiments and results}

\subsection{Rain ratio reduction}

The marine biological pumps (Volk and Hoffert, 1985), i.e. the organic matter and the carbonate pumps, are central drivers of the ocean carbon cycle. For two separate reasons, they are of great importance for the regulation of the atmospheric $\mathrm{CO}_{2}$ level by the oceans. First, they establish systematic gradients in dissolved inorganic carbon (DIC) and alkalinity between the surface and the deep ocean. The overall impact of both pumps together is lower $p \mathrm{CO}_{2}$ levels in the surface ocean compared to an abiotic ocean.
Second, accumulation of organic matter and $\mathrm{CaCO}_{3}$ sediments is driven by the deposition of biogenic material on the seafloor. Any change in the marine biological pumps thus also affects organic matter and $\mathrm{CaCO}_{3}$ sedimentation with potentially significant impacts on atmospheric $\mathrm{CO}_{2}$ through perturbations of the marine organic matter and $\mathrm{CaCO}_{3}$ balances.

The ocean carbonate pump is driven by the production of biogenic $\mathrm{CaCO}_{3}$ shells in the sea surface. The sinking $\mathrm{CaCO}_{3}$ shells entrain alkalinity to the deep ocean and hence increase sea surface $p \mathrm{CO}_{2}$ by shifting the speciation of the surface ocean DIC towards dissolved $\mathrm{CO}_{2}$. A reduced export ratio between $\mathrm{CaCO}_{3}$ and organic matter export (rain ratio) would reduce sea surface $p \mathrm{CO}_{2}$, not only due to an ocean-internal redistribution of alkalinity but also as a result of a lower carbonate concentration in the deep ocean triggering redissolution of marine $\mathrm{CaCO}_{3}$ sediments. The resulting imbalance between the weathering flux of dissolved $\mathrm{CaCO}_{3}$ into the ocean and marine $\mathrm{CaCO}_{3}$ sedimentation would drive a rise in the ocean's total alkalinity and additionally contribute to lower sea surface $p \mathrm{CO}_{2}$. Carbonate compensation is the feedback mechanism responsible for re-establishing the ocean $\mathrm{CaCO}_{3}$ balance on a time-scale of order $10 \mathrm{kyr}$ through shifts in the depth of the $\mathrm{CaCO}_{3}$ saturation horizon (Archer et al., 2000a).

By reason of their central role in the regulation of the ocean's alkalinity budget, rain ratio mechanisms were among the first candidates made responsible for driving glacialinterglacial $\mathrm{CO}_{2}$ fluctuations in the atmosphere (e.g., Archer et al., 2000a; Berger and Keir, 1984). A reduced rain ratio during glacial times may have resulted, for instance, from increased diatom productivity in lower latitudes at the expense of coccolithophorids (silica leakage hypothesis, Matsumoto et al., 2002) or from relaxed nutrient-limitation in the sea surface (Margalef, 1978). The inferred $\mathrm{CaCO}_{3}$ preservation history recorded in marine sediments, however, constrains the contribution of whole-ocean alkalinity changes to roughly a third of glacial-interglacial $\mathrm{CO}_{2}$ variations (Marchitto et al., 2005).

In our first model experiment, we attempt to disentangle and quantify the complex response in ocean biogeochemistry to a reduced rain ratio. We perform parallel simulations in a coupled ocean-sediment setup and in an ocean-only setup to separate ocean-internal mechanisms from interactions with the sediments. Following Sigman et al. (1998), we abruptly reduce $\mathrm{CaCO}_{3}$ export by $20 \%$ uniformly in the global sea surface. This corresponds in our model to a decline in the global rain ratio from 0.088 to 0.071 .

\subsubsection{Results}

Figure 3 shows the time-dependent carbon cycle responses as simulated with the ocean-only model (black lines) and the ocean-sediment model (red lines). In response to decreased $\mathrm{CaCO}_{3}$, export atmospheric $\mathrm{CO}_{2}$ drops from $278 \mathrm{ppm}$ to 
a)

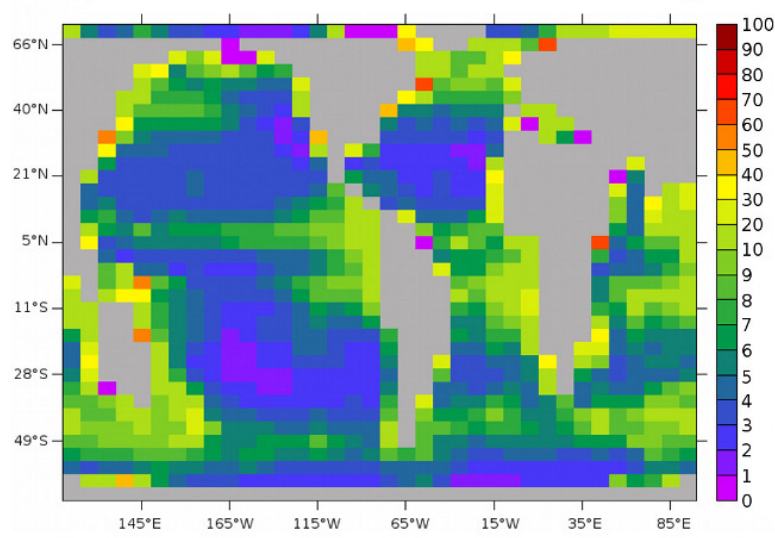

Particulate Organic matter (dry weight-\%)

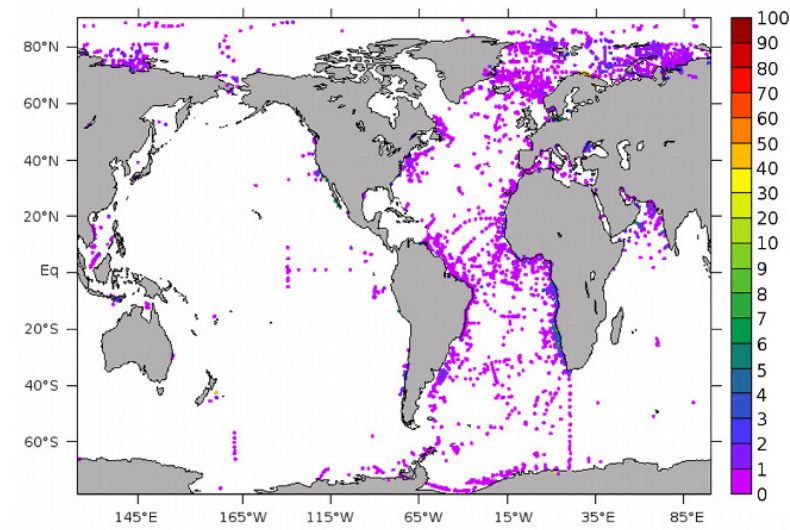

b)
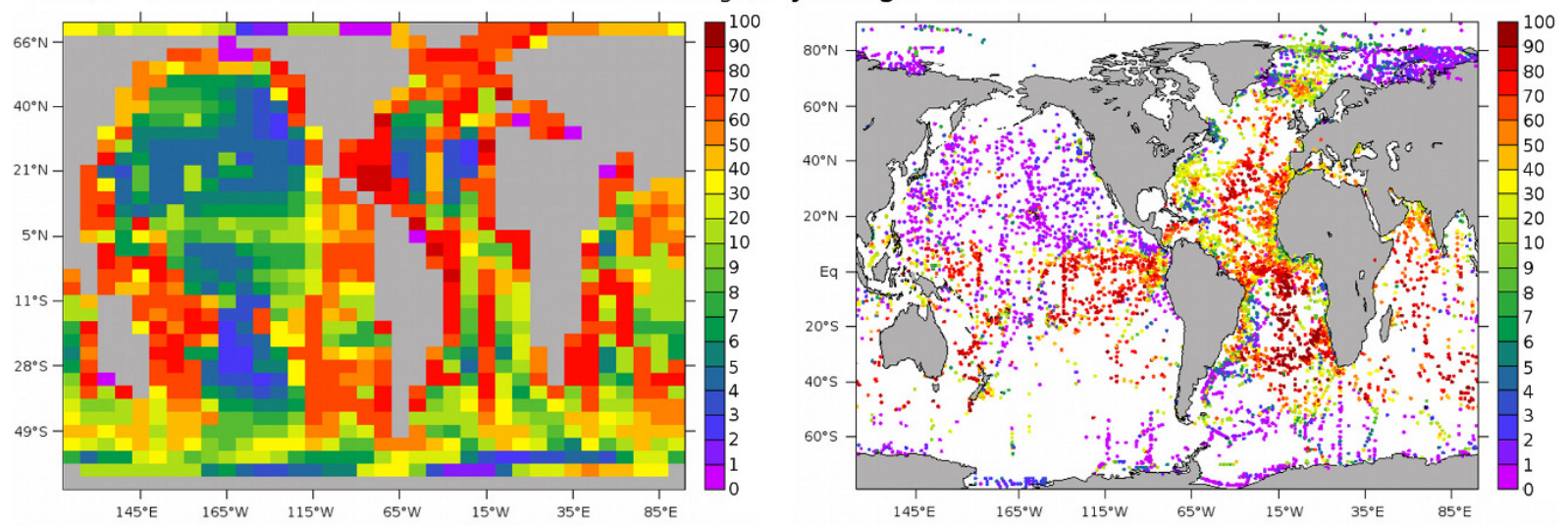

C)

Opal (dry weight-\%)
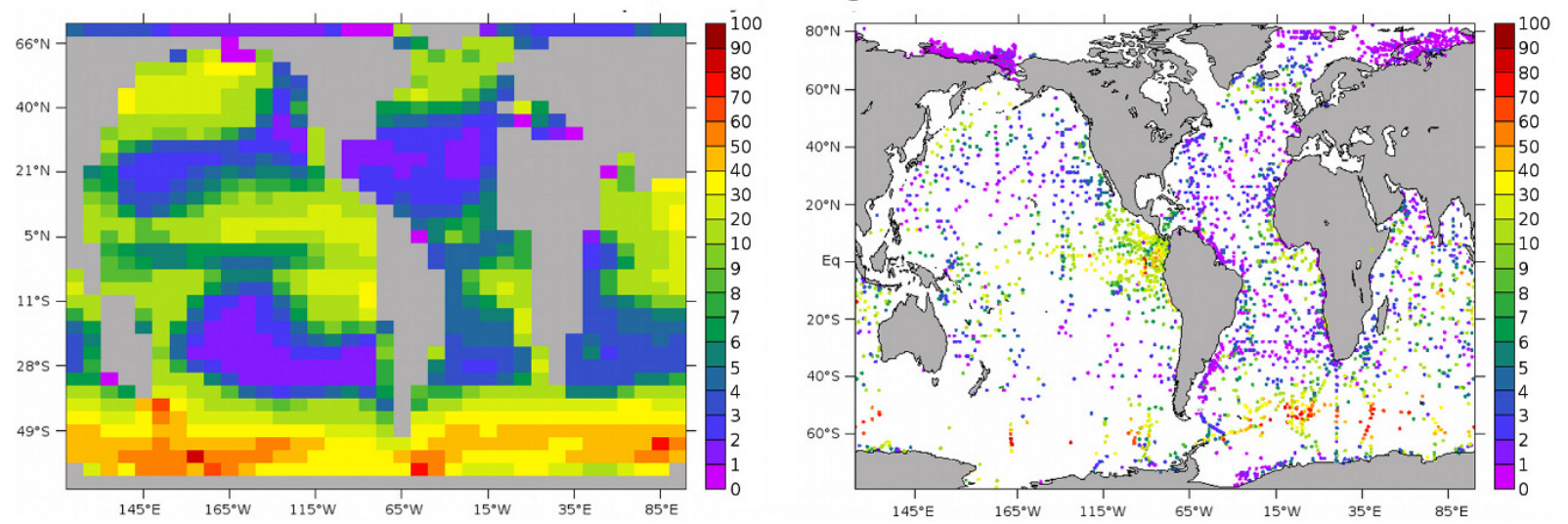

Fig. 1. Modelled (left row) and observed (right row) composition of surface sediments on the ocean bottom: (a) particulate organic matter, (b) $\mathrm{CaCO}_{3}$ and (c) opal. Modelled sediment composition is averaged over the top $1.1 \mathrm{~cm}$ of the sediment column. Sediment data is from the Pangaea database (publishing Network for Geoscientific \& Environmental Data, http://orfois.pangaea.de). Note that the color scale is not linear.

$268 \mathrm{ppm}$ within centuries (e-folding time scale: $390 \mathrm{yr}$ ) in the ocean-only model (Fig. 3a, black line). Mean surface alkalinity rises as less $\mathrm{CaCO}_{3}$ shells sink from the surface to the ocean interior (Fig. 3b, black line). Reduced alkalinity in the ocean interior in turn lowers $\left[\mathrm{CO}_{3}^{2-}\right]$ pushing the $\mathrm{CaCO}_{3}$ saturation horizon upwards by approximately $300 \mathrm{~m}$ (Fig. 3d, black line).
In the ocean-sediment model, the $\mathrm{CO}_{2}$ drawdown is strongly amplified to $237 \mathrm{ppm}$ due to the increase in wholeocean alkalinity (Fig. 3a and b, red line). Carbonate compensation responds rather slowly with an e-folding time scale of $11.7 \mathrm{kyr}$. Reduced $\mathrm{CaCO}_{3}$ export and deposition on the seafloor drive a deepening in the $\mathrm{CaCO}_{3}$ saturation horizon as to provide a larger area on the seafloor where the rain of 


$$
\Delta^{14} C_{\text {DIC }}[\% o]
$$

a) ocean bottom water

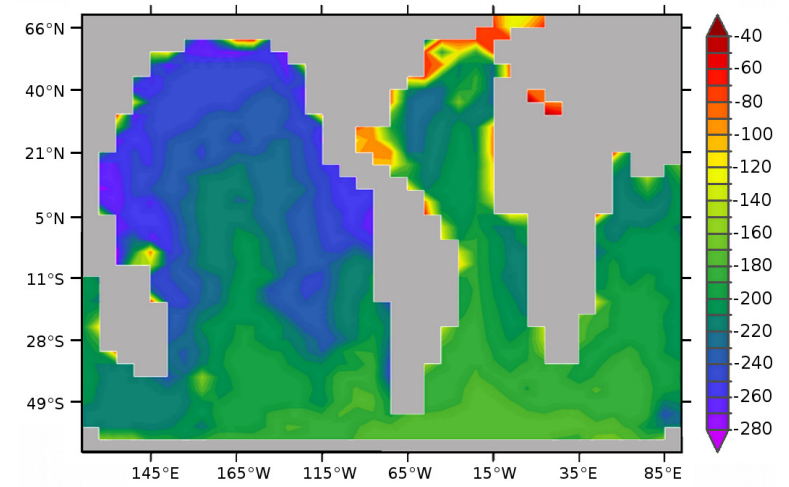

b) Atlantic zonal mean

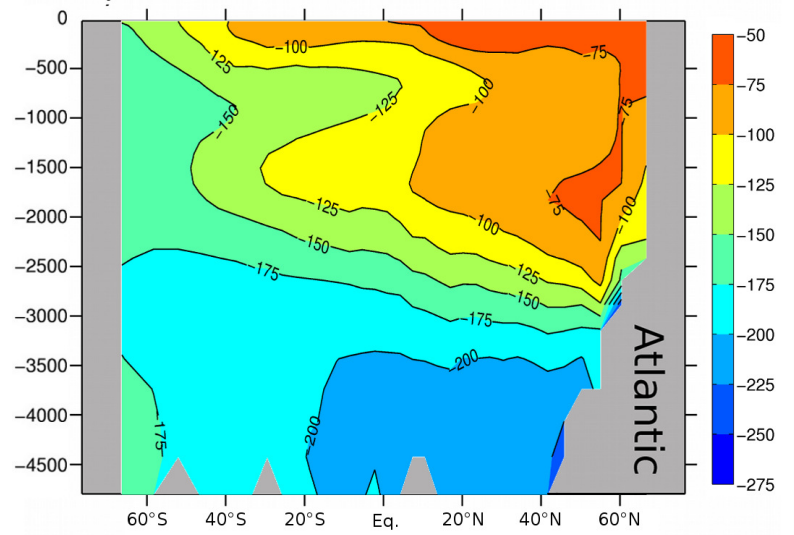

c) Pacific zonal mean

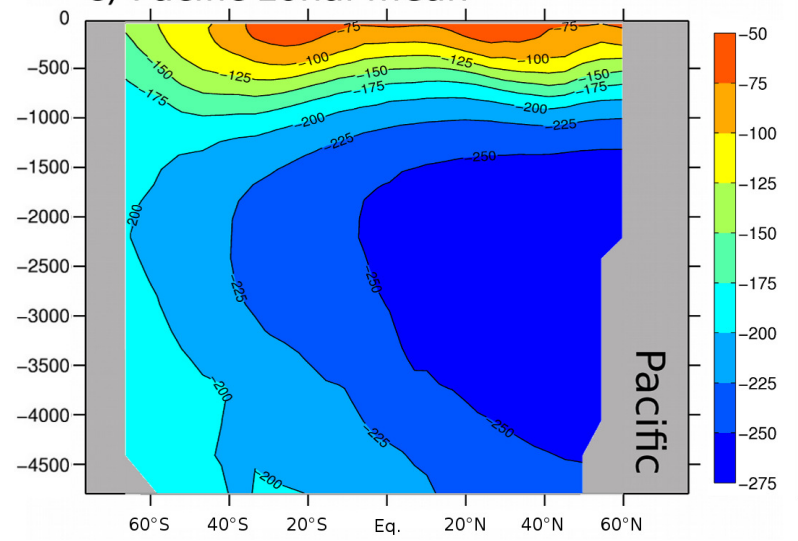

$\delta^{13} \mathrm{C}_{\text {oIC }}[\%$ o]

\section{d) ocean bottom water}

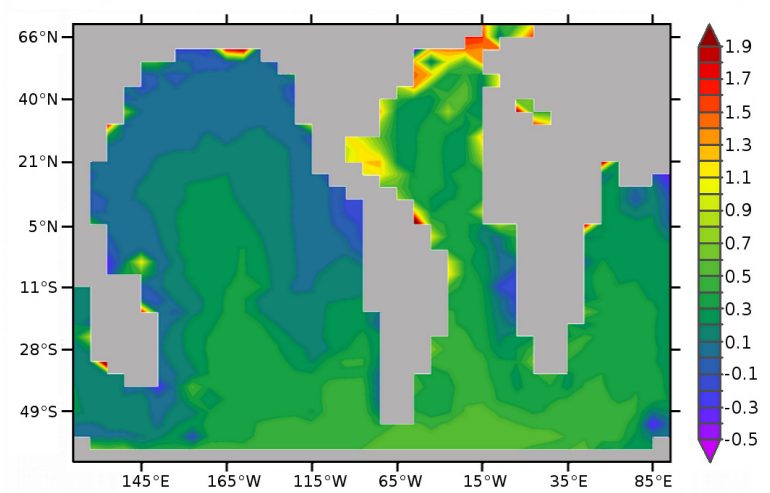

e) Atlantic zonal mean

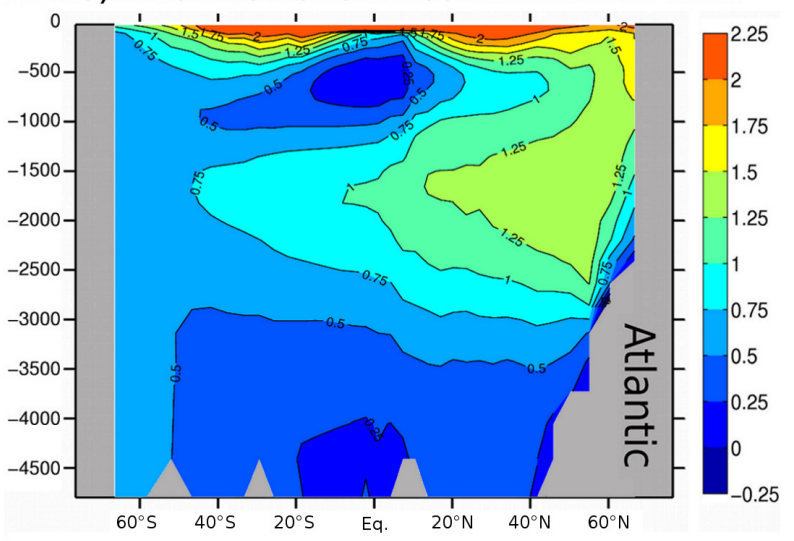

f) Pacific zonal mean

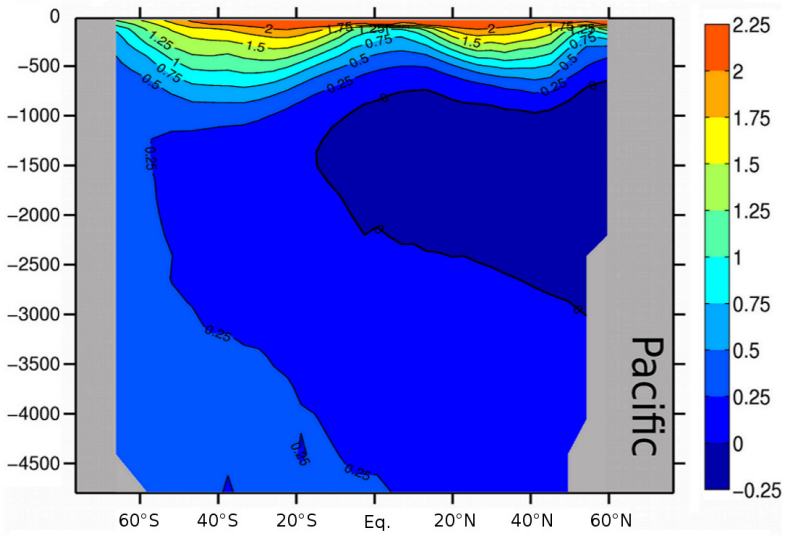

Fig. 2. Modelled distribution of the isotope signatures in ocean dissolved inorganic carbon for preindustrial boundary conditions. $\Delta^{14} C_{D I C}$ is shown in the left row and $\delta^{13} \mathrm{C}_{\text {DIC }}$ in the right row. Top panels (a) and (d) show bottom water signatures, the middle row panels (b) and (e) display Atlantic and bottom panels (c) and (f) Pacific zonal mean sections in preindustrial steady state.

$\mathrm{CaCO}_{3}$ is efficiently preserved (Fig. $3 \mathrm{~d}$, red line). As a consequence, the simulated $\mathrm{CaCO}_{3}$ sedimentation rate starts to recover after the initial abrupt decline in order to restore the ocean's $\mathrm{CaCO}_{3}$ balance in the model (Fig. 3c). The final total shift in steady state saturation depth in the ocean-sediment model amounts to a deepening of $700 \mathrm{~m}$ in the Atlantic and of $800 \mathrm{~m}$ in the Pacific basin (Fig. 3d, red line).
The simulated responses in atmospheric $\delta^{13} \mathrm{C}_{\mathrm{CO}_{2}}$ and $\Delta^{14} \mathrm{C}_{\mathrm{CO}_{2}}$ to changes in the rain ratio are small. The ocean-internal distribution of $\delta^{13} \mathrm{C}_{\mathrm{DIC}}$ and $\Delta^{14} \mathrm{C}_{\mathrm{DIC}}$ is only marginally affected by the marine $\mathrm{CaCO}_{3}$ cycle. In the ocean-only experiment, we therefore simulate negligible changes in atmospheric $\delta^{13} \mathrm{C}_{\mathrm{CO}_{2}}$ and $\Delta^{14} \mathrm{C}_{\mathrm{CO}_{2}}$ as $\mathrm{CaCO}_{3}$ export is reduced. In fact, there is virtually no response in 
a) Atmospheric $\mathrm{CO}_{2}[\mathrm{ppm}]$

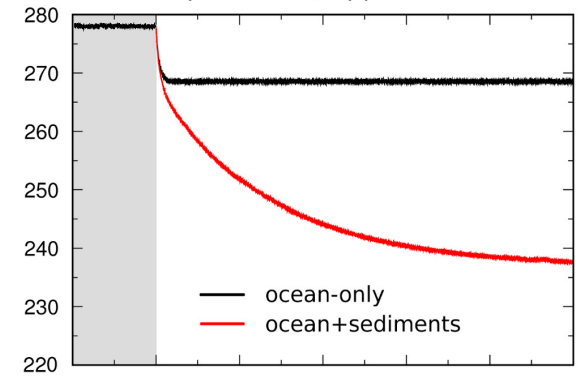

c) $\mathrm{CaCO}_{3}$ sediment burial [GtC/yr]

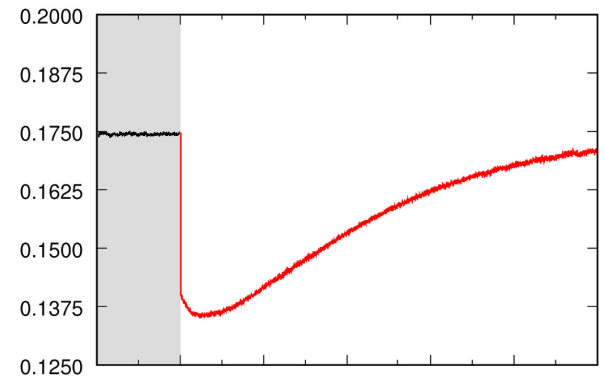

e) Atmospheric $\delta^{13} \mathrm{C}_{\mathrm{CO}_{2}}[\%$ \% $]$

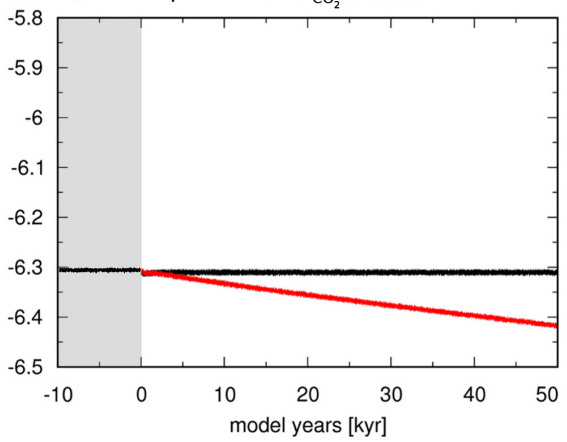

b) Mean surface alkalinity $[\mathrm{mol} / \mathrm{m} 3]$

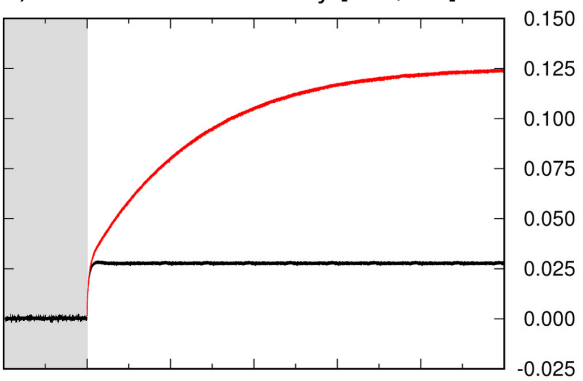

d) Shift in Pacific saturation horizon [m]

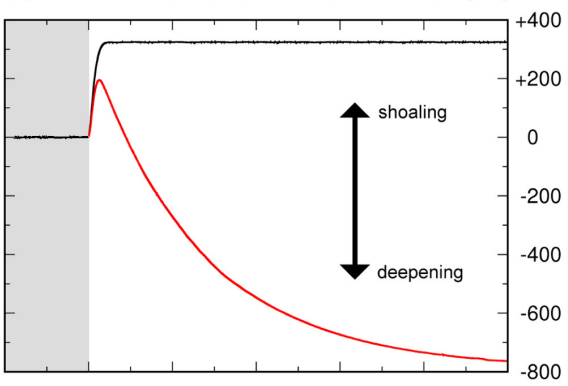

f) Atmospheric $\Delta^{14} \mathrm{C}_{\mathrm{CO}_{2}}[\%$ o $]$

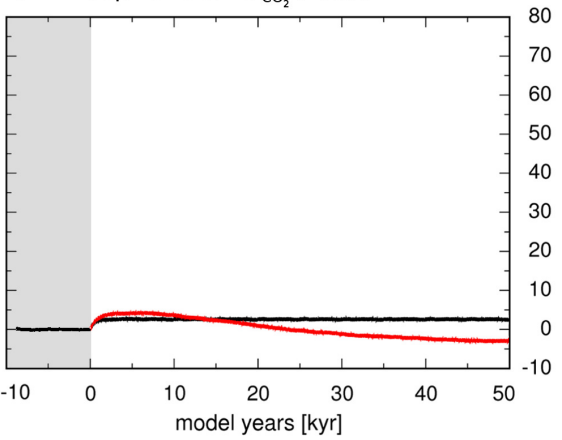

Fig. 3. Rain ratio reduction: Simulated response to a 20\%-reduction in $\mathrm{CaCO}_{3}$ export. (a) Atmospheric $\mathrm{CO}_{2}$, (b) mean surface alkalinity, (c) $\mathrm{CaCO}_{3}$ sedimentation, (d) shift in Pacific $\mathrm{CaCO}_{3}$ saturation horizon, (e) atmospheric $\delta^{13} \mathrm{C}_{\mathrm{CO}_{2}}$ and (f) atmospheric $\Delta^{14} \mathrm{C}_{\mathrm{CO}_{2}}$.

atmospheric $\delta^{13} \mathrm{C}_{\mathrm{CO}_{2}}$ (Fig. 3e, black line) and $\Delta^{14} \mathrm{C}_{\mathrm{CO}_{2}}$ is raised by a modest $3 \%$ (Fig. 3f, black line).

In the coupled ocean-sediment experiment, the system response in carbon isotope signatures of atmospheric $\mathrm{CO}_{2}$ is additionally sensitive to the decline in marine $\mathrm{CaCO}_{3}$ sedimentation. However, the responses of $\delta^{13} \mathrm{C}_{\mathrm{CO}_{2}}$ and $\Delta{ }^{14} \mathrm{C}_{\mathrm{CO}_{2}}$ to carbonate compensation are rather slow and remain small (Fig. $3 \mathrm{e}$ and $\mathrm{f}$, red lines).

\subsubsection{Comparison to other studies}

Heinze et al. (1991) have simulated a relatively modest sensitivity of atmospheric $\mathrm{CO}_{2}$ to changes in the rain ratio. They have found a $\mathrm{CO}_{2}$ drawdown of $28.5 \mathrm{ppm}$ when the rain ratio is reduced by $50 \%$ in the 3-D Hamburg Carbon Cycle Model which was coupled to a simplistic model for sediment diagenesis with fixed sediment resuspension rates. Archer and Maier-Reimer (1994) have shown that including organiccarbon-driven dissolution of $\mathrm{CaCO}_{3}$ sediments substantially increases the $p \mathrm{CO}_{2}$ response to rain ratio changes in their model. They reach glacial $\mathrm{CO}_{2}$ levels by reducing the rain ratio by $40 \%$, which amounts to a $\mathrm{CO}_{2}$ sensitivity comparable to this study.

Sigman and Boyle (2000) have reduced the ratio of organic matter to $\mathrm{CaCO}_{3}$ export in the low latitudes by $50 \%$ in the CYCLOPS box model. They obtain a drawdown of $22 \mathrm{ppm}$ in the ocean-only model and of $63 \mathrm{ppm}$ in the ocean-sediment model. $\mathrm{CaCO}_{3}$ compensation amplifies the $\mathrm{CO}_{2}$ reduction by a factor of three in their study compared to a factor of four in this study. The reason for the comparatively lower impact of $\mathrm{CaCO}_{3}$ compensation in the box model study is probably the shorter relaxation time of $\mathrm{CaCO}_{3}$ burial. The original rate is restored after about $15 \mathrm{kyr}$, whereas in the Bern $3 \mathrm{D}+\mathrm{C}$ model it takes roughly $50 \mathrm{kyr}$. The longer relaxation time in our study results in a larger imbalance between $\mathrm{CaCO}_{3}$ burial and weathering when integrated over time such that the increase in whole-ocean alkalinity is larger in response to carbonate compensation. 
Chikamoto et al. (2009) have lowered the rain ratio by $25 \%$ in the High-Latitude Exchange/Interior Diffusion Advection (HILDA) model coupled to a similar dynamical sediment model as used in this study. They find a drawdown of $59 \mathrm{ppm}$ in atmospheric $\mathrm{CO}_{2}$ together with a deepening of the calcite saturation horizon by $1870 \mathrm{~m}$. The response time scale of atmospheric $\mathrm{CO}_{2}$ and the magnitude of the drawdown are comparable to the results of our study; however, we find a deepening of the order of only $800 \mathrm{~m}$ in the $\mathrm{CaCO}_{3}$ saturation horizon.

In conclusion, it appears to be challenging to robustly quantify the effect of rain ratio changes on atmospheric $\mathrm{CO}_{2}$ by means of carbon cycle models. The simulated $\mathrm{CO}_{2}$ response depends on the specific biogeochemical model state, such as the initial rain ratio or the $\mathrm{CaCO}_{3}$ throughput in the oceans, as well as on the model parametrization of the oceansediment interactions. Our results are consistent with current understanding, suggesting that carbonate compensation would amplify the $\mathrm{CO}_{2}$ response to changes in the ocean carbonate pump by a factor of as much as $3-4$.

\subsection{Strengthening of the marine biological cycle}

As an alternative to a reduced rain ratio, low atmospheric $\mathrm{CO}_{2}$ during glacial periods might have resulted from more vigorous biological carbon cycling in the ocean. A strengthened marine biological cycle might be driven for instance by increased nutrient availability (Broecker and Peng, 1982), iron fertilization (Martin and Fitzwater, 1988) or changes in nitrogen cycling (Falkowski, 1997).

In the next experiment, we examine the response in atmospheric $\mathrm{CO}_{2}, \delta^{13} \mathrm{C}_{\mathrm{CO}_{2}}$ and $\Delta{ }^{14} \mathrm{C}_{\mathrm{CO}_{2}}$ to a stimulated ocean biology by increasing the marine nutrient inventory in the Bern3D+C model. The experiment is again performed with and without coupling to sediments to isolate the effect of ocean-sediment interactions.

Following the procedure of Archer et al. (2000a); Sigman et al. (1998) and Broecker and Peng (1987), we have abruptly increased $\mathrm{PO}_{4}$ concentrations uniformly by $30 \%$ to stimulate simultaneously both the organic matter and the carbonate pumps. With our model biology the global rain ratio remained virtually unchanged. Therefore, the sedimentary response on atmospheric $\mathrm{CO}_{2}$ is dominated in our model by excess organic matter sedimentation rather than by carbonate compensation.

\subsubsection{Atmospheric $\mathrm{CO}_{2}$}

In the ocean-only model, the augmented $\mathrm{PO}_{4}$ inventory drives a persistent increase in organic matter and $\mathrm{CaCO}_{3}$ export production both by roughly $11 \%$ (Fig. $4 \mathrm{c}$ and d, black lines). The elevated rates of organic matter and $\mathrm{CaCO}_{3}$ export have opposite effects on sea surface $p \mathrm{CO}_{2}$. As the strengthened organic matter pump dominates the net ocean response, atmospheric $\mathrm{CO}_{2}$ gets reduced to $255 \mathrm{ppm}$ with an e-folding time scale of 470 years in the ocean-only experiment (Fig. 4a, black line). As the concurrent changes in downward fluxes of $\mathrm{POC}$ and $\mathrm{CaCO}_{3}$ have roughly opposing effects on $\left[\mathrm{CO}_{3}^{2-}\right]$ at the depth of the saturation horizon, there is only a small shift in calcite saturation depth of less than $20 \mathrm{~m}$ in the ocean-only model (Fig. 4b, black line).

Biological export of carbon from the sea surface augments primarily in the Atlantic and in the Indian oceans, and to a lesser degree in the Northern Pacific. There is almost no change in export production in the equatorial and South $\mathrm{Pa}$ cific as well as in the Southern Ocean (south of $51^{\circ} \mathrm{S}$ ) because biological productivity in these regions is limited by iron or light availability. Note that a glacial increase in export production in the North Pacific is at odds with paleoproductivity reconstructions (see Jaccard et al., 2009; Galbraith et al., 2007; Crusius et al., 2004), suggesting that the history of export production from the North Pacific surface was predominantely controlled by processes other than changes in the whole-ocean nutrient inventory such as changes in water column stratification and associated upwelling of nutrients from the deep (Galbraith et al., 2007).

In the coupled ocean-sediment setup, atmospheric $\mathrm{CO}_{2}$ is reduced to $232 \mathrm{ppm}$ within $30 \mathrm{kyr}$ (Fig. $4 \mathrm{a}$, red line). Thereafter, $\mathrm{CO}_{2}$ slightly increases by $2 \mathrm{ppm}$ until the full balance between weathering and burial of organic matter and $\mathrm{CaCO}_{3}$ is re-established after $50 \mathrm{ky}$ (Fig. 4e and f). The effect of ocean-sediment interactions thus enhances the $\mathrm{CO}_{2}$ drawdown in the coupled system by a factor of two.

The nutrient increase abruptly boosts the export of organic matter and $\mathrm{CaCO}_{3}$ by $8.5 \%$ in the ocean-sediment model (Fig. $4 \mathrm{c}$ and d, red lines). Subsequently, both export rates decline and reach almost original values after $50 \mathrm{kyr}$. As both changes in $\mathrm{CaCO}_{3}$ and organic matter burial are taken into consideration, elevated organic matter export is not sustained in the long run here, in contrast to previous studies (Sigman et al., 1998; Broecker and Peng, 1987) which have accounted solely for changes in $\mathrm{CaCO}_{3}$ sedimentation.

Excess organic matter burial draws nutrients out of the ocean to bring organic sedimentation back to balance the riverine input of nutrients. The initial increase in the nutrient inventory is thereby neutralized in the long run. The simulated decline in $\mathrm{CaCO}_{3}$ export also follows directly from the gradual decrease in nutrient availability. In our model biology, $\mathrm{CaCO}_{3}$ export is computed from primary productivity and is not affected by changes in the calcite saturation state. The effect of $\mathrm{CaCO}_{3}$ compensation on restoring $\mathrm{CaCO}_{3}$ burial is therefore only of secondary importance, in contrast to the rain ratio reduction experiment.

The modeled $\mathrm{CaCO}_{3}$ saturation horizon deepens by about $150 \mathrm{~m}$ in the Atlantic and by $300 \mathrm{~m}$ in the Pacific during the first 15000 years with a subsequent shoaling in both basins thereafter (Fig. 4b, red line). The first part of the response is dominated by excess POC burial, the second part by excess $\mathrm{CaCO}_{3}$ burial. Since excess POC burial implies a loss of whole-ocean DIC, it tends to push the saturation horizon 
a) Atmospheric $\mathrm{CO}_{2}$ [ppm]

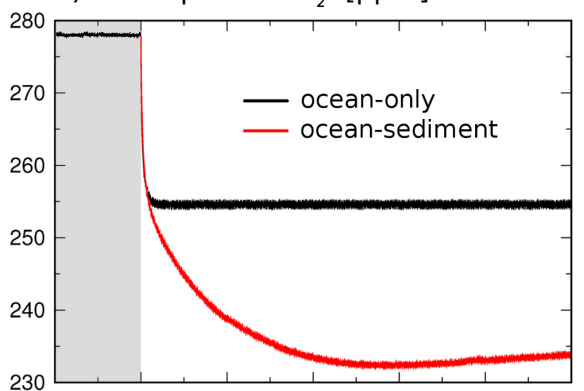

c) POC export production [GtC/yr]

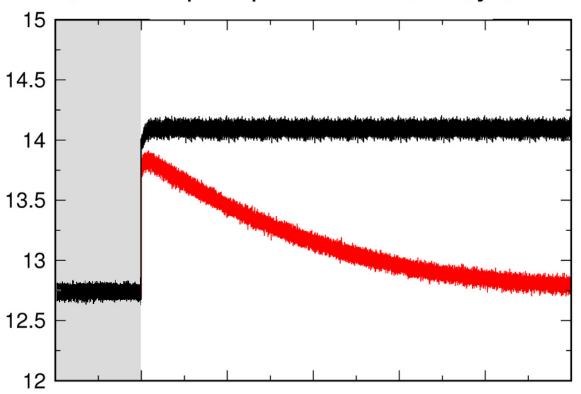

e) POC sediment burial [GtC/yr]

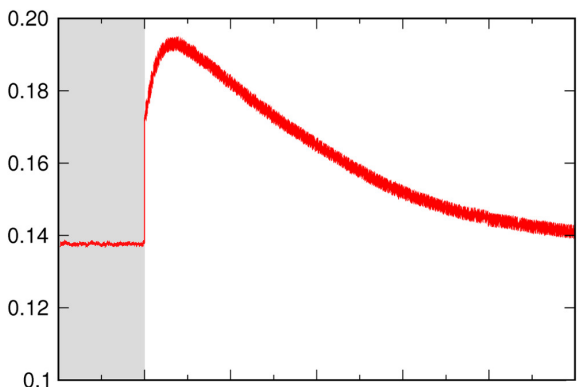

g) Atmospheric $\delta^{13} \mathrm{C}_{\mathrm{CO}_{2}}[\%$ \% $]$

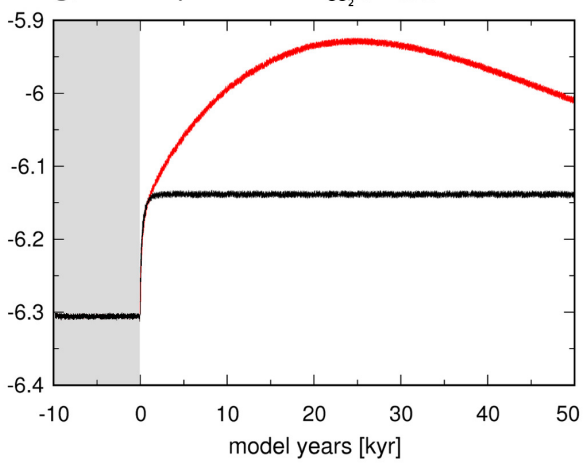

b) Shift in Pacific saturation horizon [m]

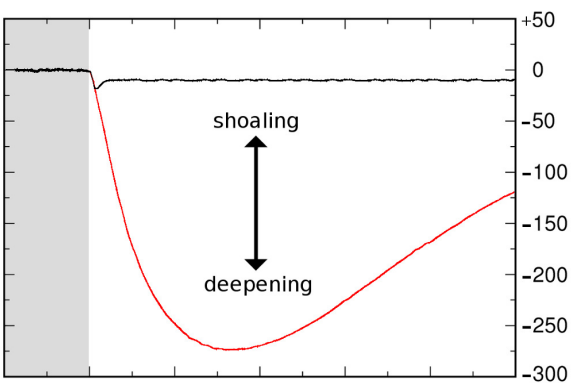

d) $\mathrm{CaCO}_{3}$ export production [GtC/yr]

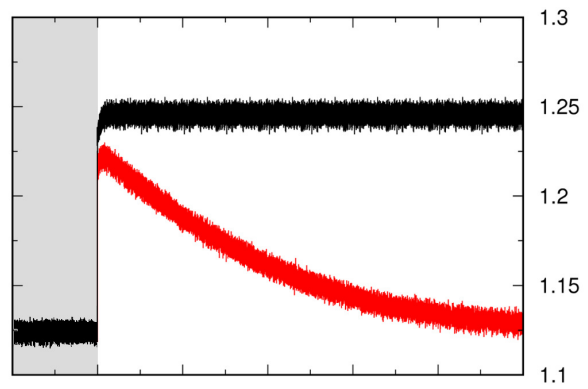

f) $\mathrm{CaCO}_{3}$ sediment burial [GtC/yr]

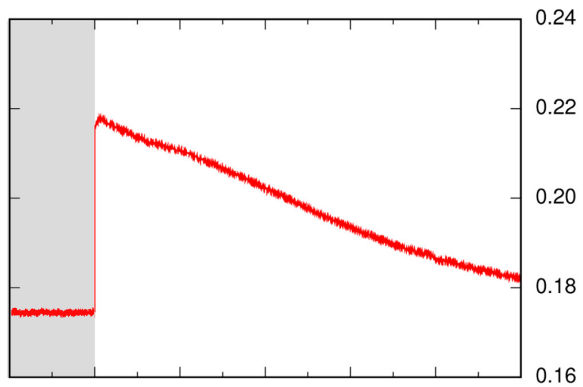

h) Atmospheric $\Delta^{14} \mathrm{C}_{\mathrm{CO}_{2}}[\%$ \% $]$

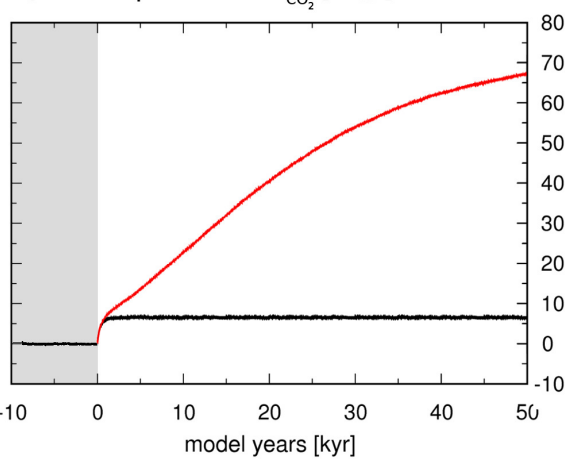

Fig. 4. Strengthening of the marine biological cycle: Simulated response to an abrupt $30 \%$-increase in the ocean's phosphate content. (a) Atmospheric $\mathrm{CO}_{2}$, (b) shift in Pacific $\mathrm{CaCO}_{3}$ saturation horizon, (c) $\mathrm{POC}$ export production, (d) $\mathrm{CaCO}$ export production, (e) $\mathrm{POC}$ sedimentation, (f) $\mathrm{CaCO}_{3}$ sedimentation, (g) atmospheric $\delta^{13} \mathrm{C}_{\mathrm{CO}_{2}}$ and (h) atmospheric $\Delta^{14} \mathrm{C}_{\mathrm{CO}_{2}}$.

downwards. On the contrary, excess $\mathrm{CaCO}_{3}$ burial leads to a shoaling of the saturation horizon as alkalinity and DIC are removed from the ocean in a 2:1-ratio. The final shift in the calcite saturation horizon after $50 \mathrm{kyr}$ is a deepening of less than $100 \mathrm{~m}$.

\subsubsection{Atmospheric $\delta^{13} \mathrm{C}_{\mathrm{CO}_{2}}$ and $\Delta{ }^{14} \mathrm{C}_{\mathrm{CO}_{2}}$}

The simulated changes in atmospheric $\delta^{13} \mathrm{C}_{\mathrm{CO}_{2}}$ and $\Delta^{14} \mathrm{C}_{\mathrm{CO}_{2}}$ are predominantly controlled by the response in organic matter cycling. In the ocean-only model, atmospheric 
$\delta^{13} \mathrm{C}_{\mathrm{CO}_{2}}$ rises by $0.16 \%$ and $\Delta{ }^{14} \mathrm{C}_{\mathrm{CO}_{2}}$ by 7 in response to the strengthened marine biological cycle (Fig. $4 \mathrm{~g}$ and h, black lines). $\quad \delta^{13} \mathrm{C}_{\mathrm{CO}_{2}}$ rises as surface ocean $\delta^{13} \mathrm{C}_{\mathrm{DIC}}$ is shifted towards more positive values due to enhanced production of organic matter. The increase in $\Delta^{14} \mathrm{C}_{\mathrm{CO}_{2}}$ is the direct consequence of reduced atmospheric $\mathrm{CO}_{2}$ under a constant ${ }^{14} \mathrm{C}$-production rate.

In the ocean-sediment model, $\delta^{13} \mathrm{C}_{\mathrm{CO}_{2}}$ increases by $\sim 0.4 \%$ and $\Delta^{14} \mathrm{C}_{\mathrm{CO}_{2}}$ rises by roughly $70 \%$ in response to a strengthened marine biological cycle (red lines in Fig. $4 \mathrm{~g}$ and $\mathrm{h}$ ). The time-dependent response in the carbon isotope signatures of atmospheric $\mathrm{CO}_{2}$ is more complex than in the ocean-only system. In particular, relaxation times are much longer due to the slow ocean-sediment interactions.

Next to the (transient) changes in the individual pumps' strengths, elevated sedimentation rates of organic matter and $\mathrm{CaCO}_{3}$ additionally affect the response in isotopic carbon signatures in the ocean-sediment setup. The sedimentary response in atmospheric ${ }^{13} \mathrm{C}_{\mathrm{CO}_{2}}$ is rather involved since excess organic matter burial removes carbon with negative $\delta^{13} \mathrm{C}$ and excess $\mathrm{CaCO}_{3}$ burial draws carbon with positive $\delta^{13} \mathrm{C}$ out of the system. Excess organic matter sedimentation dominates the response in atmospheric $\delta^{13} \mathrm{C}_{\mathrm{CO}_{2}}$ during the initial $25 \mathrm{kyr}$, whereas excess $\mathrm{CaCO}_{3}$ burial drives a slow reduction in $\delta^{13} \mathrm{C}_{\mathrm{CO}_{2}}$ thereafter (red line in Fig. $4 \mathrm{~g}$ ). This timedependent behavior results from the longer relaxation time of the marine $\mathrm{CaCO}_{3}$ cycle to the intensified marine biology as compared to the relaxation time of the organic matter cycle.

The sedimentary response pushes atmospheric $\Delta^{14} \mathrm{C}_{\mathrm{CO}_{2}}$ signatures towards more positive values (red line in Fig. 4h). On the one hand, the ocean-sediment interactions draw $\mathrm{CO}_{2}$ out of the atmosphere which elevates $\Delta{ }^{14} \mathrm{C}_{\mathrm{CO} 2}$ under constant ${ }^{14} \mathrm{C}$-production. On the other hand, enhanced organic matter and $\mathrm{CaCO}_{3}$ sedimentation further contribute to rising atmospheric $\Delta^{14} \mathrm{C}_{\mathrm{CO}_{2}}$ as excess burial removes relatively old carbon (with low $\Delta{ }^{14} \mathrm{C}$ ) from the combined oceanatmosphere system.

\subsubsection{Comparison to other studies}

Heinze et al. (1991) have increased the marine $\mathrm{PO}_{4}$ inventory by $30 \%$ in the 3-D Hamburg ocean-sediment model. They have found that atmospheric $\mathrm{CO}_{2}$ decreased by $60 \mathrm{ppm}$ and the Pacific $\mathrm{CaCO}_{3}$ saturation horizon deepened by roughly $900 \mathrm{~m}$. Sigman et al. (1998) only let low-latitude production rise upon a $30 \%$-increase in whole-ocean $\mathrm{PO}_{4}$ inventory in the CYCLOPS box model. They find an increase of $32 \%$ in low-latitude export production together with a $\mathrm{CO}_{2}$ reduction of $32 \mathrm{ppm}$ in the ocean-only setting. When $\mathrm{CaCO}_{3}$ sedimentation is additionally taken into account, the simulated $\mathrm{CO}_{2}$ decline is only of $19 \mathrm{ppm}$. As opposed to our results, the sedimentary response in their simulation is to counteract the $\mathrm{CO}_{2}$ drawdown resulting from strengthened biological pumps. Sigman et al. (1998) find a mean global shoaling in $\mathrm{CaCO}_{3}$ saturation depth of $500 \mathrm{~m}$, whereas here we obtain only a modest deepening.

The reason for this discrepancy is mainly the fact that POC burial is not taken into account explicitly by Sigman et al. (1998). The nutrient-feedback is thus not considered. In our simulations, the loss of nutrients through excess POC burial on the one hand draws carbon out of the ocean and on the other hand limits excess $\mathrm{CaCO}_{3}$ export in such a way that $\mathrm{CaCO}_{3}$ compensation has only a minor effect opposing the $\mathrm{CO}_{2}$ reduction. The impact of $\mathrm{CaCO}_{3}$ compensation on atmospheric $\mathrm{CO}_{2}$ is seen in a small increase occurring after 30 kyr (Fig. 4a, red line).

The following conclusions emerge. Perturbations in global burial fluxes due to ocean processes are removed on a multimillennial time scale to re-establish the balance between removal of organic matter, $\mathrm{CaCO}_{3}$, and opal by burial and corresponding weathering inputs from rivers and winds. As a consequence of this sedimentary compensation, some proxy signals that arise from changes in the internal ocean carbon cycle are partly or completely muted with time (see also next Sect. 3.3). Differences in proxies between distant time periods, for instance between the LGM and the late Holocene, may therefore partly reflect changes in the balance of the weathering-sedimentation cycle.

Kohfeld et al. (2005) compared productivity records for the late Holocene, the Last Glacial Maximum and marine isotope stage $5 \mathrm{a}$ to $5 \mathrm{~d}$. They concluded that export production was globally higher during the LGM than during either stage $5 \mathrm{a}-5 \mathrm{~d}$ or the Late Holocene. They suggest a limited role for the marine biological cycle to explain glacial-interglacial $\mathrm{CO}_{2}$ variations. Our results indicate that such a conclusion should be viewed with caution, because differences in proxies might also be related to imbalances in the weatheringsedimentation cycle. Potential secular trends arising from these imbalances should also be considered when analyzing whole ocean changes in $\delta^{13} \mathrm{C}$ to infer variations in organic matter pools (Shackleton, 1977; Bird et al., 1994) or in atmospheric $\delta^{13} \mathrm{C}_{\mathrm{CO}_{2}}$ (Leuenberger et al., 1992), as well as when interpreting the recorded evolution of nitrogen and silicate isotope signatures (Deutsch et al., 2004; De La Rocha, 2006).

\subsection{Global ocean ventilation}

The last set of simulations focusses on the response in atmospheric $\mathrm{CO}_{2}, \delta^{13} \mathrm{C}_{\mathrm{CO}_{2}}$ and $\Delta^{14} \mathrm{C}_{\mathrm{CO}_{2}}$ to changes in the rate of deep ocean ventilation. In these idealized experiments we vary deep ocean ventilation in the model by uniformly scaling the prescribed amplitude of both zonal and meridional wind stress in the Southern Ocean (south of $51^{\circ} \mathrm{S}$ ). The timedependent model response in atmospheric $\mathrm{CO}_{2}, \delta^{13} \mathrm{C}_{\mathrm{CO}_{2}}$ and $\Delta^{14} \mathrm{C}_{\mathrm{CO}_{2}}$ is then calculated as the result of the interplay between changes in ocean circulation, marine biogeochemical cycling and sediment diagenesis subsequent to abrupt change in wind boundary conditions. Note that gas-exchange velocities are kept unaffected and feedbacks mediated by SST 
Table 1. Bulk numbers characterising the preindustrial steady state of the coupled ocean-sediment Bern3D+C model compared to previous modelling results and independent estimates.

\begin{tabular}{lllll}
\hline Variable & Units & this study & Heinze et al. (2003) & Ind. estimates \\
\hline atm. $\mathrm{CO}_{2}$ & $\mathrm{ppm}_{\mathrm{POC} \text { export production }}$ & 278.0 & 277.7 & - \\
POC rain onto sediments & $\mathrm{GtC} \mathrm{yr}^{-1}$ & 12.76 & 8.66 & $6.5-13.1^{\mathrm{a}}$ \\
POC accumulation & $\mathrm{GtC} \mathrm{yr}^{-1}$ & 0.49 & 0.12 & $1.7-3.3^{\mathrm{a}}$ \\
$\mathrm{CaCO}_{3}$ export production & $\mathrm{GtC} \mathrm{yr}^{-1}$ & 1.13 & 1.64 & $0.12-0.26^{\mathrm{a}}$ \\
$\mathrm{CaCO}_{3}$ rain onto sediments & $\mathrm{GtC} \mathrm{yr}^{-1}$ & 0.40 & 0.42 & $0.8-1.2^{\mathrm{b}}$ \\
$\mathrm{CaCO}_{3}$ accumulation & $\mathrm{GtC} \mathrm{yr}^{-1}$ & 0.17 & 0.18 & $0.5^{\mathrm{c}}$ \\
Opal export production & $\mathrm{Tmol} \mathrm{Si} \mathrm{yr}^{-1}$ & 95 & 185 & $0.1-0.14^{\mathrm{d}}$ \\
Opal rain onto sediments & $\mathrm{Tmol} \mathrm{Si} \mathrm{yr}^{-1}$ & 64.9 & 81.3 & $102-178^{\mathrm{b}}$ \\
Opal accumulation & $\mathrm{Tmol} \mathrm{Si} \mathrm{yr}^{-1}$ & 1.12 & 5.5 & $13-47^{\mathrm{e}}$ \\
POC sediment pool & $\mathrm{GtC}$ & 428 & 241.9 & $5.3-8.9^{\mathrm{e}}$ \\
$\mathrm{CaCO}$ & & 881 & 1010 & - \\
Opal sediment pool & $\mathrm{GtC}$ & 9779 & 19986 & - \\
\hline
\end{tabular}

${ }^{a}$ Sarmiento and Gruber (2006), ${ }^{\text {b Jin et al. (2006), }}{ }^{\mathrm{c}}$ Millimann and Droxler (1996), ${ }^{\mathrm{d}}$ Feely et al. (2004), ${ }^{\mathrm{e}}$ Treguer et al. (1995)

changes and the response in terrestrial biosphere is not taken into account. The simulation set consists of separate runs in which SO wind stress is gradually varied between $20 \%$ and $180 \%$ relative to the original strength by steps of $20 \%$.

It has been found in several global ocean models (including ours) that deep mixing in the $\mathrm{SO}$ is driven to a large degree by momentum transfer from SH westerly winds to the ocean surface in the latitudinal band spanned by the Drake Passage (e.g., Toggweiler et al., 2006; Menviel et al., 2008; Tschumi et al., 2008). Furthermore, the modeled characteristics of deep ocean water masses are affected on a global scale by changes in SO deep mixing. Accordingly, the SO represents a major route of deep ocean ventilation in these ocean models.

Yet, it remains hard to draw conclusions on the physical mechanisms controlling deep mixing in the real SO. In recent studies, factors other than wind stress have been proposed to play a major role for the control of SO deep mixing. These are for instance sea-ice dynamics and buoancy forcing (e.g., Fischer et al., 2010; Watson and Naveira-Garabato, 2006), small-scale eddy flows which are not represented explicitely in most global ocean models (e.g., Spence et al., 2009; Böning et al., 2008) or other processes affecting the vertical stratification in the SO (Sigman et al., 2004; Paillard and Parennin, 2004). The relative importance of the different mechanisms capable of driving glacial-interglacial variations in SO deep mixing remains under debate. For this reason, the amplitude of SO winds in our simulations is regarded as a mere tuning knob for the circulation state in the model.

\subsubsection{Ocean circulation response}

The two most prominent features in the circulation response to $\mathrm{SO}$ wind variations are: (1) changes in the frequency and depth of convective events in the SO and (2) changes in the intensity and depth of the Atlantic meridional overturning circulation (AMOC). Stronger winds intensify deep convection and Ekman upwelling in the SO and strengthen the AMOC (Fig. 5b and Tschumi et al., 2008). Weaker winds induce the opposite response characterized by a more stably stratified Southern Ocean and less intense AMOC.

In case of strongly reduced wind stress $(20 \%$ or $40 \%$ of the original amplitude), the AMOC breaks down completely in the model, leaving the SO as the sole region of deep water formation. These latter circulation states are named "offstates" here, whereas the model states with active AMOC are denoted as "on-states".

As long as the AMOC remains active, i.e. in the on-states, deep ocean ventilation scales quite homogeneously across all ocean basins with the changes in SO wind amplitude (Fig. 5a). Deep ventilation ages below $2000 \mathrm{~m}$ vary almost linearly with the strength of SO wind stress. Globally averaged deep ventilation ages increase by 32 years per $10 \%$ reduction in $\mathrm{SO}$ wind strength. The Atlantic deep water age is slightly more sensitive (43 years/10\%-reduction) than in the other basins, owing to the changes in AMOC strength.

In case of the off-states the link between deep ocean ventilation ages and $\mathrm{SO}$ wind stress deviates from the quasi-linear relationship (Fig. 5a). In particular in the deep Atlantic, the AMOC shutdown results in a large anomalous drop of roughly 600 years in ventilation age. This model response indicates the change in end-members of Atlantic deep water subsequent to the collapse of AMOC. 


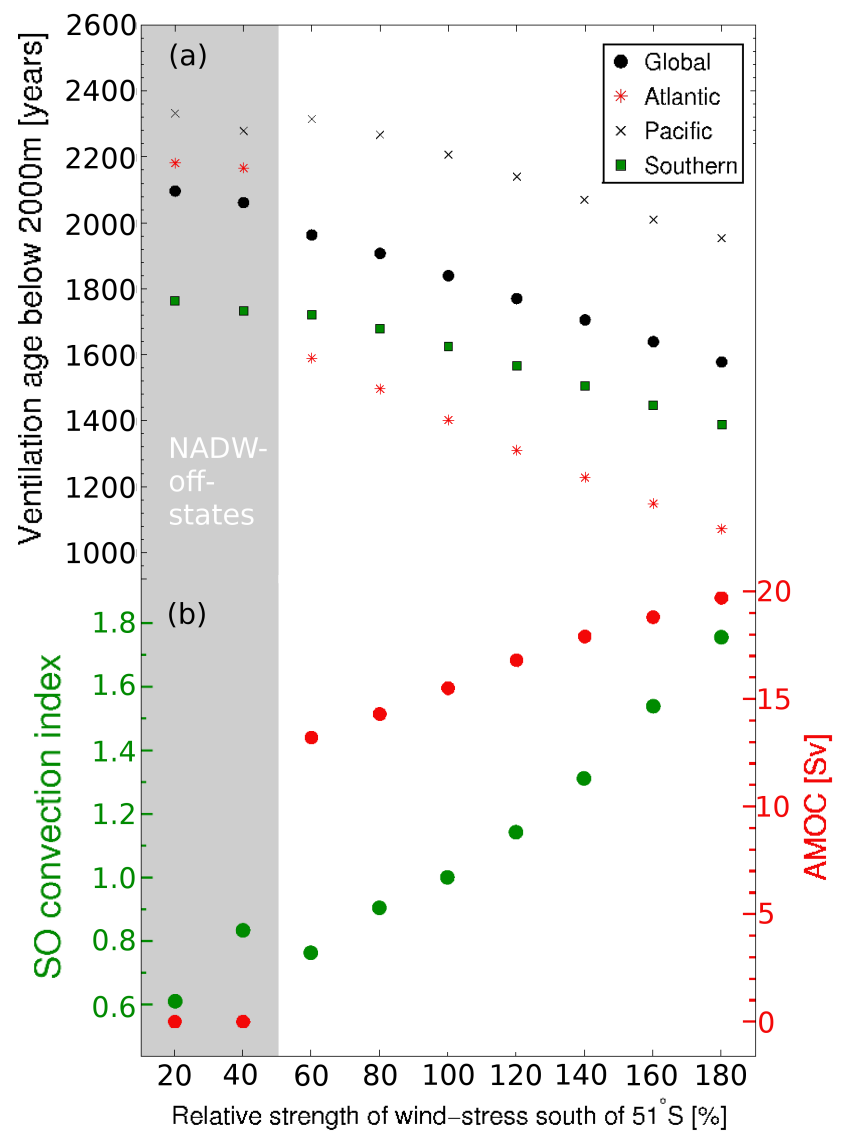

Fig. 5. (a) Ventilation age in different ocean basins as a function of the SO wind stress amplitude. Ventilation age is calculated from simulated ${ }^{14} R$-signatures in the ocean below $2000 \mathrm{~m}$ depth. ${ }^{14} R$ is treated here as an ideal age tracer in the sense that it is transported only by ocean circulation and the atmospheric signature is held constant $\left({ }^{14} R_{\mathrm{atm}}=1.0\right)$. Ventilation age is calculated as $\tau_{\text {basin }}=\frac{1}{\lambda} \ln \left({ }^{14} R_{\mathrm{atm}} / \overline{{ }^{14} R_{\text {basin }}}\right)$ where $\lambda=1 / 8267 \mathrm{yr}^{-1}$ is the decay constant for ${ }^{14} \mathrm{C}$ and $\overline{{ }^{14} R_{\text {basin }}}$ is the average ${ }^{14} R$-signature in the respective basin. (b) Southern Ocean convection index and Atlantic Meridional Overturning Circulation (AMOC) versus SO wind stress. The SO convection index is proportional to the number of model grid cells in the SO participating in convective mixing.

To sum up, changing wind stress in our model proves itself as an effective method to gradually vary globally averaged deep water age in a range between 1580 years $(180 \%$ SO wind stress) and 2100 years (20\% SO wind stress). Major structural shifts in the modeled global circulation pattern occur only if SO wind stress is strongly reduced to $20 \%$ or $40 \%$ where AMOC breaks completely.

\subsubsection{Response to sub-millennial processes}

Figure 6 shows the time-dependent response for a set of informative carbon cycle parameters. The reaction of atmospheric $\mathrm{CO}_{2}$ and its isotopic composition to changes in deep ocean ventilation is characterized by a major fast response unfolding during approximately the first $2 \mathrm{kyr}$ and a minor slow response over several $10 \mathrm{kyr}$ (Fig. 6a, g and h). The fast response arises from the reorganization of the ocean carbon pumps, the long-term response is driven by the slow adaptation of sediment formation to the altered biogeochemical state of the ocean. Atmospheric $\mathrm{CO}_{2}, \delta^{13} \mathrm{C}_{\mathrm{CO}_{2}}$ and $\Delta^{14} \mathrm{C}_{\mathrm{CO}_{2}}$ have reached a quasi-equilibrium after $2 \mathrm{kyr}$ in the oceanonly model, whereas in the ocean-sediment model sedimentation processes affect atmospheric carbon on a time scale of several $10 \mathrm{kyr}$.

Figure 7 shows the correlation between simulated deep ocean ventilation age and the changes in atmospheric $\mathrm{CO}_{2}$, $\delta^{13} \mathrm{C}_{\mathrm{CO}_{2}}$ and $\Delta^{14} \mathrm{C}_{\mathrm{CO}_{2}}$ at the time slice $2 \mathrm{kyr}$ after perturbing $\mathrm{SO}$ wind stress forcing. The results unambiguously display that better ventilated deep ocean watermasses drive an increase in atmospheric $\mathrm{CO}_{2}$, whereas $\delta^{13} \mathrm{C}_{\mathrm{CO}_{2}}$ and $\Delta^{14} \mathrm{C}_{\mathrm{CO}_{2}}$ decline. Model results of the ocean-sediment model at $2 \mathrm{kyr}$ are not substantially different from those of the ocean-only model since the effect of changes in sedimentation has not yet fully materialized at this early stage of the response.

Atmospheric $\mathrm{CO}_{2}$ and its isotopic signatures follow an almost linear relationship with deep ocean ventilation age for both without and with sediments as long as there is no AMOC collapse. Linearized sensitivities for $\delta^{13} \mathrm{C}_{\mathrm{CO}_{2}}$ $\left(0.08 \%\right.$ o/100 years) and for $\Delta^{14} \mathrm{C}_{\mathrm{CO}_{2}}(10 \% / 100$ years $)$ are almost identical in both model settings (Fig. $7 \mathrm{~b}$ and c). Changes in atmospheric $\mathrm{CO}_{2}$ are slightly larger ( $-8 \mathrm{ppm} / 100$ years) at the $2 \mathrm{kyr}$ time slice (Fig. 7a).

AMOC shutdowns significantly affect atmospheric $\mathrm{CO}_{2}$ and $\Delta^{14} \mathrm{C}_{\mathrm{CO}_{2}}$. The simulated changes for off-states clearly deviate from the linear relationship as displayed in Fig. 7a and $\mathrm{c}$. The AMOC shutdown induces an anomalous drawdown in atmospheric $\mathrm{CO}_{2}$ of $\sim 10 \mathrm{ppm}$ without sediments and of $\sim 20 \mathrm{ppm}$ with sediments. The anomalous rise in $\Delta^{14} \mathrm{C}_{\mathrm{CO}_{2}}$ is of $\sim 10 \%$ in the ocean-only model and of $\sim 15 \%$ o in the ocean-sediment model. Atmospheric $\delta^{13} \mathrm{C}_{\mathrm{CO}_{2}}$ on the other hand is rather unsensitive to the shutdown of AMOC. There is no substantial deviation from linearity in the relation between $\delta^{13} \mathrm{C}_{\mathrm{CO}_{2}}$ with the rate of deep ocean ventilation when AMOC shuts down (Fig. 7b).

The biological pump strongly dominates the net $\mathrm{CO}_{2}$ response subsequent to wind stress changes in our model (see also Tschumi et al., 2008). The effect of the solubility pump is minor as simulated changes in (potential) deep ocean temperature (below $2000 \mathrm{~m}$ ) are $\sim 0.5^{\circ} \mathrm{C}$ at most (Table 2). This translates into a maximum effect on atmospheric $\mathrm{CO}_{2}$ of roughly 5 ppm given the sensitivity of $\mathrm{CO}_{2}$-solubility to temperature in seawater (e.g., Sigman and Boyle, 2000). On the other hand, the imposed changes in ocean ventilation have a strong impact on the marine biological carbon pumps. Enhanced (reduced) ocean ventilation implies increased (diminished) upwelling of nutrients, thus promoting (weakening) biological export from the surface.

Table 2 indicates that organic matter export diagnosed at 2 kyr after the wind stress switch scales roughly linearly with 
a) Atmospheric $\mathrm{pCO}_{2}[\mathrm{ppm}]$

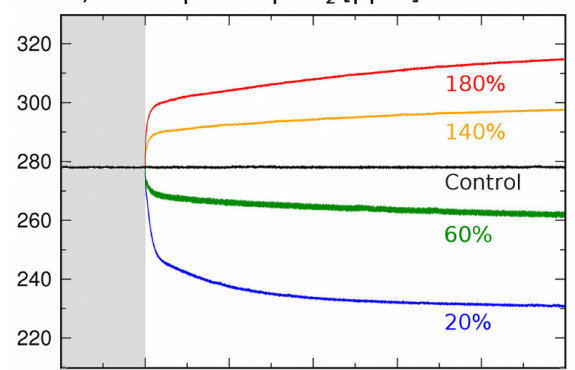

C) POC export production [GtC/yr]

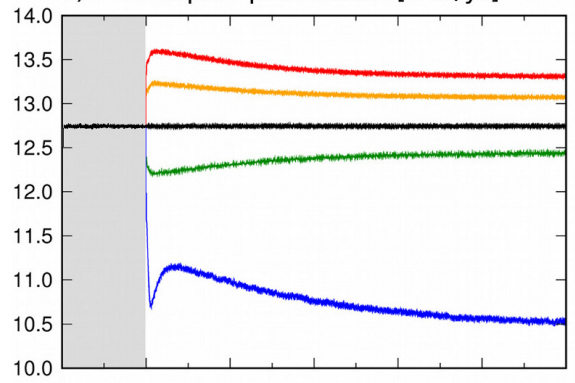

e) POC sediment burial [GtC/yr]

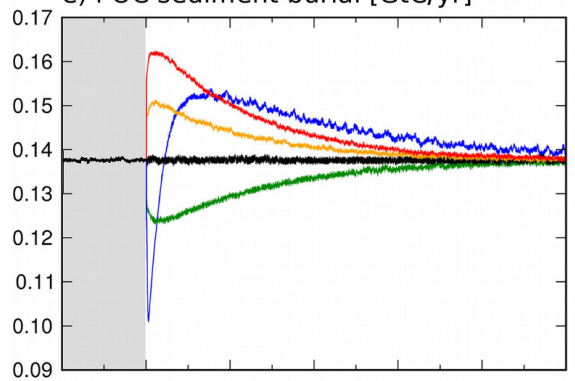

g) Atmospheric $\left.\delta^{13} \mathrm{C}^{[0} \%_{\text {oo }}\right]$

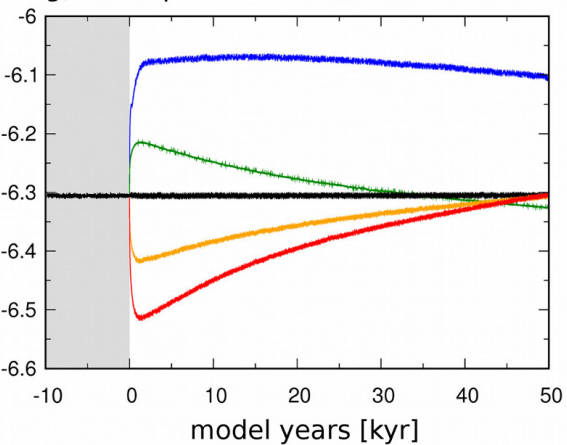

b) Pacific $\mathrm{CaCO} 3$ sat. horizon $[\mathrm{m}]$

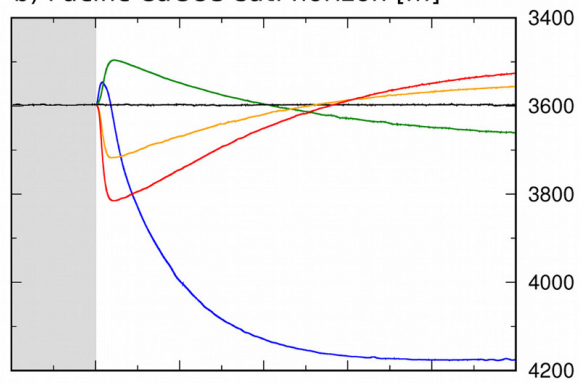

d) Opal export production [Tmol Si/yr]

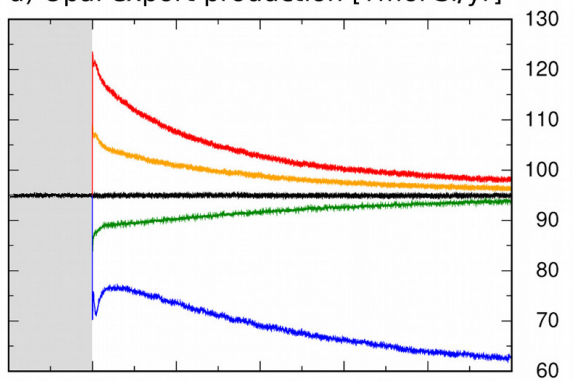

f) Opal sediment burial [Tmol Si/yr]

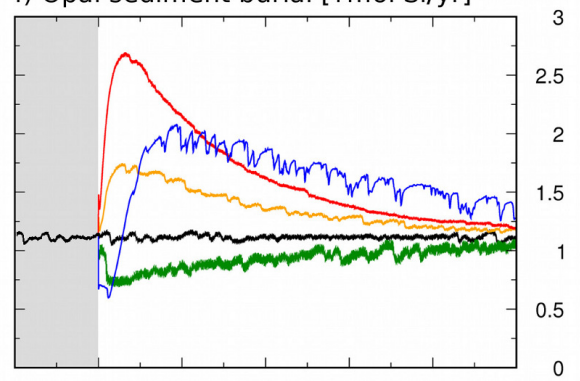

h) Atmospheric $\Delta^{14} \mathbf{C}\left[{ }^{\circ}{ }_{o o}\right]$

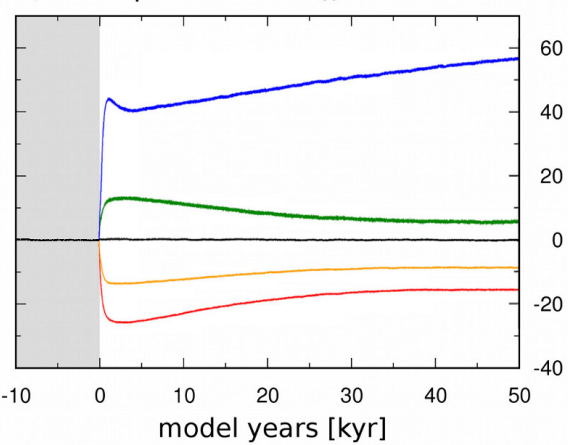

Fig. 6. Ocean ventilation experiments: time-dependent carbon cycle response of the coupled ocean-sediment system to changes in deep ocean ventilation induced by scaling the amplitude of windstress and deep convection in the Southern Ocean.

ventilation in case of the on-states (rising by $2.9 \%$ per 100 year reduction in global deep water age). The marine silica cycle reacts substantially more sensitively to the ocean ventilation changes than the organic matter cycle: Opal export at $2 \mathrm{kyr}$ increases by $8.6 \%$ upon a 100 year-reduction in global deep water age and decreases by $7.6 \%$ per 100 year-increase. The full time-dependent response in POC and opal export is shown in Fig. 6c and d.
Note that the efficiency of the soft-tissue pump $P *$, defined here as the ratio between regenerated and total phosphate in the deep ocean (Ito and Follows, 2005), behaves conversely, i.e. $P *$ increases as export production decreases parallel to slowed ventilation (Table 3). As long as NADW formation is active, a linear relation is found between atmospheric $\mathrm{CO}_{2}$ and $P *$ (Fig. 8), which reflects a maximum impact of the biological pumps of $336 \mathrm{ppm}$ at full efficiency. 
Table 2. Ocean ventilation experiments in the ocean-sediment model: simulated changes in the global mean deep ocean temperature, biological production and in the effeciency of the soft-tissue pump at the time slice $2 \mathrm{kyr}$ after the abrupt variation in ocean ventilation.

\begin{tabular}{|c|c|c|c|c|c|c|c|c|}
\hline $\begin{array}{l}\text { SO wind stress } \\
\text { amplitude }\end{array}$ & $\begin{array}{l}\text { Atm. } \\
p \mathrm{CO}_{2} \\
\mathrm{ppm}\end{array}$ & $\begin{array}{l}\text { Mean deep } \\
\text { water age }^{\mathrm{a}}\end{array}$ & $\begin{array}{c}\text { Mean deep } \\
\text { water temp. }{ }^{\text {a }} \\
{ }^{\circ} \mathrm{C}\end{array}$ & $\begin{array}{c}\text { POM } \\
\text { export } \\
\text { GtC yr }{ }^{-1}\end{array}$ & $\begin{array}{c}\mathrm{CaCO}_{3} \\
\text { export } \\
\mathrm{GtC} \mathrm{yr}^{-1}\end{array}$ & $\begin{array}{c}\text { Global mean } \\
\text { rain ratio }\end{array}$ & $\begin{array}{c}\text { Opal } \\
\text { export } \\
\text { Tmol Si yr }^{-1}\end{array}$ & $\begin{array}{c}\text { Efficiency of } \\
\text { soft-tissue } \\
\text { pump }^{b} \\
\%\end{array}$ \\
\hline $20 \%$ & 246.2 & 2097 & 2.02 & 11.07 & 0.99 & 0.089 & 76.8 & 52.0 \\
\hline $40 \%$ & 250.0 & 2062 & 1.51 & 11.42 & 1.02 & 0.089 & 79.1 & 48.8 \\
\hline $60 \%$ & 268.2 & 1963 & 1.49 & 12.14 & 1.08 & 0.089 & 86.4 & 47.7 \\
\hline $80 \%$ & 273.1 & 1908 & 1.54 & 12.54 & 1.11 & 0.089 & 92.7 & 46.7 \\
\hline Control & 278.0 & 1840 & 1.61 & 12.76 & 1.13 & 0.088 & 95.5 & 45.4 \\
\hline $120 \%$ & 284.2 & 1770 & 1.62 & 12.99 & 1.14 & 0.088 & 98.6 & 43.5 \\
\hline $140 \%$ & 290.1 & 1706 & 1.69 & 13.24 & 1.16 & 0.088 & 104.2 & 41.7 \\
\hline $160 \%$ & 295.3 & 1640 & 1.77 & 13.46 & 1.17 & 0.087 & 110.7 & 40.0 \\
\hline $180 \%$ & 300.0 & 1578 & 1.90 & 13.62 & 1.18 & 0.087 & 116.4 & 38.4 \\
\hline
\end{tabular}

${ }^{\mathrm{a}}$ Global mean values below $2000 \mathrm{~m}$ depth.

b Defined as the fraction of regenerated $\mathrm{PO}_{4}$ versus total $\mathrm{PO}_{4}$ after Ito and Follows (2005), Eq. (4).
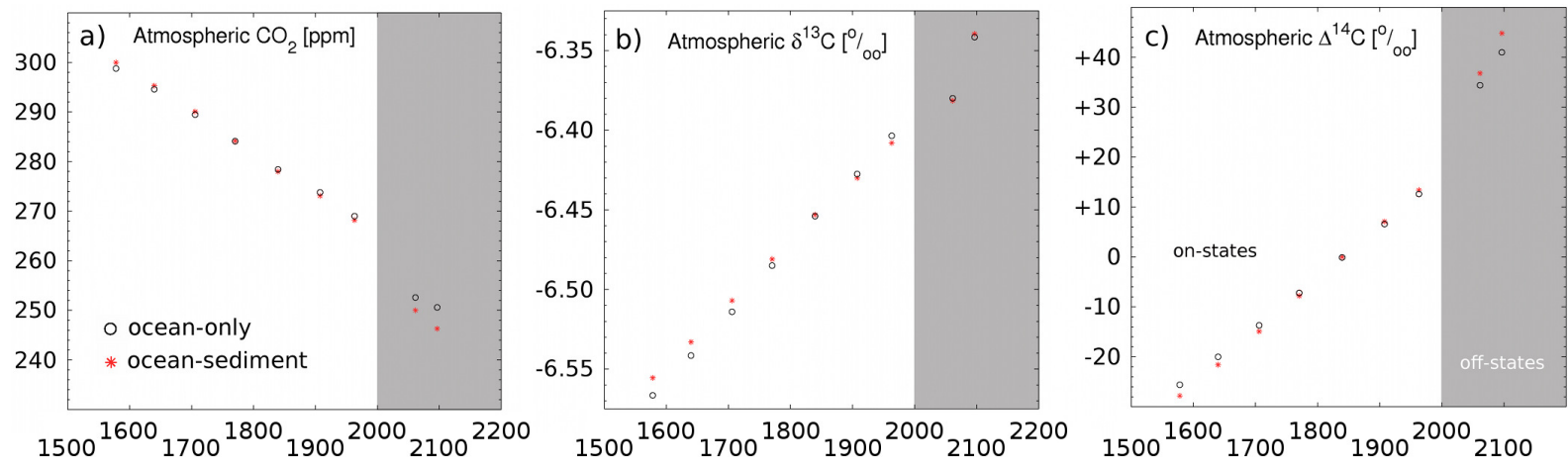

Deep water ventilation age below 2000m [years]

Fig. 7. Response in atmospheric (a) $\mathrm{CO}_{2}$, (b) $\delta^{13} \mathrm{C}_{\mathrm{CO}_{2}}$, and (c) $\Delta^{14} \mathrm{C}_{\mathrm{CO}_{2}}$ to changes in ocean ventilation. Displayed values are diagnosed for the time slice at $2 \mathrm{kyr}$ after the perturbation in $\mathrm{SO}$ wind forcing. At this time carbon, cycling has reached a new equilibrium in the ocean-only model (circles), whereas the ocean-sediment model (stars) is still under relaxation at 2 kyr due to the millennial-scale response of ocean-sediment interactions.

This value is close to the $312 \mathrm{ppm}$ found by Ito and Follows (2005) on the basis of a simple theory combining the mass balance for carbon and nutrients in the ocean-atmosphere system and the linearization of carbonate chemistry. The relatively close correspondence between this theoretical value and the sensitivity of atmospheric $\mathrm{CO}_{2}$ to $P *$ found in our experiments indicates that the predominant part of the simulated $\mathrm{CO}_{2}$ response to changes in $\mathrm{SO}$ deep water formation is due to changes in the biological pump efficiency.

The simulated relation between atmospheric $\mathrm{CO}_{2}$ and the soft-tissue pump efficiency $P *$ deviates from linearity as soon as NADW formation shuts down in response to weak $\mathrm{SO}$ winds (Fig. 8). Thus, the anomalous $\mathrm{CO}_{2}$ reduction of $\sim 10 \mathrm{ppm}$ due to the AMOC collapse cannot be explained with changes in the biological carbon pumps. Further, the absence of a drop in simulated global mean deep water temperature and in the global rain ratio (Table 2) seems to preclude a dominant role of the solubility and carbonate pumps. We conjecture that the simulated anomalous $\mathrm{CO}_{2}$ drop in response to collapsed AMOC results primarily from an increase in the deep water DIC disequilibrium component (Marinov et al., 2008).

The simulated interplay between ocean ventilation, marine carbon cycling and atmospheric $\mathrm{CO}_{2}$ displayed in our wind stress-experiments is in good qualitative agreement with the results of Schmittner et al. (2007), who find a similar response in marine biogeochemistry to changes in the global strength of wind stress. However, the effect of AMOC shutdowns on marine carbon cycling in our experiments cannot be readily compared with the corresponding results of 


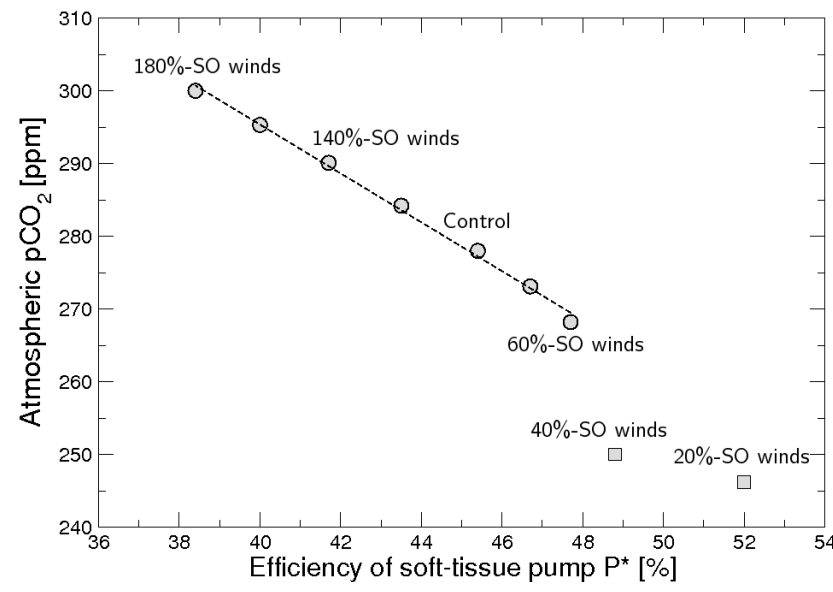

Fig. 8. Ocean ventilation experiments: quasi-linear relation between simulated atmospheric $\mathrm{CO}_{2}$ and the efficiency of the softtissue pump $P *$ (Ito and Follows, 2005) for the ventilation states with active NADW formation (circles). The linear relation is perturbed when NADW formation is shutdown in response to strongly reduced windstress in the Southern Ocean (rectangles).

Schmittner et al. (2007), since AMOC is suppressed by freshwater forcing in the North Atlantic in their experiments rather than by weak SO winds.

The reorganization of the marine biological cycle is further reflected in the simulated change in the nutrient distribution and $\delta^{13} \mathrm{C}_{\mathrm{DIC}}$ signatures. The total phosphate concentrations decrease and $\delta^{13} \mathrm{C}_{\mathrm{DIC}}$ signatures increase in the sea surface as ocean ventilation is slowed and euphotic zone nutrients are utilized more efficiently (Table 3 ). After propagation of this signal across the air-sea interface $\delta^{13} \mathrm{C}_{\mathrm{CO}_{2}}$ is shifted towards less negative values in the atmosphere. The radiocarbon signature in atmospheric $\mathrm{CO}_{2}, \Delta{ }^{14} \mathrm{C}_{\mathrm{CO}_{2}}$, increases in response to reduced ventilation due to slowed physical transport of radiocarbon to the deep ocean which ultimately reduces ocean uptake of ${ }^{14} \mathrm{C}$.

A specific consequence of the Southern Ocean ventilation mechanism is that vertical $\delta^{13} \mathrm{C}_{\mathrm{DIC}}$-gradients in the Southern Ocean should have steepened during glacials (Hodell et al., 2003; Ninnemann and Charles, 2002). Our results reproduce this connection between deep mixing in the Southern Ocean and the vertical gradient in $\delta^{13} \mathrm{C}_{\mathrm{DIC}}$. Reduced deep mixing evidenced by a larger $\Delta^{14} \mathrm{C}_{\text {DIC }}$ difference between the surface and deep Southern Ocean is accompanied by steeper vertical gradients in total phosphate and $\delta^{13} \mathrm{C}_{\text {DIC }}$ (Table 3). According to our results, upon a reduction of 100 years in the difference between surface and deep water age (mean value below $2000 \mathrm{~m}$ ) in the Southern Ocean, the $\delta^{13} \mathrm{C}_{\mathrm{DIC}}$-gradient (difference between surface and mean signature below $2000 \mathrm{~m}$ in the Southern Ocean) increases by $0.16 \%$ and the vertical phosphate-gradient grows by $0.13 \mathrm{~mol} \mathrm{~m}^{-3}$ (Table 3 ).

\subsubsection{The long-term effect of ocean-sediment interactions}

The long-term millennial-scale trends in atmospheric $\mathrm{CO}_{2}$, $\delta^{13} \mathrm{C}_{\mathrm{CO}_{2}}$ and $\Delta^{14} \mathrm{C}_{\mathrm{CO}_{2}}$ arise from the slow response in sediment diagenesis to the changing biogeochemical state of the ocean. The sedimentary processes tend to restore in the long run burial rates of $\mathrm{CaCO}_{3}, \mathrm{POC}$ and opal towards initial unperturbed values in order to re-establish the balance with the fixed weathering inputs.

The simulated variations in atmospheric $\mathrm{CO}_{2}$ are amplified by $30 \%-60 \%$ within $50 \mathrm{kyr}$ through the net effect of the sedimentary feedbacks subsequent to ventilation changes (Table 4). The overall simulated sedimentary $\mathrm{CO}_{2}$ response is dominated by the changes in $\mathrm{CaCO}_{3}$ burial. In fact, the shifts in organic matter burial counteract the simulated $\mathrm{CO}_{2}$ variations as long as AMOC is maintained (on-states). For instance, accelerated ocean ventilation leads to a net rise in atmospheric $\mathrm{CO}_{2}$, whereas elevated organic matter burial tends to reduce $\mathrm{CO}_{2}$ by drawing carbon out of the oceanatmosphere system. In the on-states, the sedimentary $\mathrm{CO}_{2}$ response amplification is of 30\%-40\% (Table 4). In case of collapsing AMOC on the other hand, $\mathrm{CO}_{2}$ changes are reinforced by the sedimentary feedbacks by as much as $60 \%$, since both carbonate compensation from reduced $\mathrm{CaCO}_{3} \mathrm{ex}-$ port as well as excess POC burial driven by the reduction in deep ocean oxygen availability reinforce the $\mathrm{CO}_{2}$ drawdown from slowed ventilation.

In contrast to the previous experiment in which the wholeocean nutrient content is enhanced, the concomitant variations in deep ocean oxygen availability subsequent to ventilation changes weaken the importance of the nutrient-feedback by decoupling the link between shifts in POC export and in POC sediment burial. Enhanced (decreased) ventilation promotes (reduces) remineralization within the sediments through increased (decreased) oxygen concentrations in pore waters. A specific consequence is that the changes in POC export arising from altered deep ocean ventilation are maintained to a substantial degree in the long term (Fig. 6c). The POC burial flux, however, relaxes again to initial conditions to re-establish the balance with weathering input. In conclusion, the variations in oxygen availability in the ocean driven by the ventilation changes significantly decouple the link between POC export and POC burial. This decoupling complicates the reconstruction of past POC export on the basis of sedimentary records.

The sedimentary response in atmospheric $\delta^{13} \mathrm{C}_{\mathrm{CO}_{2}}$ is dominated by the temporal evolution of POC burial. For instance, in the model states with accelerated ocean ventilation, excess POC burial draws organic matter with low $\delta^{13}(\sim-20 \%)$ out of the ocean-atmosphere system. As a consequence, the sediment response is to shift $\delta^{13} \mathrm{C}_{\mathrm{CO}_{2}}$ towards less negative values (Fig. 6g, red and yellow lines). Excess burial of POC and $\mathrm{CaCO}_{3}$ both remove carbon with low $\Delta^{14} \mathrm{C}$ from the ocean-atmosphere system in response to a better ventilated 
Table 3. Ocean ventilation experiments in the ocean-sediment model: simulated changes in ocean biogeochemistry of different ocean regions at $2 \mathrm{kyr}$.

\begin{tabular}{|c|c|c|c|c|c|c|c|c|c|c|}
\hline \multirow[t]{2}{*}{$\begin{array}{l}\text { SO wind stress } \\
\text { amplitude }\end{array}$} & \multicolumn{5}{|c|}{$\begin{array}{l}\text { North Atlantic below } 2000 \mathrm{~m} \\
\qquad\left(0^{\circ}-71^{\circ} \mathrm{N}\right)\end{array}$} & \multicolumn{5}{|c|}{$\begin{array}{l}\text { North Pacific below } 2000 \mathrm{~m} \\
\qquad\left(0^{\circ}-63^{\circ} \mathrm{N}\right)\end{array}$} \\
\hline & $\begin{array}{c}\Delta^{14} \mathrm{C} \\
{[\% o]}\end{array}$ & $\begin{array}{l}\delta^{13} \mathrm{C} \\
{[\% o]}\end{array}$ & $\begin{array}{c}\mathrm{PO}_{4} \\
{\left[\mu \mathrm{moll} 1^{-1}\right]}\end{array}$ & $\begin{array}{c}\mathrm{PO}_{4}^{\mathrm{reg}} \\
{\left[\mu \mathrm{moll}^{-1}\right]}\end{array}$ & $\begin{array}{c}\mathrm{O}_{2} \\
{\left[\mu \mathrm{mol} 1^{-1}\right]}\end{array}$ & $\begin{array}{r}\Delta^{14} \mathrm{C} \\
{[\% o]}\end{array}$ & $\begin{array}{l}\delta^{13} \mathrm{C} \\
{[\% \circ]}\end{array}$ & $\begin{array}{r}\mathrm{PO}_{4} \\
{\left[\mu \mathrm{moll}^{-1}\right]}\end{array}$ & $\begin{array}{c}\mathrm{PO}_{4}^{\mathrm{reg}} \\
{\left[\mu \mathrm{moll}^{-1}\right]}\end{array}$ & 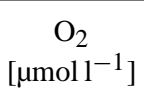 \\
\hline $20 \%$ & -260 & 0.171 & 2.54 & 1.31 & 118.2 & -273 & 0.092 & 2.61 & 1.37 & 106.4 \\
\hline $40 \%$ & -258 & 0.179 & 2.55 & 1.23 & 134.7 & -265 & 0.011 & 2.60 & 1.26 & 129.1 \\
\hline $60 \%$ & -195 & 0.632 & 1.98 & 0.88 & 191.0 & -279 & 0.011 & 2.74 & 1.33 & 117.5 \\
\hline $80 \%$ & -188 & 0.671 & 1.94 & 0.85 & 194.8 & -279 & 0.026 & 2.73 & 1.31 & 121.4 \\
\hline Control & -180 & 0.711 & 1.88 & 0.81 & 198.9 & -278 & 0.049 & 2.70 & 1.28 & 127.1 \\
\hline $120 \%$ & -173 & 0.734 & 1.84 & 0.77 & 203.3 & -276 & 0.077 & 2.68 & 1.22 & 136.7 \\
\hline $140 \%$ & -168 & 0.745 & 1.82 & 0.73 & 205.9 & -274 & 0.102 & 2.66 & 1.17 & 144.6 \\
\hline $160 \%$ & -163 & 0.754 & 1.78 & 0.70 & 208.5 & -273 & 0.123 & 2.64 & 1.13 & 151.4 \\
\hline $180 \%$ & -156 & 0.774 & 1.74 & 0.66 & 211.9 & -272 & 0.141 & 2.62 & 1.10 & 156.9 \\
\hline \multirow[t]{2}{*}{$\begin{array}{l}\text { SO wind stress } \\
\text { amplitude }\end{array}$} & \multicolumn{5}{|c|}{$\begin{array}{c}\text { Southern Ocean below } 2000 \mathrm{~m} \\
\left(\text { South of } 51^{\circ} \mathrm{S}\right)\end{array}$} & \multicolumn{5}{|c|}{$\begin{array}{l}\text { Southern Ocean surface } \\
\left(\text { South of } 51^{\circ} \mathrm{S}\right)\end{array}$} \\
\hline & $\begin{array}{l}\Delta^{14} \mathrm{C} \\
{[\% o]}\end{array}$ & $\begin{array}{l}\delta^{13} \mathrm{C} \\
{[\% o]}\end{array}$ & $\begin{array}{c}\mathrm{PO}_{4} \\
{\left[\mu \mathrm{mol} 1^{-1}\right]}\end{array}$ & $\begin{array}{c}\mathrm{PO}_{4}^{\mathrm{reg}} \\
{\left[\mu \mathrm{moll}^{-1}\right]}\end{array}$ & $\begin{array}{c}\mathrm{O}_{2} \\
{\left[\mu \mathrm{moll} 1^{-1}\right]}\end{array}$ & $\begin{array}{r}\Delta^{14} \mathrm{C} \\
{[\% o]}\end{array}$ & $\begin{array}{l}\delta^{13} \mathrm{C} \\
{[\% o]}\end{array}$ & $\begin{array}{r}\delta^{13} \mathrm{C}_{\mathrm{S}-\mathrm{D}} \\
{[\% \circ]}\end{array}$ & $\begin{array}{c}\mathrm{PO}_{4} \\
{\left[\mu \mathrm{moll} 1^{-1}\right]}\end{array}$ & $\begin{array}{c}\mathrm{O}_{2} \\
{\left[\mu \mathrm{mol} 1^{-1}\right]}\end{array}$ \\
\hline $20 \%$ & -196 & 0.385 & 2.27 & 1.06 & 160.8 & -61 & 2.350 & 1.964 & 0.57 & 297.3 \\
\hline $40 \%$ & -198 & 0.377 & 2.30 & 0.98 & 178.9 & -73 & 2.198 & 1.821 & 0.69 & 296.9 \\
\hline $60 \%$ & -208 & 0.308 & 2.40 & 1.01 & 175.3 & -99 & 2.049 & 1.741 & 1.04 & 296.7 \\
\hline $80 \%$ & -208 & 0.330 & 2.39 & 0.98 & 180.1 & -106 & 1.944 & 1.614 & 1.11 & 296.5 \\
\hline Control & -207 & 0.358 & 2.36 & 0.94 & 186.5 & -112 & 1.871 & 1.513 & 1.18 & 295.8 \\
\hline $120 \%$ & -205 & 0.392 & 2.34 & 0.88 & 197.2 & -119 & 1.799 & 1.407 & 1.24 & 295.4 \\
\hline $140 \%$ & -204 & 0.425 & 2.32 & 0.82 & 206.1 & -125 & 1.725 & 1.301 & 1.31 & 295.0 \\
\hline $160 \%$ & -202 & 0.455 & 2.30 & 0.77 & 214.5 & -130 & 1.658 & 1.203 & 1.37 & 294.6 \\
\hline $180 \%$ & -199 & 0.490 & 2.27 & 0.72 & 222.3 & -135 & 1.603 & 1.113 & 1.41 & 294.5 \\
\hline
\end{tabular}

deep ocean. As a result, atmospheric $\Delta^{14} \mathrm{C}_{\mathrm{CO}_{2}}$ is driven towards slightly less negative values (Fig. $6 \mathrm{~h}$, red and yellow lines).

Figure $6 \mathrm{~b}$ (red and yellow lines) displays that an accelerated ocean ventilation further induces an initial deepening in the $\mathrm{CaCO}_{3}$ saturation horizon which is offset after $1-2 \mathrm{kyr}$. The first part of the response results from the removal of carbon from the ocean interior as a result of rejuvenated deep water masses and excess POC sedimentation. The subsequent shoaling is due to the slowly responding effect of carbonate compensation to excess $\mathrm{CaCO}_{3}$ burial.

The model experiments with collapsing AMOC exhibit the strongest reduction in nutrient supply to the surface and in globally integrated POC export from the surface (blue line in Fig. 6c). Global POC export remains reduced significantly in the long run. However, subsequent to the strong initial decrease, POC export in the North Atlantic eventually increases after about 200 years driven by diffusion of nutrients along isopycnals to the North Atlantic ocean surface. This response in POC export production is qualitatively similar to the results of Chikamoto et al. (2008) where AMOC has been shut down through a freshwater discharge in the
North Atlantic. In our model, we additionally find a longterm decreasing trend in global POC export after $5 \mathrm{kyr}$ which is due to whole-ocean nutrient loss by excess POC burial. This nutrient-feedback has not been taken into account by Chikamoto et al. (2008).

Similarly to POC export, organic matter burial strongly declines during the first 200 years (blue line in Fig. 6e). Thereafter, the burial rate sharply recovers as a result of increasing POC export in the North Atlantic and a strongly reduced deep ocean oxygen supply. After around 2500 years, there is excess POC burial in spite of the reduction in global POC export production. Opal export and opal sediment burial exhibit a similar response as POC export and burial do (Fig. 6d and f): The AMOC shutdown induces major shifts also in the spatial pattern of opal export and sedimentation, with the North Atlantic becoming a region of deep nutrient upwelling similar to the North Pacific.

The reorganization in the marine biological carbon cycle in case of AMOC shutdowns is further reflected in the timedependent model response for the depth of the $\mathrm{CaCO}_{3}$ saturation horizon. The AMOC collapse induces an initial shoaling of the $\mathrm{CaCO}_{3}$ saturation horizon as DIC accumulates in 
Table 4. Long-term response in atmospheric $\mathrm{CO}_{2}$ and amplification by sedimentary feedbacks.

\begin{tabular}{ccccc}
\hline $\begin{array}{c}\text { SO wind stress } \\
\text { amplitude }\end{array}$ & $\begin{array}{c}\text { Global Deep } \\
\text { Water Age } \\
\text { [years] }\end{array}$ & $\begin{array}{c}\text { Atmospheric } \mathrm{CO}_{2} \\
\text { without sediments } \\
\text { after 50 kyr } \\
\text { [ppm] }\end{array}$ & $\begin{array}{c}\text { Atmospheric } \mathrm{CO}_{2} \\
\text { with sediments } \\
\text { after 50 kyr } \\
\text { [ppm] }\end{array}$ & $\begin{array}{c}\text { Sedimentary } \\
\text { amplification } \\
\text { of the } \mathrm{CO}_{2} \text { response } \\
{[\%]}\end{array}$ \\
\hline $20 \%$ & 2097 & 251 & 234 & $63 \%$ \\
$40 \%$ & 2062 & 252 & 236 & $62 \%$ \\
\hline $60 \%$ & 1963 & 269 & 265 & $44 \%$ \\
$80 \%$ & 1908 & 273 & 271 & $40 \%$ \\
Control & 1840 & 278 & 278 & - \\
$120 \%$ & 1770 & 285 & 287 & $33 \%$ \\
$140 \%$ & 1706 & 290 & 294 & $30 \%$ \\
$160 \%$ & 1640 & 295 & 302 & $30 \%$ \\
$180 \%$ & 1578 & 299 & 308 & \\
\hline
\end{tabular}

the deep from the slowed ventilation and reduced POC burial (Fig. 6b). Consistently, the shoaling is more pronounced in the Atlantic than in the Pacific basin. After 1-2 kyr the saturation horizon starts to deepen again in both basins as deep $\left[\mathrm{CO}_{3}^{2-}\right]$ rises from the combined effects of reduced $\mathrm{CaCO}_{3}$ burial and increasing POC burial. The final steady state shift in the $\mathrm{CaCO}_{3}$ saturation horizon is a deepening of $100-200 \mathrm{~m}$ in the Atlantic and of 500-600 m in the Pacific.

\section{Discussion}

Our modelling approach is associated with a number of conceptual and methodological limitations worth mentioning. First, the model scenarios are idealized and not intended to directly reflect the temporal evolution of paleo-proxy signals as recorded in climatic archives. Second, changes in deep ocean ventilation are generated by varying the magnitude of the wind stress in the Southern Ocean by more than a factor of two. This is a convenient technical tuning mechanism to adjust the deep ocean ventilation age in the model. However, we stress the fact that these variations in $\mathrm{SO}$ wind strength exceed the range of realistic changes. The atmospheric $\mathrm{CO}_{2}$ response to realistic variations has been found to be rather modest (Tschumi, 2009; Menviel et al., 2008).

The model simulations have been tailored to investigate the specific response in atmospheric $\mathrm{CO}_{2}$ and other paleoproxies to uniform variations in deep ocean ventilation age. Several possibly important processes to explain the full glacial-interglacial $\mathrm{CO}_{2}$ variability have not been taken into account. We have neglected, for instance, the well-recorded variations of AMOC (McManus et al., 2004), changes in the terrestrial biosphere, in sea surface temperatures or in sea ice cover. Further, the Bern $3 \mathrm{D}+\mathrm{C}$ is a model of intermediate complexity with coarse resolution and does not resolve eddies and other processes operating on small scales. Marine biological production is represented as simple prognostic formulations considering the competition between opal and calcite producers and changes in the uptake ratio of silica to phosphate.

When interpreting the model results in the context of carbon cycle changes during the last deglaciation it should be kept in mind that the starting point of all sensitivity experiments is a stationary state corresponding to the preindustrial climate and carbon cycle. This modelling approach has been chosen, as the knowledge about glacial climate is subject to considerable uncertainty. The focus of this study is further laid upon a more qualitative interpretation of the interplay between different carbon cycle processes which depends less critically on the specific choice of initial conditions than the quantitative interpretation of a single paleoclimatic process or signal.

Nevertheless, we have have performed an additional sensitivity experiment in order to quantify the uncertainty associated with the initial state of ocean ventilation: Starting from a stationary state with preindustrial carbon cycle boundary conditions but with low ocean ventilation as resulting from $60 \%$-SO winds, SO wind stress has been increased to $140 \%$. Comparing the response in atmospheric $\mathrm{CO}_{2},{ }^{13} \mathrm{C}_{\mathrm{CO}_{2}}$ and $\Delta^{14} \mathrm{C}_{\mathrm{CO}_{2}}$ with the corresponding $180 \%$-SO winds experiment starting from standard winds (red lines in Fig. 6) has shown that the sensitivity to the initial ventilation state of the ocean is negligible as long as there is no structural shift in the large-scale circulation pattern such as a breakdown of AMOC.

In spite of the inherent limitations mentioned above, the results of our study allow for a number of robust conclusions. We argue in the following that the processes represented in our model played a dominant role for reorganizing the global carbon cycle during the early part of the last deglaciation. 


\subsection{Southern Ocean ventilation hypothesis}

The "Southern Ocean ventilation hypothesis" (e.g., Francois et al., 1997) is the starting point for discussion of our modelling results. According to this hypothesis, low glacial $\mathrm{CO}_{2}$ values are related to a poorly ventilated deep ocean and a stably stratified Southern Ocean. Such a configuration would lead to an accumulation of carbon in the deep ocean during glacial periods relative to interglacials. The rise in atmospheric $\mathrm{CO}_{2}$ over the glacial transition is driven by the breakup of Southern Ocean stratification and the resumption of modern-scale upwelling, bringing water rich in carbon, silica, and other nutrients and depleted in ${ }^{13} \mathrm{C}$ and ${ }^{14} \mathrm{C}$ to the surface. The characteristics of these upwelled water masses are further communicated within the intermediate and surface ocean by entrainment into the Subantarctic Mode Water and Antarctic Intermediate Water and to the atmosphere by air-sea gas-exchange. During recent years, a large number of observational evidence has been published supporting the view that changes in SO deepwater formation and in deep ocean ventilation have played an important role for glacialinterglacial $\mathrm{CO}_{2}$ variations (e.g., Fischer et al., 2010; Spero and Lea, 2002; Adkins et al., 2002; Anderson et al., 2009; Muscheler et al., 2004; Brovkin et al., 2007; Hodell et al., 2003; Marchitto et al., 2007; Francois et al., 1997).

The response of our ocean-sediment carbon cycle model to strengthened Southern Hemisphere westerly winds reproduces some of the key mechanisms attributed to the "Southern Ocean ventilation hypothesis". Invigorated wind stress promotes vertical exchange of water masses in the SO, thereby significantly affecting the physical and biogeochemical properties of deep ocean water on a global scale. Our results highlight in particular a rather close correlation between changes in ventilation age, the amount of biologically sequestered carbon and the $\delta^{13} \mathrm{C}$-signature in sea water as shown in Fig. 9.

In the following sub-sections we will discuss paleo-data from sediment analyses and from ice cores which indicate that large changes in Southern Ocean ventilation indeed occurred during the early part of the deglaciation, roughly in the interval between $18 \mathrm{kaBP}$ and the onset of the Antarctic Cold reversal and the Bølling/Allerød Northern Hemisphere warming at about $14.6 \mathrm{ka} \mathrm{BP}$ (Severinghaus and Brook, 1999). We will then compare the data with our model results to constrain the magnitude of the change in atmospheric $\mathrm{CO}_{2}$ over the last termination which is driven by a $\mathrm{SO}$ ventilation mechanism.

\subsubsection{Changes in Southern Ocean opal sedimentation}

Anderson et al. (2009) report reconstructed opal fluxes in Southern Ocean sediments which show a rapid increase starting roughly together with the rise in atmospheric $\mathrm{CO}_{2}$ around $17 \mathrm{ka} \mathrm{BP}$, followed by a deglacial maximum and a long-term decrease into the Holocene (Fig. 9). Opal flux rates are typically several-fold higher during the transition compared to glacial and late-Holocene values. Anderson et al. (2009) interpret these opal flux changes as variations in Southern Ocean upwelling, concluding that there was a rapid increase in the upwelling of silica and carbon rich deep water to the Southern Ocean surface at the onset of deglaciation $(\sim 18 \mathrm{ka} \mathrm{BP})$. They propose a direct link between the increased ventilation of deep water to the deglacial rise in atmospheric $\mathrm{CO}_{2}$.

The step-wise strengthening of SO wind stress as applied in our ocean ventilation experiments drives an immediate rise in deep upwelling in the Southern Ocean in response to enhanced Ekman pumping and more vigorous deep convection in the model. These simulations may thus serve as model scenarios for an abrupt resumption of upwelling in the SO. Figure 9 shows that our model results for strengthened SO wind stress are in good qualitative agreement with the sediment data of Anderson et al. (2009) in relative magnitude and timing: Increasing SO wind stress by $80 \%$ drives a rapid $30 \%$-rise in opal export as more silica is supplied to the surface. Additionally, opal sedimentation also increases and reaches a peak value with a delay of several millennia relative to the reinvigoration of deep upwelling in the Southern Ocean. The peak sedimentation flux is two to three times higher than the initial flux. Both opal export and sedimentation slowly decrease towards initial rates with a typical time scale of $20 \mathrm{kyr}$. Note however that simulated opal burial fluxes are about 10 times smaller than the reconstructed opal flux (Fig. 9). This is likely due to the spatial averaging over the model grid cell and the relatively low simulated global burial rate of opal as compared to available estimates (Table 1).

Anderson et al. (2009) suggest, based on the positive correlation between ${ }^{231} \mathrm{~Pa} /{ }^{230} \mathrm{Th}$ and opal flux in their records, that the deglacial maximum in opal flux reflects past changes in opal production and $\mathrm{Si}$ supply rather than variable opal preservation. In our model however, a relatively modest increase in global silica export of $30 \%$ enhances the net flux to the sediments in a highly non-linear way as pore water concentrations of silicic acid and thus the preservation of opal in the sediments greatly increases under the enhanced rain of silica particles (Archer et al., 2000a; Ridgwell et al., 2002). The majority of the simulated change in opal sedimentation flux thus reflects increased preservation rather than increased opal production as suggested by Anderson et al. (2009).

Why does the reconstructed opal sedimentation flux relax towards glacial conditions over the course of the Holocene, whereas atmospheric $\mathrm{CO}_{2}$ and, presumably, Southern Ocean upwelling remains at high interglacial values? From a continued large Southern Ocean upwelling, one might expect a continued silica supply to the surface ocean, and a sustained high export and sedimentation rate. In our simulation, increased opal burial drives a loss of whole-ocean silica. As a result, the simulated export of opal and its sedimentation rate 

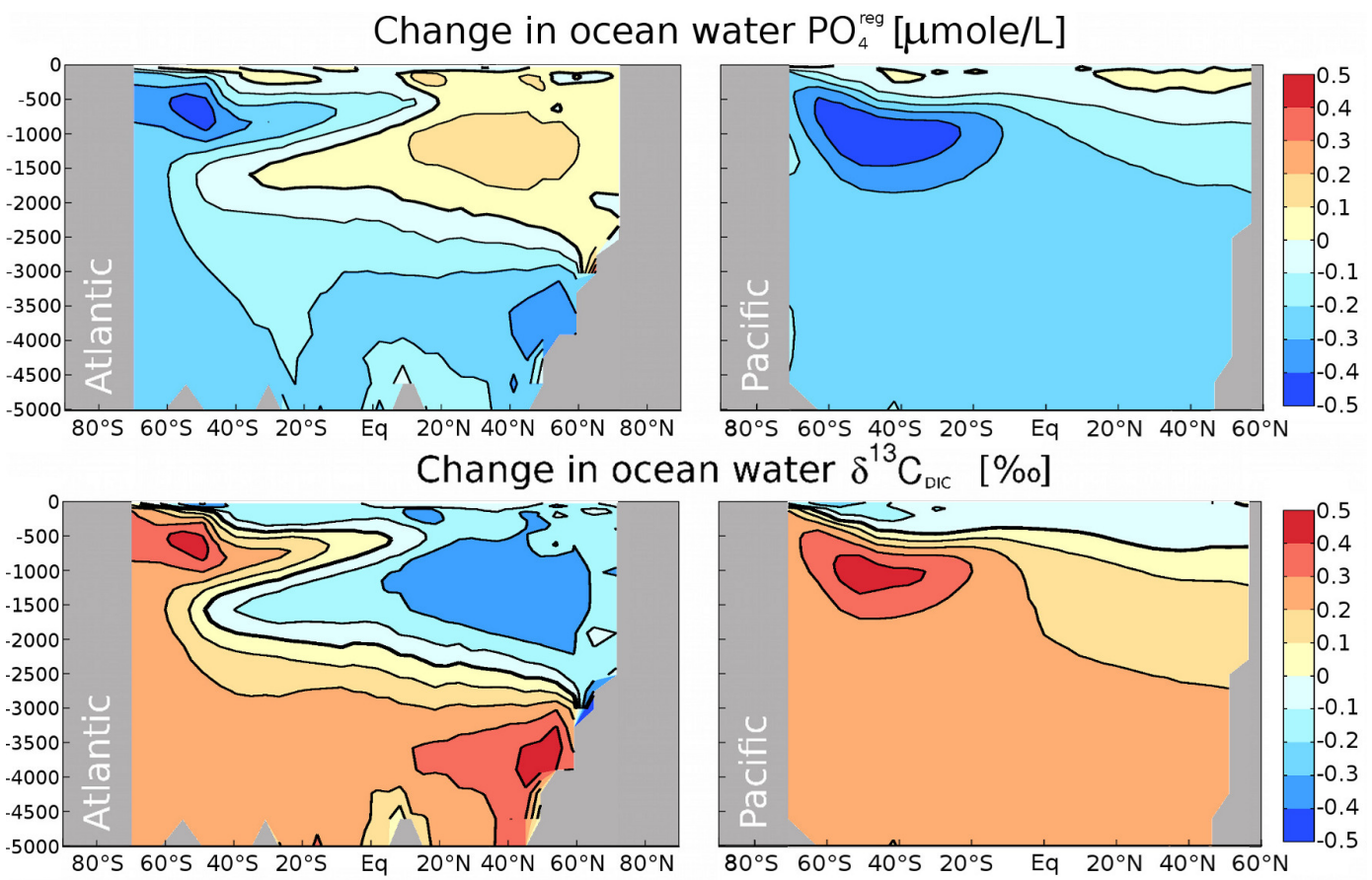

\section{Change in water ventilation age [years]}
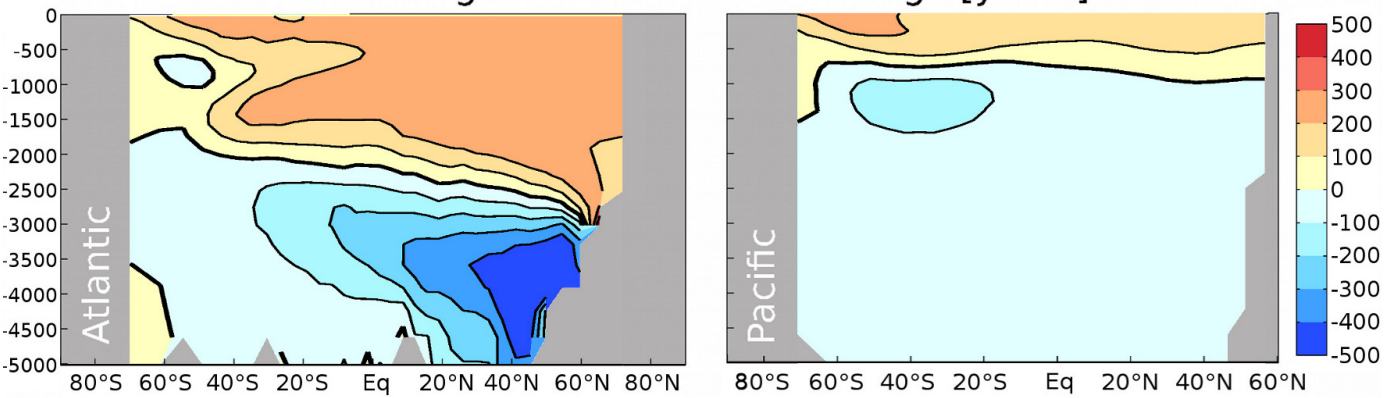

Change in ocean water $\Delta^{14} \mathrm{C}_{\mathrm{DIC}}[\%$ o]
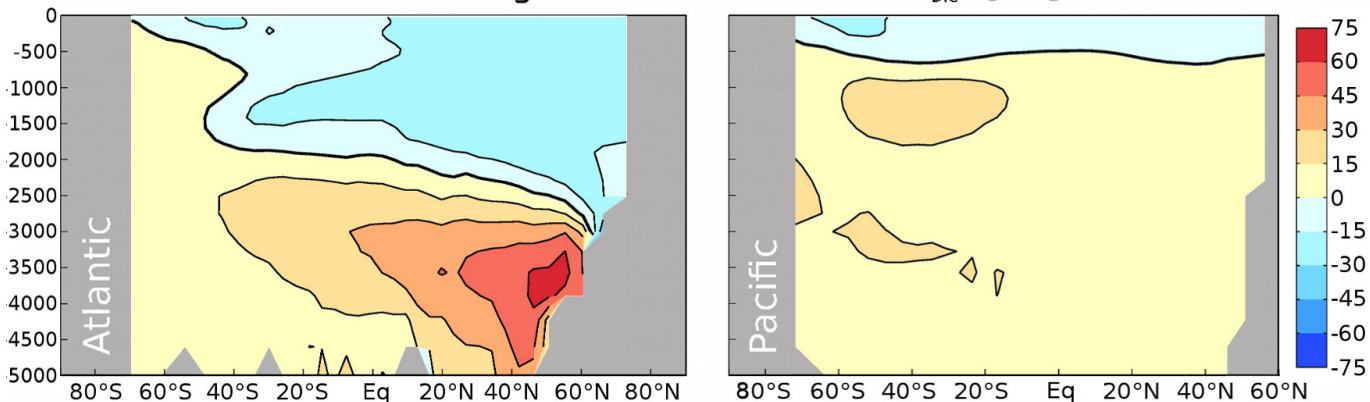

Fig. 9. Model response for $\delta^{13} \mathrm{C}_{\text {DIC }}$, ventilation age and $\Delta^{14} \mathrm{C}_{\text {DIC }}$ to stimulated deep mixing in the Southern Ocean and to more vigorous and deeper AMOC as a result of a $80 \%$-increase in SO wind stress amplitude. Shown are the simulated differences in Atlantic and Pacifc zonal mean sections at $15 \mathrm{ka}$ after the the step-wise perturbation of the model state.

relax towards initial conditions to balance riverine input with the burial flux of silica.

Is the evolution of the opal sedimentation flux directly correlated with opal export and the resumption of upwelling or are there any system time lags? The simulated peak in opal sedimentation is delayed by several millennia compared to the onset of the ventilation in our model. This suggests that the temporal evolution of the ventilation history may be difficult to disentangle exactly from the temporal evolution of the opal sedimentation flux. Nevertheless, the opal records appear consistent with a change in deep ocean ventilation that occurred during the early deglacial period and that may or may not have been abrupt. 


\subsubsection{Changes in the stable carbon isotope ratio $\delta^{13} \mathrm{C}$}

Figure 10 displays the currently available $\delta^{13} \mathrm{C}_{\mathrm{CO}_{2}}$ records from Antarctic ice cores covering the period of the last deglaciation (Smith et al., 1999; Lourantou et al., 2010; Elsig, 2009) together with reconstructed atmospheric $\mathrm{CO}_{2}$ (Monnin et al., 2001) and $\delta^{18} \mathrm{O}_{\mathrm{H}_{2} \mathrm{O}}$ (Stenni et al., 2001), which is a proxy for local temperature on the ice sheet. The $\delta^{13} \mathrm{C}_{\mathrm{CO}_{2}}$ records consistently show an early deglacial decrease of $0.3-0.4 \%$ o to reach a minimum at around $15 \mathrm{ka} \mathrm{BP}$ and a millennial-scale long-term increase by the same magnitude to attain approximately constant values at $7 \mathrm{ka} \mathrm{BP}$ (Elsig et al., 2009). However, the records disagree on the details of the $\delta^{13} \mathrm{C}_{\mathrm{CO}_{2}}$ evolution during the $\mathrm{B} \varnothing l$ ling/Allerød-Younger Drias climate swings.

Sediment cores from different ocean basins (Indo-Pacific, sub-Antarctic, and South Atlantic) reveal that the occurrence of carbon isotope minima at the beginning of glacial terminations is a widespread feature in planktic foraminifera $\delta^{13} \mathrm{C}$ records (Spero and Lea, 2002). The decrease in the $\delta^{13} \mathrm{C}$ records occurred simultaneously with the initiation of Southern Ocean warming. The data suggests a decrease in surface water $\delta^{13} \mathrm{C}$ in the early deglacial period $(\sim 20 \mathrm{kaBP}$ to $16 \mathrm{ka} \mathrm{BP}$ ), an absolute minimum at the same time as the ice core record of Smith et al. (1999) which is followed by an increase over the rest of the deglacial period into the early Holocene. Taken together, both sediment and ice core data suggest decreasing atmospheric $\delta^{13} \mathrm{C}$ during the first stage of the deglacial period followed by a long-term increase of similar magnitude.

How can this millennial-scale $\delta^{13} \mathrm{C}$ evolution be explained? Our results lend support for the interpretation of Spero and Lea (2002) and Köhler et al. (2005) that the early deglacial $\delta^{13} \mathrm{C}$ decrease reflected renewed Circumpolar Deep Water upwelling with an enhanced transport of low $\delta^{13} \mathrm{C}$. A decrease in atmospheric $\delta^{13} \mathrm{C}_{\mathrm{CO}_{2}}$ of $0.3 \%$ would require a rejuventation of deep ocean waters by 300 to 400 years according to the $\delta^{13} \mathrm{C}_{\mathrm{CO}_{2}}$ sensitivity found in our ventilation experiments (Fig. 7b). Subsequently, this negative signal is reduced by roughly $50 \%$ over the following $15 \mathrm{kyr}$ due to excess sedimentation of organic material (Fig. $6 \mathrm{~g}$ ). This would leave an increase of $0.1-0.2 \%$ o to be explained by other processes such as carbon uptake by the terrestrial biosphere, surface ocean warming or sea ice retreat.

\subsubsection{Changes in $\mathrm{CaCO}_{3}$ saturation horizon depth}

Analyses of the sedimentary bulk composition indicate a period of enhanced preservation of $\mathrm{CaCO}_{3}$ deep sea sediments between $\sim 15-7 \mathrm{kaBP}$ (Ridgwell et al., 2003; Broecker et al., 2001). Broecker et al. (2001) attribute this sedimentary signal to an early deglacial restoration of the terrestrial biosphere. The resulting removal of carbon from the atmospheric and oceanic reservoirs is made responsible for a deepening of the $\mathrm{CaCO}_{3}$ saturation horizon between about

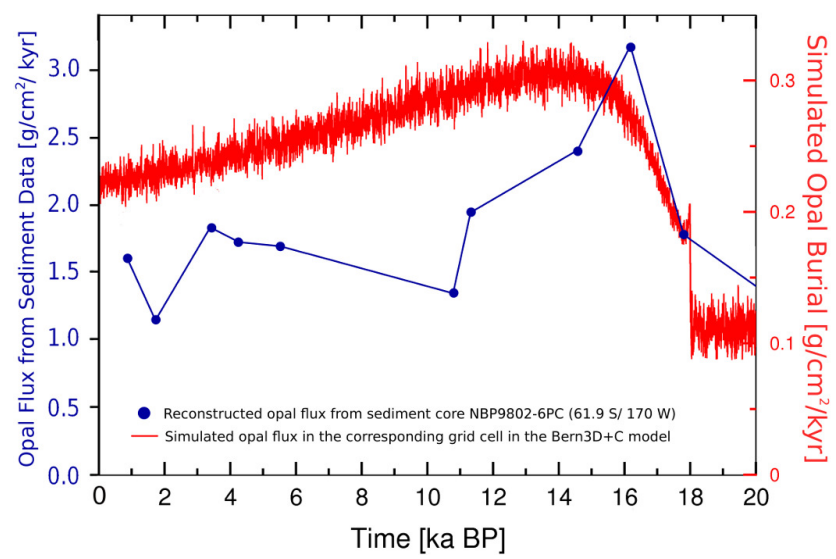

Fig. 10. Reconstructed local opal flux (blue line) at $61.9^{\circ} \mathrm{S} / 170^{\circ} \mathrm{W}$ from Anderson et al. (2009) and simulated opal burial rate in the corresponding model cell (red line) as simulated in the experiment with an abrupt $80 \%$-increase in SO wind stress at $18 \mathrm{ka} \mathrm{BP}$.

15-10 ka BP. The deepening is followed by a gradual shoaling until the latter part of the Holocene which is attributed to carbonate compensation. Ridgwell et al. (2003) invoke regrowth of coral reefs as additional factor driving the deglacial signal of the Pacific $\mathrm{CaCO}_{3}$ saturation horizon to simultaneously account for the evolution of atmospheric $\mathrm{CO}_{2}$.

In response to stimulated upwelling in the Southern Ocean rejuvenating deep waters by $300-400$ years, our model predicts a similar temporal evolution for the Pacific $\mathrm{CaCO}_{3}$ saturation horizon. We simulate a deepening saturation horizon by $300-400 \mathrm{~m}$ during the first $\sim 2 \mathrm{kyr}$ and a slow shaoling thereafter to reach initial depths after around $28 \mathrm{kyr}$ (Fig. 6b). The simulated initial deepening is a result of the flushing of the old carbon-rich deep water mass from the Pacifc basin and of excess organic matter sedimentation (Fig. 4b). This is consistent with deglacial $\mathrm{CaCO}_{3}$ and organic matter flux reconstructions from the North Pacific (e.g., Jaccard et al., 2005; Galbraith et al., 2007) as well as with $\mathrm{CO}_{3}^{2-}$ reconstructions based on benthic $\mathrm{Zn} / \mathrm{Ca}$ measured in the deep equatorial Pacific (Marchitto et al., 2005). However, the timing of our model results does not match the observations very precisely, maybe due to the unrealistic abrupt change in model boundary conditions. Nevertheless, the agreement is sufficient in order to indicate that increasing deep ocean ventilation and early deglacial excess sedimentation of organic matter may have significantly contributed to the recorded carbonate ion signal in the Pacific ocean in addition to the changes in terrestrial biosphere and growth of coral reefs as proposed by Broecker et al. (2001) and Ridgwell et al. (2003).

\subsubsection{Changes in radiocarbon signatures}

Is an increase in deep ocean ventilation consistent with marine radiocarbon data? To generate the full amplitude of 
the early deglacial $35 \mathrm{ppm}$ increase in atmospheric $\mathrm{CO}_{2}$, a decrease in the deep ocean ventilation age of about 300400 years is required according to the model-derived linear relationship between $\mathrm{CO}_{2}$ and ventilation age (Fig. 7a). Corresponding simulated changes in deep ocean $\Delta^{14} \mathrm{C}_{\mathrm{DIC}}$ are an increase of 40-45 in the deep North Atlantic of $10-15 \%$ in the deep North Pacific and in the deep Southern Ocean (Table 4). Atmospheric $\Delta^{14} \mathrm{C}$ would drop by 30-40\%o (Fig. 7c). The simulated atmosphere-deep ocean $\Delta^{14} \mathrm{C}$-difference would thus be reduced by $70-80 \%$ in the deep Atlantic and by 40-50\%o in the deep North Pacific and the deep Southern Ocean.

A decrease in deep ocean ventilation age of 300-400 years during the early deglacial period seems broadly consistent with available proxy records. However, the locally large changes between $18 \mathrm{kaBP}$ and $14.5 \mathrm{kaBP}$ in the benthicplanktonic age-difference of $\sim 1000$ years in the Atlantic sector of the SO (Skinner et al., 2010) or of $\sim 700$ years in the deep North Pacific (Galbraith et al., 2007) are not reproduced in our model. Overall, our results are in line with the modelbased interpretation of the glacial-interglacial changes in past atmospheric $\Delta^{14} \mathrm{C}$ by Köhler et al. (2006b) where a $\sim 40 \%$ ocontribution is attributed to changes in ocean circulation, compared to the $30-40 \%$ from our results.

A difficulty in the interpretation of marine $\Delta^{14} \mathrm{C}$ data in terms of ventilation age is that the $\Delta^{14} \mathrm{C}$ signature at any given time does not just reflect the ventilation age, but also the time history of the atmospheric $\Delta{ }^{14} \mathrm{C}$. The life time of radiocarbon with respect to radioactive decay is 8267 years, implying a considerable memory to earlier $\Delta^{14} \mathrm{C}$ variations. Atmospheric $\Delta{ }^{14} \mathrm{C}$ decreased by about $400 \%$ over the last transition (Hughen et al., 2004; Beck et al., 2001). A riddle presents the as yet unexplained drop of about $190 \%$ o between 17.5 to $14.5 \mathrm{ka} \mathrm{BP}$ (Broecker and Barker, 2007). This drop is almost four times larger than the scenario-based decrease of $50 \%$ and apparently also finds no correspondence in deep ocean radiocarbon change (Broecker and Barker, 2007). We are cautious to draw conclusions at this stage and believe that further evaluations are required using transient simulations of the coevolution of atmospheric $\mathrm{CO}_{2}, \Delta{ }^{14} \mathrm{C}$, and ${ }^{14} \mathrm{C}$ productivity.

\section{Conclusions}

Can we estimate the contribution of the Southern Ocean ventilation mechanism to the last deglacial $\mathrm{CO}_{2}$ rise on the basis of our model results? $\mathrm{CO}_{2}$ rose by about $35 \mathrm{ppm}$ between the LGM and $15 \mathrm{kaBP}$ (Fig. 10). If this $\mathrm{CO}_{2}$ increase is entirely attributed to rejuvenating deep ocean waters, it would translate into a global reduction in deep water age of roughly 350 years, according to the model-derived linear relationship between $\mathrm{CO}_{2}$ and ventilation age (Fig. 7a). Due to carbonate compensation in response to this ventilation change, $\mathrm{CO}_{2}$ would increase by another $\sim 10 \mathrm{ppm}$ over

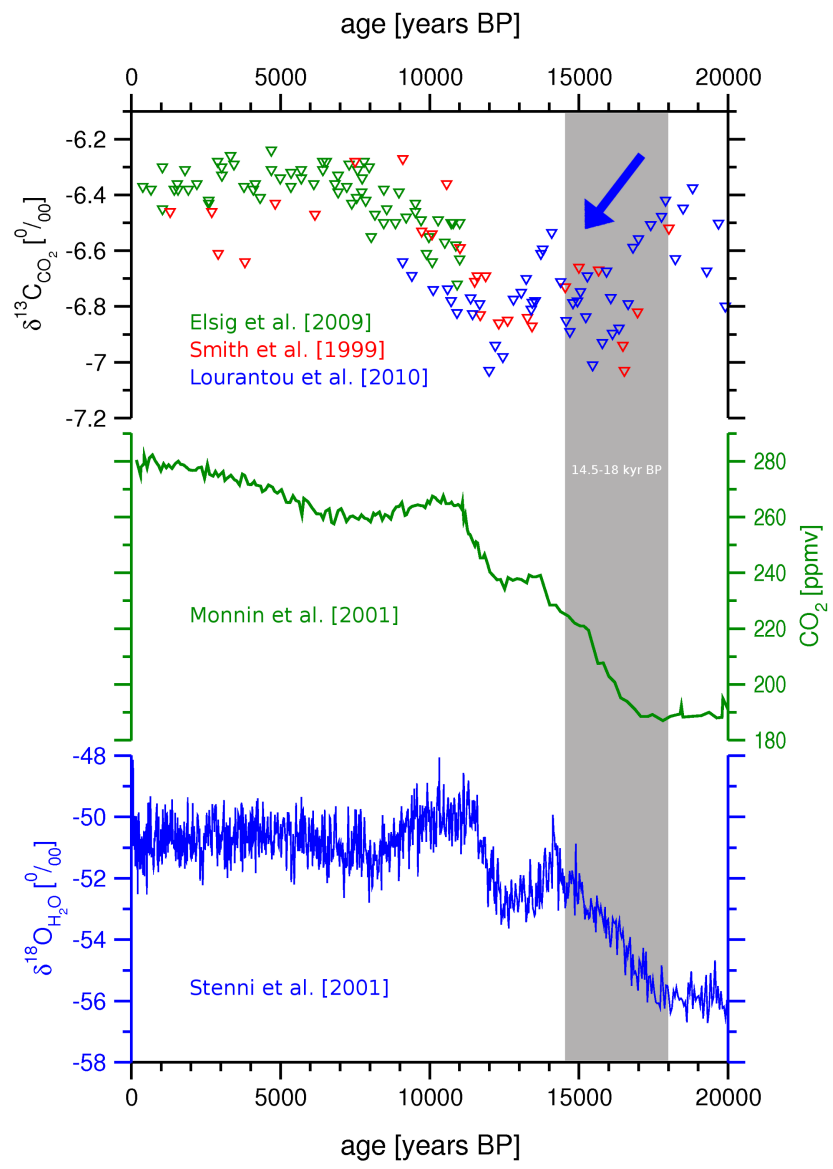

Fig. 11. Paleo-records from Antarctic ice cores: $\delta^{13} \mathrm{C}$-data is from Elsig et al. (2009) (green triangles), Smith et al. (1999) (red triangles) and Lourantou et al. (2010) (blue triangles). The blue arrow indicates the recorded drop in $\delta^{13} \mathrm{C}_{\mathrm{CO}_{2}}(\sim-0.4 \%$ ) starting around $18 \mathrm{ka} \mathrm{BP} . \mathrm{CO}_{2}$-data is from Monnin et al. (2001) and $\delta^{18} \mathrm{O}$ data from Stenni et al. (2001).

the following $15 \mathrm{kyr}$. The early deglacial $\mathrm{CO}_{2}$ increase might also reflect positive contributions from surface water temperature changes (Tschumi et al., 2008) and an estimated negative contribution from terrestrial uptake due to $\mathrm{CO}_{2}$ fertilization on ice-free land (Joos et al., 2004). The two effects might have roughly cancelled. Taken together, our model results suggest that the Southern Ocean ventilation mechanism has contributed about half to the reconstructed total glacialinterglacial $\mathrm{CO}_{2}$ increase of 90-100 ppm.

Our interpretation is further supported by a number of prominent paleo-proxy signals that are adequately reproduced in our simulations. As a response to an abrupt rejuvenation of deep ocean watermasses by 300-400 years stimulated by more vigorous deep convection in the Southern Ocean, we simulate a decline in $\delta^{13} \mathrm{C}_{\mathrm{CO}_{2}}$ by $\sim 0.3 \%$ o during the first $2 \mathrm{kyr}$ followed by a gradual rise as observed in the paleo-records. Taken at face value, the ice core data suggest a slope of $12 \mathrm{ppm}$ per $0.1 \%$ change in $\delta^{13} \mathrm{C}_{\mathrm{CO}_{2}}$ (35 ppm per 
$0.3 \%$ ) during the early deglacial period, whereas the modelderived slope amounts to $13 \mathrm{ppm}$ per $0.1 \%$. The model response also agrees well with increased opal sedimentation rates in the Southern Ocean during the early deglaciation (Anderson et al., 2009) and is further consistent with the reconstructed evolution of the Pacific $\mathrm{CaCO}_{3}$ saturation horizon (Broecker et al., 2001). We finally predict a drop of 30$40 \%$ in atmospheric $\Delta{ }^{14} \mathrm{C}_{\mathrm{CO}_{2}}$ as another result of the invigorated deep ocean ventilation.

Although the simulated model response fits rather well with these specific paleo-proxy records, a perfect match should not be expected. Modeled carbon cycle sensitivities might be subject to considerable uncertainty, in particular due to unsettled questions related to the diffusivity of the oceans (Archer et al., 2000b). Further, it turned out difficult to reproduce the exact temporal evolution of $\delta^{13} \mathrm{C}$ and $\Delta{ }^{14} \mathrm{C}$, as recorded in sediment cores in the model. These signals might sensitively depend upon regional and temporal details of the deglacial reorganization of global ocean circulation and may be further affected by the variations of AMOC (McManus et al., 2004) not considered here. Nonetheless, based on the multi-proxy comparison between our simulated response and the available paleo-data, we conclude that accelerating deep ocean ventilation linked to physical processes in the SO has been the dominant driver of early deglacial changes in global carbon cycling. Early deglacial ocean ventilation changes have continued to significantly contribute to variations in atmospheric $\mathrm{CO}_{2}$ until the latter part of the Holocene, since it takes millennia for marine sedimentation to re-establish equilibrium with weathering input.

The glacial-interglacial $\mathrm{CO}_{2}$ variations appear to be driven by a complex spatio-temporal pattern of processes involving relaxation time-scales of years to millennia. Our analysis of the time-dependent response in the coupled oceansediment system highlights that the benefit of conventional "time slice" approaches to study these processes might be rather limited. Our model results suggest that proxy signals arising from deglacial ventilation changes are sustained on a multi-millennial time-scale until the balance between carbon, nutrient and isotope input through rivers and winds and the loss through sedimentation is re-established. Thus, differences in these proxies between the LGM and the late Holocene time slice may partly reflect imbalances in the weathering-sedimentation cycles. This may also be relevant for proxies not included here such as silica or nitrogen isotopes.

We have identified a feedback between the marine nutrient inventory and sedimentation of organic matter. This mechanism emerges from the fact that marine biological productivity in the long run is limited by the riverine input of nutrients into the ocean. Our results indicate that this nutrientsediment feedback might be important for glacial-interglacial changes in global carbon cycling. For instance, invigorated ocean circulation promotes export production and excess sediment burial of organic matter. The implications for the combined ocean-atmosphere carbon cycle are similar to those of a postulated early deglacial restoration of the terrestrial biosphere (Broecker et al., 2001).

In this study, we have analyzed the time-dependent response in atmospheric $\mathrm{CO}_{2}$ and its isotopic signatures only to the specific mechanisms of deep ocean ventilation changes and biological pump reorganizations. To improve the process-related understanding of the $\mathrm{CO}_{2}, \delta^{13} \mathrm{C}_{\mathrm{CO}_{2}}$ and $\Delta^{14} \mathrm{C}_{\mathrm{CO}_{2}}$ records over the last deglaciation, further mechanisms such as sea surface temperature changes, coral reef growth, changes in the carbon stock on land and the spatiotemporal details of the various regional oceanic reorganizations should be considered in coupled 3-D global carbon cycle models. Simultaneous model-data comparison on the basis of multiple proxy records wisely chosen seems to be a promising approach towards a better understanding of the dynamical interplay between the multiple factors driving glacial-interglacial $\mathrm{CO}_{2}$ fluctuations. A particular challenge is to identify and simulate the physical mechanisms responsible for the changes in Southern Ocean ventilation.

\section{Appendix A}

\section{Sediment diagenesis model}

The sediment diagenesis component used in this study is built on previous work by Heinze et al. (1999) and Gehlen et al. (2006) where the basic modelling concept is based on Archer et al. (1993). The spatial model domain is restricted to the diagenetical zone of the sediments which is assumed here to be the top $10 \mathrm{~cm}$ of the surface sediments. Any solid material leaving this domain disappears into the subjacent diagenetically consolidated zone. The interfaces of the 10 model layers are defined at depths of $0,0.3,0.6,1.1,1.6,2.1$, $3.1,4.1,5.1,7.55$, and $10.0 \mathrm{~cm}$. The fraction of pore water volume (porosity) decreases from 0.95 to 0.75 , following observations from Ullman and Aller (1982). Model geometry remains fixed during integration.

The vertical movement of solid material in the sediment column is calculated on the basis of the equilibrium: burial $=$ rain redissolution. When the particulate rain onto the sediment is larger than the redissolution of solid material within the diagenetical zone, the entire column is shifted downwards and sediment burial occurs. Conversely, whenever redissolution is larger than rain, gaps of solid material are produced within the model geometry. These are filled with clay from below. Lateral movements in the sediments are not considered.

Modeled tracers are the four solid components $\left(\mathrm{CaCO}_{3}\right.$, opal, POM and clay) and the six pore water substances (DIC, total alkalinity, phosphate, nitrate, oxygen and silicic acid). $\mathrm{CaCO}_{3}$ is only considered in the form of calcite. The less stable aragonite form is assumed to be only of secondary importance for the global sediments (Berner and Honjo, 1981). 
Table A1. Parameters for the sediment component of the Bern3D+C model along with standard values and references.

\begin{tabular}{|c|c|c|c|}
\hline Symbol & Parameter & Value & Reference \\
\hline & Number of time steps per year & 48 & this study \\
\hline$\rho$ & Density of solid sediment components & $2.6 \mathrm{~g} \mathrm{~cm}^{-3}$ & Heinze et al. (1999) \\
\hline$M_{\mathrm{POM}}$ & Molar weight of POM & $32.74 \mathrm{~g} \mathrm{~mol}^{-1}$ & Heinze et al. (1999) \\
\hline$M_{\mathrm{CaCO}_{3}}$ & Molar weight of $\mathrm{CaCO}_{3}$ & $100.0 \mathrm{~g} \mathrm{~mol}^{-1}$ & Heinze et al. (1999) \\
\hline$M_{\text {opal }}$ & Molar weight of opal & $67.2 \mathrm{~g} \mathrm{~mol}^{-1}$ & Heinze et al. (1999) \\
\hline$M_{\text {clay }}$ & Molar weight of clay & $430.51 \mathrm{~g} \mathrm{~mol}^{-1}$ & Heinze et al. (1999) \\
\hline & Terrestrial clay flux & $1 \mathrm{~g} \mathrm{~m}^{-2} \mathrm{yr}^{-1}$ & Heinze et al. (1999) \\
\hline$r_{\mathrm{CaCO}_{3}}$ & Rate constant for $\mathrm{CaCO}_{3}$ redissolution & \multirow{2}{*}{$\begin{array}{l}10001 \mathrm{~mol}^{-1} \mathrm{yr}^{-1} \\
201 \mathrm{~mol}^{-1} \mathrm{yr}^{-1}\end{array}$} & Heinze et al. (1999) \\
\hline$r_{\text {opal }}$ & Rate constant for opal redissolution & & this study \\
\hline$r_{\text {oxy }}$ & Rate constant for oxydation & $501 \mathrm{~mol}^{-1} \mathrm{yr}^{-1}$ & Heinze et al. (1999) \\
\hline$r_{\text {denit }}$ & Rate constant for denitrification & $501 \mathrm{~mol}^{-1} \mathrm{yr}^{-1}$ & Gehlen et al. (2006) \\
\hline$[\mathrm{Si}]_{\text {sat }}$ & $\begin{array}{l}\text { Saturation concentration } \\
\text { for pore water silicic acid }\end{array}$ & $800 \mu \mathrm{moll}^{-1}$ & Heinze et al. (2003) \\
\hline$D$ & Pore water diffusion coefficient & \multirow{3}{*}{$\begin{array}{l}8 . \times 10^{-6} \mathrm{~cm}^{2} \mathrm{~s}^{-1} \\
15 . \times 10^{-3} \mathrm{~cm}^{2} \mathrm{yr}^{-1} \\
1 \mu \mathrm{mol} 1^{-1}\end{array}$} & Heinze et al. (1999) \\
\hline$D_{\mathrm{B}}$ & Bioturbation diffusion coefficient & & Heinze et al. (1999) \\
\hline$\left[\mathrm{O}_{2}\right]_{\text {crit }}$ & $\begin{array}{l}\text { Critical oxygen concentration } \\
\text { for denitrification }\end{array}$ & & Gehlen et al. (2006) \\
\hline $\mathcal{R}_{\mathrm{PO}_{4}}$ & Redfield coefficient for phosphate & Anderso & Anderson and Sarmiento (1994) \\
\hline $\mathcal{R}_{\mathrm{O}_{2}}$ & Redfield coefficient for oxygen & Anderso & Anderson and Sarmiento (1994) \\
\hline $\mathcal{R}_{\mathrm{NO}_{3}}^{-}$ & Redfield coefficient for nitrate & Anderso & Anderson and Sarmiento (1994) \\
\hline $\mathcal{R}_{\mathrm{C}}$ & Redfield coefficient for carbon & Anderso & Anderson and Sarmiento (1994) \\
\hline $\mathcal{R}_{\text {denit }}$ & Redfield coefficient for denitrification & \multicolumn{2}{|r|}{ Gehlen et al. (2006) } \\
\hline
\end{tabular}

All the solid components are taken to have equal densities $\left(\rho=2.6 \mathrm{~g} \mathrm{~cm}^{-3}\right)$.

Considered processes occurring during sediment diagenesis are the dissolution of opal and $\mathrm{CaCO}_{3}$ as well as the oxydation and denitrification of POM. The mixing of sediments by burrowing animals such as clams and worms (bioturbation) is parametrized as a diffusion of solid components with closed boundaries at the sediment-water interface and at the bottom of the bioturbated zone.

The mathematical formulation of the sediment model consists of two sets of dynamical equations, one for the four solid components and one for the six pore water substances, along with adequate boundary conditions. The two sets of equations are coupled to each other through the four reaction rates of the sediment-pore water processes (redissolution / remineralization). All of these reactions follow first order kinetics with spatially uniform reaction rate constants. The model parameters of the sediment component are listed in Table A1 along with their standard values and references.

\section{A1 Redissolution/remineralization}

The rate of opal dissolution $R_{\mathrm{opal}}\left[\mathrm{mol} \mathrm{Si} \mathrm{m}{ }^{-3} \mathrm{yr}^{-1}\right.$ ] is proportional to the amount of opal in the sediment, $c_{\text {opal }}$, the pore water undersaturation with respect to silicic acid, $\left(\left[\mathrm{Si}_{\text {sat }}\right]-[\mathrm{Si}]\right)$, and the rate constant, $r_{\text {opal }}$ :

$$
\begin{aligned}
R_{\mathrm{opal}} & =r_{\mathrm{opal}} \cdot c_{\mathrm{opal}} \cdot \Phi \cdot(1-\Phi) \cdot \frac{\rho}{M_{\mathrm{opal}}} \\
& \cdot\left(\left[\mathrm{Si}_{\mathrm{sat}}\right]-[\mathrm{i}]\right) \cdot \mathrm{H}\left([\mathrm{Si}]_{\mathrm{sat}}-[\mathrm{Si}]\right)
\end{aligned}
$$

$M_{\text {opal }}$ stands for the molar weight of opal, $\rho$ for the density, $\Phi$ for porosity and $c_{\text {opal }}$ corresponds to the weight-fraction of opal sediments. $H(x)$ is the Heaviside step function, preventing spontaneous precipitation of solid opal in case of pore water supersaturation. The silicic acid saturation concentration, $[\mathrm{Si}]_{\text {sat }}$, is a spatially constant model parameter set to $800 \mu \mathrm{mol}^{-l}$.

Since $\left[\mathrm{Ca}^{2+}\right]$ is fairly constant and has a relatively high background concentration, $\mathrm{CaCO}_{3}$ preservation is primarily governed by the concentration of carbonate ions in the pore water. The rate of $\mathrm{CaCO}_{3}$ dissolution $R_{\mathrm{CaCO}_{3}}$ $\left[\mathrm{mol} \mathrm{C} \mathrm{m}{ }^{-3} \mathrm{yr}^{-1}\right]$ is thus linearly related to the pore water undersaturation with respect to carbonate ions, $\left(\left[\mathrm{CO}_{3}\right]_{\mathrm{sat}}-\right.$ $\left[\mathrm{CO}_{3}\right]$ ), the weight-fraction of $\mathrm{CaCO}_{3}, c_{\mathrm{CaCO}_{3}}$, and the rate constant, $r_{\mathrm{CaCO}_{3}}$ :

$$
\begin{gathered}
R_{\mathrm{CaCO}_{3}}=r_{\mathrm{CaCO}_{3}} \cdot c_{\mathrm{CaCO}_{3}} \cdot \Phi \cdot(1-\Phi) \cdot \frac{\rho}{M_{\mathrm{CaCO}_{3}}} \\
\times\left(\left[\mathrm{CO}_{3}\right]_{\mathrm{sat}}-\left[\mathrm{CO}_{3}\right]\right) \cdot \mathrm{H}\left(\left[\mathrm{CO}_{3}\right]_{\mathrm{sat}}-\left[\mathrm{CO}_{3}\right]\right), \\
{\left[\mathrm{CO}_{3}\right]_{\mathrm{sat}}=\frac{\left[\mathrm{Ca}^{2+}\right]}{K_{\mathrm{sp}}^{\prime}} .}
\end{gathered}
$$


The solubility product of calcite $K_{\mathrm{sp}}^{\prime}$ is calculated after Mucci (1983) with a pressure dependence following Millero (1995). The calcium ion concentration $\left[\mathrm{Ca}^{2+}\right]$ is proportional to salinity.

The rate of organic matter oxydation $R_{\text {oxy }}\left[\mathrm{molC} \mathrm{m}^{-3}\right.$ $\left.\mathrm{yr}^{-1}\right]$ is limited by the availability of oxygen in the pore water, $\left[\mathrm{O}_{2}\right]$, and by the amount of POC, $c_{\mathrm{POC}}$, in the sediment:

$$
\begin{aligned}
R_{\mathrm{oxy}}= & r_{\mathrm{oxy}} \cdot c_{\mathrm{POC}} \cdot \Phi \cdot(1-\Phi) \cdot \frac{\rho}{M_{\mathrm{POC}}} \cdot \frac{\mathcal{R}_{\mathrm{C}}}{\mathcal{R}_{\mathrm{O}_{2}}} \\
& \cdot\left[\mathrm{O}_{2}\right] \cdot \mathrm{H}\left(\left[\mathrm{O}_{2}\right]\right) .
\end{aligned}
$$

The rate constant for oxydation, $r_{\text {oxy }}$, is set to $501 \mathrm{~mol}^{-1}$ $\mathrm{yr}^{-1} \cdot \mathcal{R}_{\mathrm{C}}$ and $\mathcal{R}_{\mathrm{O}_{2}}$ are the Redfield ratios for carbon and oxygen, respectively.

Organic matter denitrification only occurs in suboxic conditions, i.e. below a critical oxygen concentration in the pore water $\left[\mathrm{O}_{2}\right]_{\text {crit }}$. The reaction rate $R_{\text {denit }}\left[\mathrm{mol} \mathrm{C} \mathrm{m}^{-3} \mathrm{yr}^{-1}\right]$ is proportional to the POC weight-fraction, $c_{\mathrm{POC}}$, the availability of nitrate, $\left[\mathrm{NO}_{3}^{-}\right]$, and the rate constant $r_{\text {denit }}$ :

$$
\begin{aligned}
R_{\text {denit }} & =r_{\text {denit }} \cdot c_{\mathrm{POC}} \cdot \Phi \cdot(1-\Phi) \cdot \frac{\rho}{M_{\mathrm{POC}}} \cdot \frac{\mathcal{R}_{\mathrm{C}}}{\mathcal{R}_{\text {denit }}} \\
& \cdot\left[\mathrm{NO}_{3}^{-}\right] \cdot \mathrm{H}\left(\left[\mathrm{NO}_{3}^{-}\right]\right) \cdot \mathrm{H}\left(\left[\mathrm{O}_{2}\right]_{\text {crit }}-\left[\mathrm{O}_{2}\right]\right) .
\end{aligned}
$$

$\mathcal{R}_{\text {denit }}$ is the Redfield coefficient for denitrification. The reaction rate, $r_{\text {denit }}$, is set to $501 \mathrm{~mol}^{-1} \mathrm{yr}^{-1}$.

Inert clay is not subject to redissolution in the sediments:

$R_{\text {clay }}=0$.

\section{A2 Solid components}

The four solid sediment components are subject to bioturbation, advection and remineralization/redissolution. They satisfy the following equations:

$$
\begin{aligned}
\frac{\partial c_{\mathrm{CaCO}_{3}}}{\partial t} & =D_{\mathrm{B}} \frac{\partial^{2}}{\partial z^{2}}\left(c_{\mathrm{CaCO}_{3}}\right)-\frac{\partial}{\partial z}\left(w c_{\mathrm{CaCO}_{3}}\right) \\
& -R_{\mathrm{CaCO}_{3}} \cdot \frac{M_{\mathrm{CaCO}_{3}}}{\rho} \cdot \frac{1}{1-\Phi}, \\
\frac{\partial c_{\text {opal }}}{\partial t}= & D_{\mathrm{B}} \frac{\partial^{2}}{\partial z^{2}}\left(c_{\text {opal }}\right)-\frac{\partial}{\partial z}\left(w c_{\text {opal }}\right)-R_{\text {opal }} \\
& \frac{M_{\text {opal }}}{\rho} \cdot \frac{1}{1-\Phi}, \\
\frac{\partial c_{\mathrm{POC}}}{\partial t}= & D_{\mathrm{B}} \frac{\partial^{2}}{\partial z^{2}}\left(c_{\mathrm{POC}}\right)-\frac{\partial}{\partial z}\left(w c_{\mathrm{POC}}\right) \\
- & \left(R_{\text {oxy }}+R_{\text {denit }}\right) \cdot \frac{M_{\mathrm{POC}}}{\rho} \cdot \frac{1}{1-\Phi}, \\
\frac{\partial c_{\text {clay }}}{\partial t}= & D_{\mathrm{B}} \frac{\partial^{2}}{\partial z^{2}}\left(c_{\text {clay }}\right)-\frac{\partial}{\partial z}\left(w c_{\text {clay }}\right) .
\end{aligned}
$$

$c_{\mathrm{S}}$ corresponds to the dry weight fraction of $\mathrm{CaCO}_{3}$, opal, POC or clay. $D_{\mathrm{B}}$ is the bioturbation coefficient, $w$ is the vertical advection velocity and $R_{x}$ are the reaction rates. The variable porosities are taken into account when solving Eqs. (A6)-(A9).

Below the bioturbated zone, the sediment composition remains unchanged:

$\left.\frac{\partial c_{\mathrm{S}}}{\partial z}\right|_{z \geq 10 \mathrm{~cm}}=0, \quad$ for each solid component $S$.

(A10)

At the sediment-water interface $(z=0 \mathrm{~cm})$ the vertical advection velocity is given by the sum of the volume rain rates, Rains $\cdot M_{\mathrm{S}} / \rho\left[\mathrm{cm}^{3} \mathrm{~cm}^{-2} \mathrm{yr}^{-1}\right]$, divided by the solid sediment fraction, $(1-\Phi(0))$ :

$w(0)=\frac{1}{1-\Phi(0)} \sum_{\substack{\text { solid } \\ \text { components }}}$ Rains $_{\mathrm{S}} \cdot M_{\mathrm{S}} / \rho$.

Vertical advection velocities, $w(z)$, decrease with depth due to remineralization and redissolution as well as due to increasing solid sediment fractions:

$w(z)<w(0), \quad$ for $z>0$.

The velocity $w(z)$ is given by the remaining volume flux at depth $z$ divided by the solid sediment fraction, $(1-\Phi(z))$ :

$$
\begin{aligned}
w(z) & =\frac{1}{1-\Phi(z)}\left(\sum_{\substack{\text { solid } \\
\text { components }}} \operatorname{Rain}_{\mathrm{S}} \cdot M_{\mathrm{S}} / \rho\right. \\
& \left.-\int_{z^{\prime}=0}^{z} \sum_{\substack{\text { solid } \\
\text { components }}} R_{\mathrm{S}}\left(z^{\prime}\right) \cdot M_{\mathrm{S}}\left(z^{\prime}\right) / \rho \cdot \mathrm{d} z^{\prime}\right) .
\end{aligned}
$$

The burial flux of the solid component $S$ at the base of the bioturbated zone $(z=10 \mathrm{~cm}), F_{\mathrm{S}}^{\text {burial }}\left[\mathrm{mol} \mathrm{cm}^{-2} \mathrm{yr}^{-1}\right]$, is given by:

$$
F_{\mathrm{S}}^{\text {burial }}=w(10) \cdot c_{\mathrm{S}}(10) \cdot \frac{\rho}{M_{\mathrm{S}}} \cdot(1-\Phi(10)) .
$$

In case total redissolution is larger than total rain in the sediment column, gaps of solid material are produced within the fixed model geometry. These are filled with clay in order to ensure mass conservation:

$c_{\text {opal }}+c_{\text {cal }}+c_{\text {org }}+c_{\text {clay }}=1$.

\section{A3 Pore water solutes}

The concentrations of pore water solutes are subject to sediment remineralization and redissolution as well as to pore water diffusion. Here, the diffusion in a porous medium is represented by multiplying the uniform pore water diffusion coefficient $D$ by the porosity $\Phi$. Experimentally derived diffusion coefficients do not deviate much from these values 
(Ullman and Aller, 1982). The dynamical equations for the pore water solutes are:

$$
\begin{aligned}
\frac{\partial \mathrm{Si}}{\partial t}= & \frac{\partial}{\partial z}\left(\Phi D \frac{\partial \mathrm{Si}}{\partial z}\right)+R_{\mathrm{opal}} / \Phi \\
\frac{\partial \mathrm{O}_{2}}{\partial t}= & \frac{\partial}{\partial z}\left(\Phi D \frac{\partial \mathrm{O}_{2}}{\partial z}\right)-\frac{\mathcal{R}_{\mathrm{O}_{2}}}{\mathcal{R}_{\mathrm{C}}} \cdot R_{\mathrm{oxy}} / \Phi \\
\frac{\partial \mathrm{NO}_{3}^{-}}{\partial t}= & \frac{\partial}{\partial z}\left(\Phi D \frac{\partial \mathrm{NO}_{3}^{-}}{\partial z}\right)+\frac{\mathcal{R}_{\mathrm{NO}_{3}^{-}}}{\mathcal{R}_{\mathrm{C}}} \\
& \cdot R_{\mathrm{oxy}} / \Phi-\frac{\mathcal{R}_{\text {denit }}}{\mathcal{R}_{\mathrm{C}}} \cdot R_{\mathrm{denit}} / \Phi \\
\frac{\partial \mathrm{PO}_{4}}{\partial t}= & \frac{\partial}{\partial z}\left(\Phi D \frac{\partial \mathrm{PO}_{4}}{\partial z}\right)+\frac{\mathcal{R}_{\mathrm{PO}_{4}}}{\mathcal{R}_{\mathrm{C}}} \\
& \cdot\left(R_{\mathrm{oxy}}+R_{\mathrm{denit}}\right) / \Phi \\
\frac{\partial \mathrm{DIC}}{\partial t}= & \frac{\partial}{\partial z}\left(\Phi D \frac{\partial \mathrm{DIC}}{\partial z}\right) \\
& +\left(R_{\text {calc }}+R_{\text {oxy }}+R_{\mathrm{denit}}\right) / \Phi \\
\frac{\partial \mathrm{ALK}}{\partial t} & =\frac{\partial}{\partial z}\left(\Phi D \frac{\partial \mathrm{ALK}}{\partial z}\right)-\frac{\mathcal{R}_{\mathrm{NO}_{3}^{-}}+2 \cdot \mathcal{R}_{\mathrm{PO}_{4}}}{\mathcal{R}_{\mathrm{C}}} \\
& \cdot R_{\text {oxy }} / \Phi+\frac{\mathcal{R}_{\text {denit }}-2 \cdot \mathcal{R}_{\mathrm{PO}_{4}}}{\mathcal{R}_{\mathrm{C}}} \cdot R_{\mathrm{denit}} / \Phi \\
& +2 \cdot R_{\text {cal }} / \Phi .
\end{aligned}
$$

The boundary condition for pore water solutes at the ocean-sediment interface is:

$$
\left.C\right|_{z=0 \mathrm{~cm}}=C_{\text {bottom water }}, \quad \text { for each solute tracer } C \text {. }
$$

Below the bioturbated zone the solute concentrations are assumed to remain constant:

$$
\left.\frac{\partial C}{\partial z}\right|_{z \geq 10 \mathrm{~cm}}=0, \quad \text { for each solute tracer } C .
$$

The $\mathrm{pH}$-equilibrium in the pore water is given by:

$$
\frac{\left[\mathrm{CO}_{2}\right]\left[\mathrm{CO}_{3}^{=}\right]}{\left[\mathrm{HCO}_{3}^{-}\right]^{2}}=\frac{K_{1}^{\prime}}{K_{2}^{\prime}} \text {. }
$$

The apparent dissociation constants $K_{1}^{\prime}$ and $K_{2}^{\prime}$ are calculated after Mehrbach et al. (1973) with pressure dependence following Millero (1995).

Acknowledgements. This study received support by the Swiss National Science Foundation, by the Swiss Staatssekretariat für Bildung und Forschung (\#C07.0068; COST Action 735), and by the European Commission through the FP7 projects Past4Future (grant no. 243908), CARBOCHANGE (grant no. 264879), and EPOCA (grant no. 211384). This is publication no. A 343 of the Bjerknes Centre for Climate Research. The comments by T. F. Stocker are greatly appreciated.

Edited by: J. Singarayer

\section{References}

Adkins, J., McIntyre, K., and Schrag, D.: The salinity, temperature and $\delta^{18} \mathrm{O}$ content of the glacial deep ocean, Science, 298, 17691773, 2002.

Anderson, L. and Sarmiento, J.: Redfield ratios of remineralization determined by nutrient data analysis, Global Biogeochem. Cy., 8, 65-80, 1994.

Anderson, R., Ali, S., Bradtmiller, L., Nielsen, S., Fleisher, M., Anderson, B., and Burckle, L.: Wind-Driven Upwelling in the Glacial Southern Ocean and the Deglacial Rise in Atmospheric $\mathrm{CO}_{2}$, Science, 323, 1443-1448, 2009.

Archer, D. and Maier-Reimer, E.: Effect of deep-sea sedimentary calcite preservation on atmospheric $\mathrm{CO}_{2}$ concentration, Nature, 367, 292-294, 1994.

Archer, D., Lyle, M., Rodgers, K., and Froelich, P.: What Controls Opal Preservation in Tropical Deep Sea Sediments?, Paleoceanography, 8, 7-21, 1993.

Archer, D., Peltzer, E., and Kirchman, D.: A timescale for dissolved organic carbon production in equatorial Pacific surface waters, Global Biogeochem. Cy., 11, 435-452, 1997.

Archer, D., Winguth, A., Lea, D., and Mahowald, N.: What caused the glacial/interglacial atmospheric $p \mathrm{CO}_{2}$ cycles?, Rev. Geophys., 38, 159-189, 2000a.

Archer, D., Eshel, G., Winguth, A., Broecker, W., Pierrehumbert, R., Tobis, M., and Jacob, R.: Atmospheric $p \mathrm{CO}_{2}$ sensitivity to the biological pump of the cean, Global Biogeochem. Cy., 14, 1219-1230, 2000b.

Aumont, O. and Bopp, L.: Globalizing results from ocean in situ iron fertilization studies, Global Biogeochem. Cy., 20, GB2017, doi:10.1029/2005GB002591, 2006.

Beck, J., Warren, J., Richards, D., Edwards, R., Smart, B. S. P., Donahue, D., Hererra-Osterheld, S., Burr, G., Calsoyas, L., Jull, A., and Biddulph, D.: Extremely Large Variations of Atmospheric ${ }^{14} \mathrm{C}$ Concentration During the Last Glacial Period, Science, 292, 2453-2458, doi:10.1126/science.1056649, 2001.

Berger, W. and Keir, R.: Glacial-Holocene Changes in atmospheric $\mathrm{CO}_{2}$ and the deep-sea record, in: Climate Processes and Climate Sensitivity, edited by: Hansen, J. E. and Takahashi, T., 303-317, 1984.

Berner, R. and Honjo, S.: Pelagic Sedimentation of Aragonite: Its Geochemical Significance, Science, 211, 940-942, doi:10.1126/science.211.4485.940, 1981.

Bird, M., Lloyd, J., and Farquhar, G.: Terrestrial carbon storage at the LGM, Nature, 371, 566, doi:10.1038/371566a0, 1994.

Böning, C., Dispert, A., Visbeck, M., Rintoul, S., and Schwarzkopf, F.: The response of the Antarctic Circumpolar Current to recent climate change, Nat. Geosci., 1, 864-869, 2008.

Boyle, E.: Vertical oceanic nutrient fractionation and glacial/interglacial $\mathrm{CO}_{2}$ cycles, Nature, 331, 55-56, 1988.

Bradtmiller, L., Anderson, R., Sachs, J., and Fleisher, M.: A deeper respired carbon pool in the glacial equatorial Pacific Ocean, Earth Planet. Sc. Lett., 299, 417-425, 2010.

Broecker, W.: Ocean chemistry during glacial time, Geochim. Cosmochim. Acta, 46, 1689-1706, 1982.

Broecker, W. and Barker, S.: A $190 \%$ drop in atmosphere's $\Delta^{14} \mathrm{C}$ during the "Mystery Interval" (17.5 to $14.5 \mathrm{kyr}$ ), Earth Planet. Sc. Lett., 256, 90-99, 2007. 
Broecker, W. and Peng, T.: The role of $\mathrm{CaCO}_{3}$ compensation in the glacial to interglacial atmospheric $\mathrm{CO}_{2}$ change, Global Biogeochem. Cy., 1, 15-29, 1987.

Broecker, W. and Peng, T.-H.: Tracers in the Sea, Eldigo, Palisades, N. Y., 1982.

Broecker, W., Lynch-Stieglitz, J., Clark, E., Hajdas, I., and Bonani, G.: What caused the atmosphere's $\mathrm{CO}_{2}$ content to rise during the last 8000 years?, Geochem. Geophy. Geosys., 2(10), 1062-1074, doi:10.1029/2001GC000177, 2001.

Broecker, W., Clark, E., Barker, S., Hajdas, I., Bonani, G., and Moreno, E.: Radiocarbon age of late glacial deep water from the equatorial Pacific, Paleoceanography, 22, PA2206, doi:10.1029/2006PA001359, 2007.

Brovkin, V., Ganopolski, A., Archer, D., and Rahmstorf, S.: Lowering of glacial atmospheric $\mathrm{CO}_{2}$ in response to changes in ocean circulation and marine biogeochemistry, Paleoceanography, 22, PA4202, doi:10.1029/2006PA001380, 2007.

Chikamoto, M., Matsumoto, K., and Ridgewell, A.: Response of deep-sea $\mathrm{CaCO}_{3}$ sedimentation to Atlantic meridional overturning circulation shutdown, J. Geophys. Res., 113, G03017, doi:10.1029/2007JG000669, 2008.

Chikamoto, M., Matsumoto, K., and Yamananka, Y.: Influence of Export Rain Ratio Changes in Atmospheric $\mathrm{CO}_{2}$ and Sedimentary Calcite Preservation, J. Oceanogr., 65, 209-221, 2009.

Crusius, J., Pedersen, T., Kienast, S., and Keigwin, L.: Influence of northwest Pacific productivity on North Pacific Intermediate Water oxygen concentrations during the Bolling-Allerod interval (14.7-12.9 ka), Geology, 32, 633-636, 2004.

Curry, W., Labeyrie, J. D. L., and Shackleton, N.: Changes in the Distribution of $\delta^{13} \mathrm{C}$ of Deep Water $\sum \mathrm{CO}_{2}$ Between the Last Glaciation and the Holocene, Paleoceanography, 3, 317-341, 1988

De La Rocha, C.: Opal-based isotopic proxies of paleoenvironmental conditions, Global Biogeochem. Cy., 20, GB4S09, doi:10.1029/2005GB002664, 2006.

Deutsch, C., Sigman, D., Thunell, R., Meckler, A., and Haug, G.: Isotopic constraints on glacial/interglacial changes in the oceanic nitrogen budget, Global Biogeochem. Cy., 18, GB4012, doi:10.1029/2003GB002189, 2004.

Doney, S., Glover, D., and Najjar, R.: A new coupled, onedimensional biological-physical model for the upper ocean: Applications to the JGOFS Bermuda Atlantic Time-series Study (BA TS) site, Deep-Sea Res. Pt. II, 43, 591-624, 1996.

Duplessy, J. C., Shackleton, N. J., Fairbanks, R. G., Labeyrie, L., Oppo, D., and Kallel, N.: Deepwater source variations during the last climatic cycle and their impact on the global deepwater circulation, Paleoceanography, 3, 343-360, 1988.

Edwards, N. R. and Marsh, R.: Uncertainties due to transportparameter sensitivity in an efficient 3-d ocean-climate model, Clim. Dynam., 3, 67-94, 2005.

Edwards, N. R., Willmott, A. J., and Killworth, P. D.: On the role of topography and wind stress on the stability of the thermohaline circulation, J. Phys. Oceanogr., 28, 756-778, 1998.

Elsig, J.: New insights into the global carbon cycle from measurements of $\mathrm{CO}_{2}$ stable isotopes: methodological improvements and interpretation of a new EPICA Dome $\mathrm{C}$ ice core $\delta^{13} \mathrm{C}$ record, $\mathrm{Ph} . \mathrm{D}$. thesis, Climate and Environmental Physics, Physics Institute, University of Bern, 2009.
Elsig, J., Schmitt, J., Leuenberger, D., Schneider, R., Eyer, M., Leuenberger, M., Joos, F., Fischer, H., and Stocker, T.: Stable isotope constraints on Holocene carbon cycle changes from an Antarctic ice core, Nature, 461, 507-510, 2009.

Falkowski, P.: Evolution of the nitrogen cycle and its influence on the biological sequestration of $\mathrm{CO}_{2}$ in the ocean, Nature, 387, 272-275, 1997.

Feely, R., Sabine, C., Lee, K., Berelson, W., Kleypas, J., Fabry, V., and Millero, F.: Impact of Anthropogenic $\mathrm{CO}_{2}$ on the $\mathrm{CaCO}_{3}$ System in the Oceans, Science, 305, 362-366, doi:10.1126/science.1097329, 2004.

Fischer, H., Schmitt, J., Lüthi, D., Stocker, T., Tschumi, T., Parekh, P., Joos, F., Köhler, P., Völker, C., Gersonde, R., Barbante, C., Floch, M. L., Raynaud, D., Barnola, J.-M., and Wolff, E.: The role of Southern Ocean processes on orbital and millennial $\mathrm{CO}_{2}$ variations - a synthesis, Quaternary Sci. Rev., 29, 193-205, 2010.

Francois, R., Altabet, M., Yu, E., Sigman, D., Bacon, M., Frank, M., Bohrmann, G., Bareille, G., and Labeyrie, L.: Contribution of Southern Ocean surface-water stratification to low atmospheric $\mathrm{CO}_{2}$ concentrations during the last glacial period, Nature, 389, 929-935, 1997.

Freeman, K. H. and Hayes, J. M.: Fractionation of carbon isotopes by phytoplankton and estimates of ancient $\mathrm{CO}_{2}$ levels, Global Biogeochem. Cy., 6, 185-198, 1992.

Galbraith, E., Jaccard, S., Pedersen, T., Sigman, D., Haug, G., Cook, M., Southon, J., and Francois, R.: Carbon dioxide release from the North Pacific abyss during the last deglaciation, Nature, 449, 890-893, 2007.

Gehlen, M., Bopp, L., Emprin, N., Aumont, O., Heinze, C., and Ragueneau, O.: Reconciling surface ocean productivity, export fluxes and sediment composition in a global biogeochemical ocean model, Biogeosciences, 3, 521-537, doi:10.5194/bg-3521-2006, 2006.

Heinze, C., Maier-Reimer, E., and Winn, K.: Glacial $p \mathrm{CO}_{2} \mathrm{Re}-$ duction by the World Ocean: Experiments With the Hamburg Carbon Cycle Model, Paleoceanography, 6, 393-430, 1991.

Heinze, C., Maier-Reimer, E., Winguth, A., and Archer, D.: A global oceanic sediment model for long-term climate studies, Global Biogeochem. Cy., 13, 221-250, 1999.

Heinze, C., Hupe, A., Maier-Reimer, E., Dittert, N., and Ragueneau, O.: Sensitivity of the marine biospheric Si cycle for biogeochemical parameter variations, Global Biogeochem. Cy., 17, 1086, doi:10.1029/2002GB001943, 2003.

Hodell, D., Venz, K., Charles, C., and Ninnemann, U.: Pleistocene vertical carbon isotope and carbonate gradients in the South Atlantic sector of the Southern Ocean, Geochem., Geophy., Geosy., 4(1), 1004, doi:10.1029/2002GC000367, 2003.

Hughen, K. S., Lehman, J. S., Overpeck, J., Marchal, O., Herring, C., and Turnbull, J.: ${ }^{14} \mathrm{C}$ Activity and Global Carbon Cycle Changes over the Past 50'000 Years, Science, 303, 202-207, 2004.

Ito, T. and Follows, M.: Preformed phosphate, soft tissue pump and atmospheric $\mathrm{CO}_{2}$, J. Mar. Res., 63(4), 813-839, doi:10.1357/0022240054663231, 2005.

Jaccard, S., Haug, G., Sigman, D., Pedersen, T., Thierstein, H., and Röhl, U.: Glacial/Interglacial Changes in Subarctic North Pacific Stratification, Science, 308, 1003-1006, 2005. 
Jaccard, S., Galbraith, E., Sigman, D., Haug, G., Francois, R., Pedersen, T., Dulski, P., and Thierstein, H.: Subarctic Pacific evidence for a glacial deepening of the oceanic respired carbon pool, Earth Planet. Sc. Lett., 277, 156-165, 2009.

Jin, X., Gruber, N., Dunne, J., Sarmiento, J., and Armstrong, R.: Diagnosing the contribution of phytoplankton functional groups to the production and export of particulate organic carbon, $\mathrm{CaCO}_{3}$, and opal from global nutrient and alkalinity distributions, Global Biogeochem. Cy., 20, GB2015, doi:10.1029/2005GB002532, 2006.

Joos, F., Gerber, S., Prentice, I., Otto-Bliesner, B., and Valdes, P.: Transient simulations of Holocene atmospheric carbon dioxide and terrestrial carbon since the Last Glacial Maximum, Global Biogeochem. Cy., 18, GB2002, doi:10.1029/2003GB002156, 2004.

Kalnay, E., Kanamitsu, M., Kistler, R., Collins, W., Deaven, D., Gandin, L., Iredell, M., Saha, S., White, G., Woollen, J., Zhu, Y., Leetmaa, A., Reynolds, R., Chelliah, M., Ebisuzaki, W., Higgins, W., Janowiak, J., Mo, K. C., Ropelewski, C., Wang, J., Jenne, R., and Joseph, D.: The NCEP/NCAR 40-Year Reanalysis Project, B. Am. Meteorol. Soc., 77(3), 437-471, 1996.

Keigwin, L.: Glacial-Age Hydrography of the Far Northwest Pacific Ocean, Paleoceanography, 13, 323-339, 1998.

Keigwin, L. and Schlegel, M.: Ocean ventilation and sedimentation since the glacial maximum at $3 \mathrm{~km}$ in the western North Atlantic, Geochem. Geophy. Geosy., 3(6), 1034, doi:10.1029/2001GC000283, 2002.

Knox, F. and McElroy, M.: Changes in atmospheric $\mathrm{CO}_{2}-$ Influence of the marine biota at high-latitude, J. Geophys. Res., 89, 4629-4637, 1984.

Kohfeld, K. E., Le Quéré, C., Harrison, S. P., and Anderson, R. F.: Role of marine biology in glacial-interglacial $\mathrm{CO}_{2}$ cycles, Science, 308, 74-78, 2005.

Köhler, P., Fischer, H., Munhoven, G., and Zeebe, R.: Quantitative interpretation of atmospheric carbon records over the last glacial termination, Global Biogeochem. Cy., 19(4), GB4020, doi:10.1029/2004GB002345, 2005.

Köhler, P., Fischer, H., Schmitt, J., and Munhoven, G.: On the application and interpretation of Keeling plots in paleo climate research - deciphering $\delta^{13} \mathrm{C}$ of atmospheric $\mathrm{CO}_{2}$ measured in ice cores, Biogeosciences, 3, 539-556, doi:10.5194/bg-3-539-2006, 2006a.

Köhler, P., Muscheler, R., and Fischer, H.: A model-based interpretation of low-frequency changes in the carbon cycle during the last 120,000 years and its implications for the reconstruction of atmospheric $\Delta^{14} \mathrm{C}$, Geochem., Geophy., Geosy., 7, Q11N06, doi:10.1029/2005GC001228, 2006b.

Kwon, E., Primeau, F., and Sarmiento, J.: The impact of remineralization depth on the air-sea carbon balance, Nat. Geosci., 2, 630-635, 2009.

Leuenberger, M., Siegenthalter, U., and Langway, C.: Carbon Isotope Composition of Atmospheric $\mathrm{CO}_{2}$ during the Last Ice-Age from an Antarctic Ice Core, Nature, 357, 488-490, 1992.

Levitus, S. and Boyer, T.: World Ocean Atlas 1994 Volume 4: Temperature, NOAA Atlas NESDIS, US Department of Commerce, Washington, DC, 117 pp., 1994.

Levitus, S., Burgett, R., and Boyer, T.: World Ocean Atlas 1994 Volume 3: Salinity, NOAA Atlas NESDIS, US Department of Commerce, Washington, DC, 99 pp., 1994.
Lourantou, A., Lavric, J., Köhler, P., Barnola, J.-M., Paillard, D., Michel, E., Raynaud, D., and Chappellaz, J.: Constraint of the $\mathrm{CO}_{2}$ rise by new atmospheric carbon isotopic measurements during the last deglaciation, Global Biogeochem. Cy., 24(2), GB2015, doi:10.1029/2009GB003545, 2010.

Lüthi, D., Floch, M. L., Bereiter, B., Blunier, T., Barnola, J.-M., Siegenthaler, U., Raynaud, D., Jouzel, J., Fischer, H., Kawamura, K., and Stocker, T.: High-resolution carbon dioxide concentration record 650,000-800,000 years before present, Nature, 453 , 379-382, 2008.

Maier-Reimer, E., Kriest, I., Segschneider, J., and Wetzel, P.: The HAMburg Ocean Carbon Cycle Model HAMOCC5.1 - Technical Description Release 1.1, Tech. rep., Max Planck Institue for Meteorology, Hamburg, Germany, 2005.

Marchitto, T., Lynch-Stieglitz, J., and Hemming, S.: Deep Pacific $\mathrm{CaCO}_{3}$ compensation and glacial-interglacial atmospheric $\mathrm{CO}_{2}$, Earth Planet. Sc. Lett., 231, 317-336, 2005.

Marchitto, T., Lehman, S., Ortiz, J., Flückiger, J., and van Geen, A.: Marine radiocarbon evidence for the mechanism of deglacial atmospheric $\mathrm{CO}_{2}$ rise, Science, 316, 1456-1459, 2007.

Margalef, R.: Life-forms of phytoplankton as survival alternatives in an unstable environment, Oceanol. Acta, 1, 493-509, 1978.

Marinov, I., Gnanadesikan, A., Sarmiento, J. L., Toggweiler, J. R., Follows, M., and Mignone, B. K.: Impact of oceanic circulation on biological carbon storage in the ocean and atmospheric $p \mathrm{CO}_{2}$, Global Biogeochem. Cy. 22(3), GB3007, doi:10.1029/2007GB002958, 2008.

Martin, J.: Glacial-Interglacial $\mathrm{CO}_{2}$ change: The iron hypothesis, Paleoceanography, 5, 1-13, 1990.

Martin, J. and Fitzwater, S.: Iron deficiency limits phytoplankton growth in the north-east Pacific subarctic, Nature, 331, 341-343, 1988.

Matsumoto, K., Sarmiento, J., and Brzezinski, M.: Silicic acid leakage from the Southern Ocean: a possible explanation for glacial atmospheric $p \mathrm{CO}_{2}$, Global Biogeochem. Cy., 16(3), 1031-1054, doi:10.1029/2001GB001442, 2002.

Matsumoto, K., Hashioka, T., and Yamananka, Y.: Effect of temperature-dependent organic carbon decay on atmospheric $p \mathrm{CO}_{2}$, J. Geophys. Res., 112, G02007, doi:10.1029/2006JG000187, 2007.

McCorkle, D., Heggie, D., and Veeh, H.: Glacial and Holocene Stable Isotope Distributions in the Southeastern Indian Ocean, Paleoceanography, 13, 20-34, 1998.

McManus, J., Francois, R., Gherardi, J.-M., Keigwin, L., and Brown-Leger, S.: Collapse and rapid resumption of Atlantic meridional circulation linked to deglacial climate changes, Nature, 428, 834-837, 2004.

Mehrbach, C., Culberson, C., Hawley, J., and Pytkowicz, R.: Measurement of the apparent dissociation constant of carbonic acid in seawater at atmospheric pressure, Limnol. Oceanogr., 18, 897907, 1973.

Menviel, L., Timmermann, A., Mouchet, A., and Timm, O.: Climate and marine carbon cycle response to changes in the strength of the southern hemispheric westerlies, Paleoceanography, 23(4), PA4201, doi:10.1029/2008PA001604, 2008.

Millero, F.: Thermodynamics of the carbon dioxide system in the oceans, Geochim. Cosmochim. Acta, 59, 661-677, 1995. 
Millimann, J. and Droxler, A.: Neritic and pelagic carbonate sedimentation in the marine environment: ignorance is not bliss, Geol. Rundsch., 85, 496-504, 1996.

Monnin, E., Indermühle, A., Dällenbach, A., Flückiger, J., Stauffer, B., Stocker, T., Raynaud, D., and Barnola, J.: Atmospheric $\mathrm{CO}_{2}$ concentrations over the Last Glacial Termination, Science, 291, 112-114, 2001.

Mook, W. G.: ${ }^{13} \mathrm{C}$ in atmospheric $\mathrm{CO}_{2}$, Neth. J. Sea Res., 20, 211223, 1988

Mucci, A.: The solubility of calcite and aragonite in seawater at various salinities, temperatures, and on atmosphere total pressure, Am. J. Sci., 283, 780-799, 1983.

Müller, S., Joos, F., Edwards, N., and Stocker, T.: Water mass distribution and ventilation time scales in a cost-efficient, threedimensional ocean model, J. Climate, 19, 5479-5499, 2006.

Muscheler, R., Beer, J., Wagner, G., Laj, C., Kissel, C., Raisbeck, G., Yiou, F., and Kubik, P.: Changes in the carbon cycle during the last deglaciation as indicated by the comparison of ${ }^{10} \mathrm{Be}$ and ${ }^{14} \mathrm{C}$ records, Earth Planet. Sc. Lett., 238, 325-340, 2004.

Najjar, R. G., Orr, J., Sabine, C. L., and Joos, F.: Biotic-HOWTO, Internal OCMIP Report, Tech. rep., LSCE/CEA Saclay, Gif-surYvette, France, 15 pp., 1999.

Ninnemann, U. and Charles, C.: Changes in the mode of Southern Ocean circulation over the last glacial cycle revealed by foraminiferal stable isotopic variability, Earth Planet. Sc. Lett., 201, 383-396, 2002.

Orr, J., Najjar, R. G., Sabine, C. L., and Joos, F.: Abiotic-HOWTO, Internal OCMIP Report, Tech. rep., LSCE/CEA Saclay, Gif-surYvette, France, 25 pp., 1999.

Paillard, D. and Parennin, F.: The Antarctic ice sheet and the triggering of deglaciations, Earth Planet. Sc. Lett., 227, 263-271, 2004

Parekh, P., Joos, F., and Müller, S.: A modeling assessment of the interplay between aeolian iron fluxes and ironbinding ligands in controlling carbon dioxide fluctuations during Antarctic warm events, Paleoceanography, 23(4), PA4202, doi:10.1029/2007PA001531, 2008.

Peacock, S., Lane, E., and Restrepo, J.: A possible sequence of events for the generalized glacial-interglacial cycle, Global Biogeochem. Cy., 20(2), GB2010, doi:10.1029/2005GB002448, 2006.

Primeau, F.: Characterizing Transport between the Surface Mixed Layer and the Ocean Interior with a Forward and Adjoint Global Ocean Transport Model, J. Phys. Oceanogr., 35, 545-564, 2005.

Ridgwell, A., Watson, A., and Archer, D.: Modeling the response of the oceanic Si inventory to perturbation, and consequences for atmospheric $\mathrm{CO}_{2}$, Global Biogeochem. Cy., 16(4), 1071-1097, doi:10.1029/2002GB001877, 2002.

Ridgwell, A., Watson, A., Maslin, M., and Kaplan, J.: Implications of coral reef buildup for the controls on atmospheric $\mathrm{CO}_{2}$ since the Last Glacial Maximum, Paleoceanography, 18(4), 1083-1093, doi:10.1029/2003PA000893, 2003.

Sarmiento, J. and Gruber, N.: Ocean biogeochemical dynamics, chap, Chapter 8: Carbon Cycle, Princeton University Press, 318$358,2006$.

Sarmiento, J. and Toggweiler, J.: A new model for the role of the oceans in determining atmospheric $p \mathrm{CO}_{2}$, Nature, 308, 621624, 1984.
Schmittner, A. and Galbraith, E.: Glacial greenhouse-gas fluctuations controlled by ocean circulation changes, Nature, 456, 373 376,2008

Schmittner, A., Brooke, E., and Ahn, J.: Ocean Circulation: Mechanisms and Impacts, vol. 173, chap. Impact of the ocean's overturning circulation on atmospheric $\mathrm{CO}_{2}$, AGU Geophysical Monograph Series, 209-246, 2007.

Severinghaus, J. and Brook, E.: Abrupt Climate Change at the End of the Last Glacial Period Inferred from Trapped Air in Polar Ice, Science, 286, 930-934, 1999.

Shackleton, N.: Carbon-13 in uvigerina: Tropical rainforest history and the equatorial Pacific carbonate dissolution cycles, in: The Fate of Fossil Fuel $\mathrm{CO}_{2}$ in the Ocean, edited by: Andersen, $\mathrm{N}$. and Malahoff, A., Plenum, New York, 401-428, 1977.

Siegenthaler, U. and Muennich, K. O.: Carbon-13/carbon-12 fractionation during carbon dioxide transfer from air to sea, SCORE 16: Carbon Cycle Modelling, edited by: Bolin, B., Wiley, Chichester, 249-257, 1981.

Siegenthaler, U. and Oeschger, H.: Biospheric $\mathrm{CO}_{2}$ emissions during the past 200 years reconstructed by deconvolution of ice core data, Tellus B, 39, 140-154, 1987.

Siegenthaler, U. and Wenk, T.: Rapid atmospheric $\mathrm{CO}_{2}$ variations and ocean circulation, Nature, 308, 624-626, 1984.

Sigman, D. and Boyle, E.: Glacial/interglacial variations in atmospheric carbon dioxide, Nature, 407, 859-869, 2000.

Sigman, D., McCorkle, D., and Martin, W.: The calcite lysocline as a constraint on glacial/interglacial low latitude production changes, Global Biogeochem. Cy., 12, 409-428, 1998.

Sigman, D., Jaccard, S., and Haug, G.: Polar ocean stratification in a cold climate, Nature, 428, 59-63, 2004

Skinner, L., Fallon, S., Waelbroeck, C., Michel, E., and Barker, S.: Ventilation of the Deep Southern Ocean and Deglacial $\mathrm{CO}_{2}$ Rise, Science, 328, 1147-1151, doi:10.1126/science.1183627, 2010.

Smith, H., Fischer, H., Wahlen, M., Mastroianni, D., Beck, D., and Beck, B.: Dual modes of the carbon cycle since the Last Glacial Maximum, Nature, 400, 248-250, 1999.

Spence, P., Saenko, O., Eby, M., and Weaver, A.: The Southern Ocean Overturning: Parameterized versus Permitted Eddies, J. Phys. Oceanogr., 39, 1634-1651, 2009.

Spero, H. and Lea, D.: The Cause of Carbon Isotope Minimum Events on Glacial Terminations, Science, 296, 522-525, 2002.

Stenni, B., Masson-Delmotte, V., Johnsen, S., Jouzel, J., Longinelli, A., Monnin, E., Rothlisberger, R., and Selmo, E.: An Oceanic Cold Reversal During the Last Deglaciation, Science, 293, 2074 2077, doi:10.1126/science.1059702, 2001.

Talley, L., Reid, J., and Robbins, P.: Data-based meridional overturning streamfunctions for the global oceans, J. Climate, 16, 3213-3226, 2003

Toggweiler, J. R., Russell, J., and Carson, S.: Midlatitude westerlies, atmospheric $\mathrm{CO}_{2}$, and climate change during ice ages, Paleoceanography, 21(2), PA2005, doi:10.1029/2005PA001154, 2006.

Treguer, P., Nelson, D., DeMaster, A., Leynart, A., and Queguiner, B.: The silica balance in the world ocean: A reestimate, Science, 268, 375-379, 1995.

Tschumi, T.: Modeling the ocean's contribution to past and future changes in the global carbon cycle, Ph.D. thesis, Climate and Environmental Physics, Physics Institute, University of Bern, 2009. 
Tschumi, T., Joos, F., and Parekh, P.: How important are Southern Hemisphere wind changes for low glacial carbon dioxide? A model study, Paleoceanography, 23(4), PA4208, doi:10.1029/2008PA001592, 2008.

Ullman, W. and Aller, R.: Diffusion coefficients in nearshore marine environments, Limnol. Oceanogr., 27, 552-556, 1982.

Volk, T. and Hoffert, M.: Ocean carbon pumps: Analysis of relative strengths and efficiencies in ocean driven atmospheric $p \mathrm{CO}_{2}$ changes, vol. 32 of Geophys. Monogr. Ser., edited by: Sundquist, E. T. and Broecker, W. S., AGU, Washington, DC, 99-110, 1985.
Wallmann, K.: Phosphorous imbalance in the global ocean?, Global Biogeochem. Cy., 24(4), GB4030, doi:10.1029/2009GB003643, 2010.

Watson, A. and Naveira-Garabato, A.: The role of Southern Ocean mixing and upwelling in glacial-interglacial atmospheric $\mathrm{CO}_{2}$ change, Tellus B, 58(15), 73-87, 2006.

Zeng, N.: Glacial-Interglacial Atmospheric $\mathrm{CO}_{2}$ Change - The Glacial Burial Hypothesis, Adv. Atmos. Sci., 20, 677-693, 2003. 